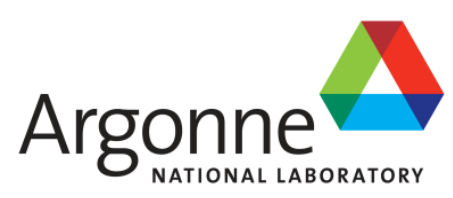

ANL-ART-144

ANL-METL-12

\title{
Gear Test Assembly - Status Report for FY2018
}

Nuclear Sciences and Engineering Division 


\begin{abstract}
About Argonne National Laboratory
Argonne is a U.S. Department of Energy laboratory managed by UChicago Argonne, LLC under contract DE-AC02-06CH11357. The Laboratory's main facility is outside Chicago, at 9700 South Cass Avenue, Argonne, Illinois 60439. For information about Argonne and its pioneering science and technology programs, see www.anl.gov.
\end{abstract}

\title{
DOCUMENT AVAILABILITY
}

Online Access: U.S. Department of Energy (DOE) reports produced after 1991 and a growing number of pre-1991 documents are available free at OSTI.GOV (http://www.osti.gov/), a service of the U.S. Dept. of Energy's Office of Scientific and Technical Information

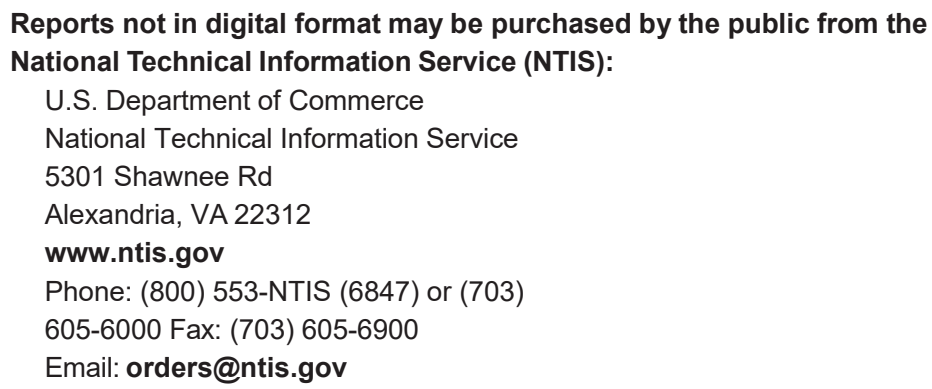

Reports not in digital format are available to DOE and DOE contractors from the Office of Scientific and Technical Information (OSTI):

U.S. Department of Energy

Office of Scientific and Technical Information

P.O. Box 62

Oak Ridge, TN 37831-0062

www.osti.gov

Phone: (865) 576-8401

Fax: (865) 576-5728

Email: reports@osti.gov

\section{Disclaimer}

This report was prepared as an account of work sponsored by an agency of the United States Government. Neither the United States Government nor any agency thereof, nor UChicago Argonne, LLC, nor any of their employees or officers, makes any warranty, express or implied, or assumes any legal liability or responsibility for the accuracy, completeness, or usefulness of any information, apparatus, product, or process disclosed, or represents that its use would not infringe privately owned rights. Reference herein to any specific commercial product, process, or service by trade name, trademark, manufacturer, or otherwise, does not necessarily constitute or imply its endorsement, recommendation, or favoring by the United States Government or any agency thereof. The views and opinions of document authors expressed herein do not necessarily state or reflect those of the United States Government or any agency thereof, Argonne National Laboratory, or UChicago Argonne, LLC. 
Argonne

ANL-ART-144

ANL-METL-12

\section{Gear Test Assembly - Status Report for FY2018}

H. Belch, E. Kent, T. Wachs, C. Grandy, S. Bakhtiari, Hual-Te Chien

Nuclear Sciences and Engineering Division

Argonne National Laboratory

September 2018 


\section{TABLE OF CONTENTS}

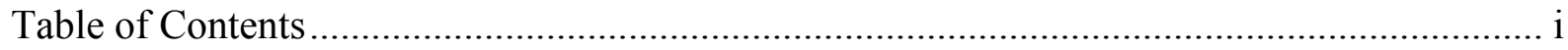

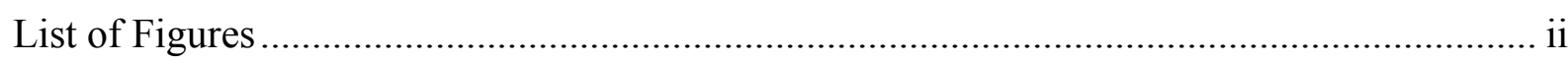

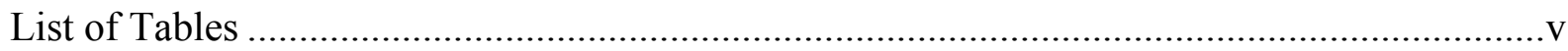

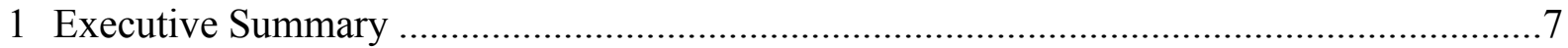

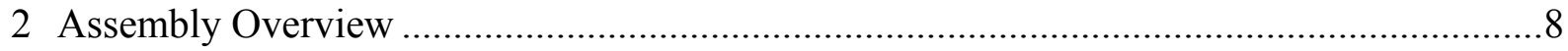

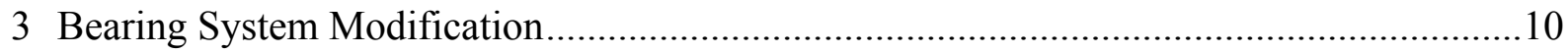

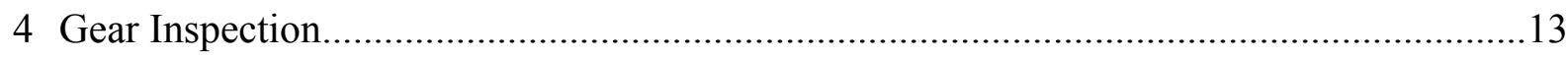

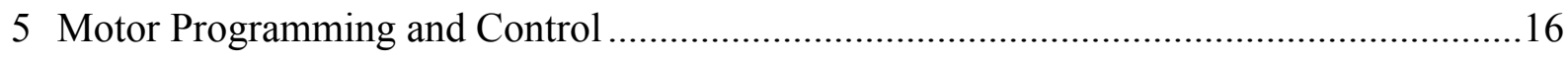

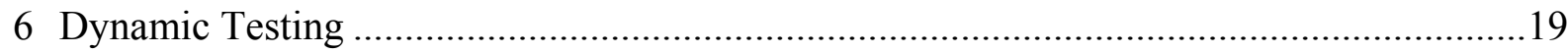

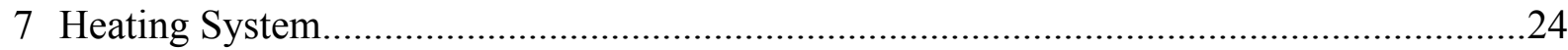

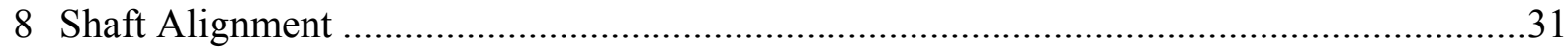

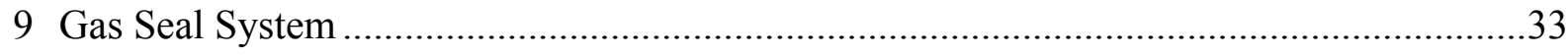

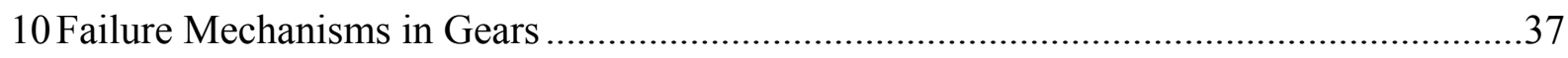

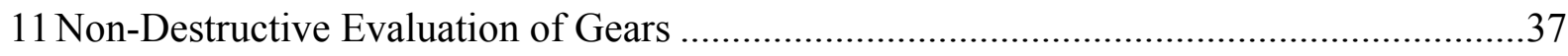

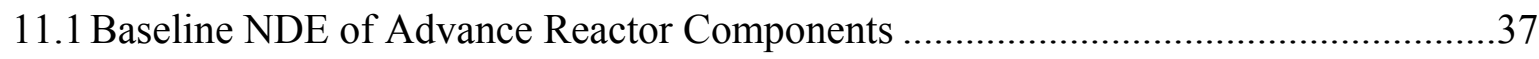

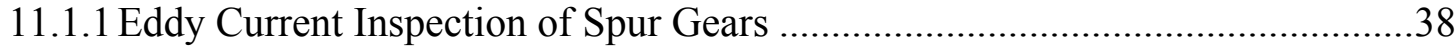

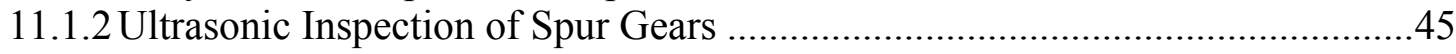

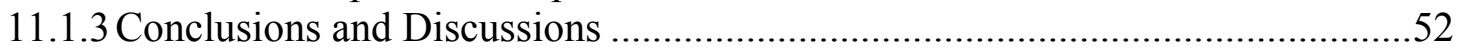




\section{LIST OF FIGURES}

Figure 1: Gear Test Assembly testing heater and torque sensor systems .............................. 9

Figure 2: Replacement tapered roller and cylindrical pin roller bearings ............................ 10

Figure 3: Wear on inconel primary drive gears after initial air and water tests...................... 13

Figure 4: Output for pair of accelerometers mounted on external gearbox ........................... 14

Figure 5 - Pin over dimensions for test gears and normal backlash dimension...................... 15

Figure 6 - Polar plots of test gear measured dimensions ................................................. 15

Figure 7: Motor Power and Control Diagram................................................................ 16

Figure 8: C3 ServoManager Configuration Panel ............................................................ 17

Figure 9: C3 Servo Manager Optimization Panel............................................................. 18

Figure 10: ACR Terminal Emulator Panel .......................................................................... 19

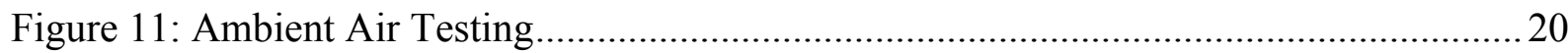

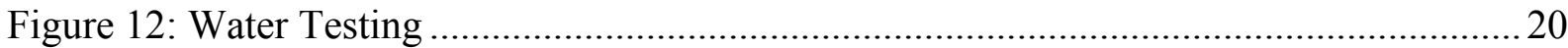

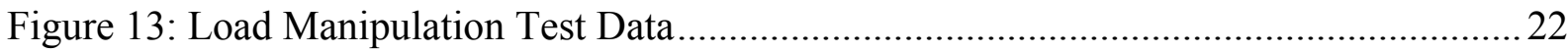

Figure 14 Exploded assembly view of external torque sensor assembly............................ 23

Figure 15: Torque Measurement Comparison ................................................................... 24

Figure 16: Heater Temperature Control System Diagram.................................................25

Figure 17: Transient Temperature Distribution through Stainless Steel Plate ........................ 26

Figure 18: ASME B\&PV Code Fatigue Limits for Stainless Steel .....................................26

Figure 19 - Equivalent stresses at (a) 8 seconds heater on (b) 52 seconds heater off............. 28

Figure 20: Strip Heater Supplied Flux vs Temperature .................................................... 28

Figure 21 - Steady state temperature distribution in the stainless steel ...............................29

Figure 22 - GTA Mid-plane temperature distribution and air velocity vectors ...................... 30

Figure 23 - Heat up rate of for GTA for various thermocouples on tank cover ..................... 31

Figure 24 - Final Measurements of Shaft Alignment to Packing Counter Bore...................... 32

Figure 25 - Location and thickness of shims required to improve shaft parallelism............... 33

Figure 26 - Argon gas supply system for seal leak testing ................................................ 33

Figure 27: Leakage detected between seal chamber flange and tank cover ........................... 34

Figure 28 - The graphite thrower design and the graphite catch cup.................................. 35

Figure 29 - Deflection for Reduced Compressive Load of 2,000 pounds ............................. 36

Figure 30. (a,b) Drawings of spur gears of two different sizes made of Inconel 718 material. Also shown are (c) photos of the four gears on which baseline NDE was performed. The teeth are numbered on the figure in accordance with the order in which EC scans were performed.

Figure 31. Eddy current inspection system consisting of (a) an MIZ-200 acquisition unit, probes, and an in-house assembled four axis translation/rotation stage. Shown in the figure are photos of a gear mounted on the stage with the probe scanning (b) the gear tooth and (c) the calibration block. Also shown in the figure is (d) the EC 
inspection data associated with the calibration block in image, strip chart and lissajous formats displayed using the ANL computer aided data analysis tool.

Figure 32. Drawing of the Alloy 718 calibration block with three machined subsurface flat-bottom holes. Also shown is a photograph of the backside of the sample manufactured at ANL and the three cylindrical inserts that fill the holes.

Figure 33. Screen captures of the user interfaces implemented at ANL in C\# for controlling the four-axis translation/rotation stage. Shown in Fig. 4(a)-(c) are the main scan configuration panel, the manual control panel, and the raster scan control panel, respectively

Figure 34. Representative baseline NDE data collected on a gear tooth with no detectable damage or degradation. Shown above are (a) photo of gear L1AT with a rectangle delineating the scanned tooth (b) photo of the tooth, (c) EC inspection data from back of tooth \#7 displayed with ANL data analysis tool and (d) expanded view of the vertical component of data in image format.

Figure 35. Representative baseline NDE data collected on a gear tooth with mechanical wear type damage over its entire surface. Shown above are (a) photo of gear T1BT with a rectangle delineating the scanned tooth (front of tooth \#1) (b) photo of the tooth, (c) EC inspection data displayed with ANL data analysis tool and (d) expanded view of the vertical component of data in image format.

Figure 36. Representative baseline data collected on a gear tooth with detectable volumetric damage. Shown above are (a) photo of gear L1AT with a rectangle delineating the damaged area (backside of tooth \#1) (b) photo of the delineated area, (c) EC inspection data over the entire area of tooth displayed with ANL data analysis tool and (d) expanded view of the vertical component of the data in image format for the region shown in (b).

Figure 37. Ultrasonic inspection system consisting of an ultrasonic pulser, a submergible ultrasonic transducer, a water tank, a three-axes step-motor scanning module, and a

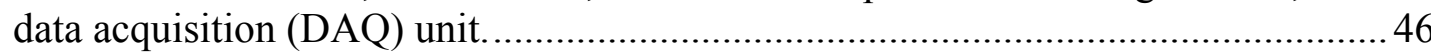

Figure 38. UT inspection of a manipulator spur gear in water test. .............................. 46

Figure 39. Typical real-time ultrasonic RF signal of from a pulse-echo test of a manipulator spur gear.

Figure 40. Real-time ultrasonic intensity images of Gear B-T1BT generated by using (left) a focused and (right) an unfocused ultrasonic transducer.

Figure 41. Ultrasonic intensity images of Gear B-T1BT rotating clockwise every three teeth. 48

Figure 42. (left) Composited ultrasonic intensity image and (right) photo of Gear BT1BT...

Figure 43. (top) Ultrasonic RF signal at the cursor, (left) TOF image, and (right) intensity image.

Figure 44. Ultrasonic intensity images of Gear A-T1IT rotating clockwise every three teeth. 50

Figure 45. (top) Ultrasonic RF signal at the cursor, (left) TOF image, and (right) intensity image. 
Figure 46. Ultrasonic intensity images of Gear AA-L1AT rotating clockwise every two teeth. 51

Figure 47. (right) Composited ultrasonic intensity image and (left) photo of Gear AA-

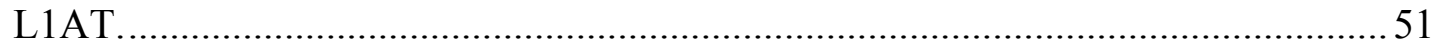

Figure 48. Ultrasonic intensity images of Gear BB-L1IT rotating clockwise every two teeth. 52 


\section{LIST OF TABLES}

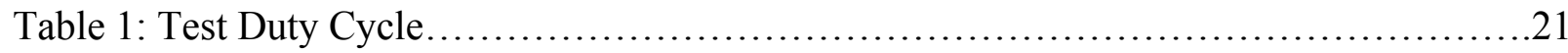





\section{Executive Summary}

The gear test assembly completed testing in air and distilled water successfully under a range of loading conditions. An external torque sensor assembly was designed and added to confirm the torque readings provided by the Parker control system. Hand calculations were performed to determine the time range that the heaters could be turned on without exceeding the ASME Boiler and Pressure Vessel code Fatigue Stress Limits for 1,000,000 cycles. Transient computational fluid dynamics analyses were performed to determine the heater cycle on/off time. Steady state computational fluid dynamics analyses were performed to determine the final temperature distribution throughout the insulated assembly using a thinner but more effective insulation configuration. The initial heating tests were completed (without insulation installed) to check the heater control system. Testing of the argon pressurized seal chambers were performed and indicated the need for re-machining of several components to eliminate some leaks. Nondestructive examination of the gears continued successfully using eddy current and ultrasonic inspection techniques. 


\section{Assembly Overview}

The Gear Test Assembly (GTA) is an experimental apparatus designed to test mechanical components used in the fuel handling systems of liquid-sodium cooled fast-spectrum nuclear reactors. The assembly will be placed in a test vessel of the Mechanisms Engineering Testing Laboratory (METL) which will provide liquefied sodium at controlled temperatures and flow rates for testing. The need for METL was identified during the development of advanced fuel handling technologies for the Advanced Reactor Concepts (ARC) program ${ }^{1}$. Reviews of existing documentation indicated a lack of testing for specific mechanical components used in the construction of advanced fuel handling systems. Most dynamic testing performed to date uses a pin rubbing on a plate to test various materials for friction, wear and self-welding. The existing data is insufficient for proper lifetime calculations of gearing components which operate under load in a high temperature flowing liquid sodium environment. The loads applied to the components in the GTA are based upon maximum design loading conditions calculated for a fuel handling system under worst case design conditions.

The system is designed for maximum flexibility by accommodating various sizes of normal and parallel helical spur gears and roller bearings. The system can also be modified to test helical spur gears, worm gears, and straight or spiral bevel gears as well as hydrostatic or hydrodynamic bearings with minimal replacement of parts inside the liquid sodium testing area. Resulting data will be taken using vibration probes, torque sensors, tachometers, thermocouples, level sensors, etc. and compared with data recorded by the METL system on sodium flow rates, purity and temperatures. There is considerable reserve capacity in the system for additional measurements and measuring devices. There will also be extensive pre- and post-test metallurgical analysis of the gears to determine the onset and evolution of mechanical failure.

An externally mounted torque sensor was added to the gear test assembly (Figure 1) to confirm the torque measurements provided by the Parker motor drive control system. A non-contacting in line Futek torque sensor was specified for the external sensor assembly and mounted in a frame assembly located between the Stober planetary reduction gear and the external gearbox on the "A" drive motor and shaft.

\footnotetext{
${ }^{1}$ The Advanced Reactor Concepts program was the predecessor of the DOE-NE Advanced Reactor Technologies program.
} 


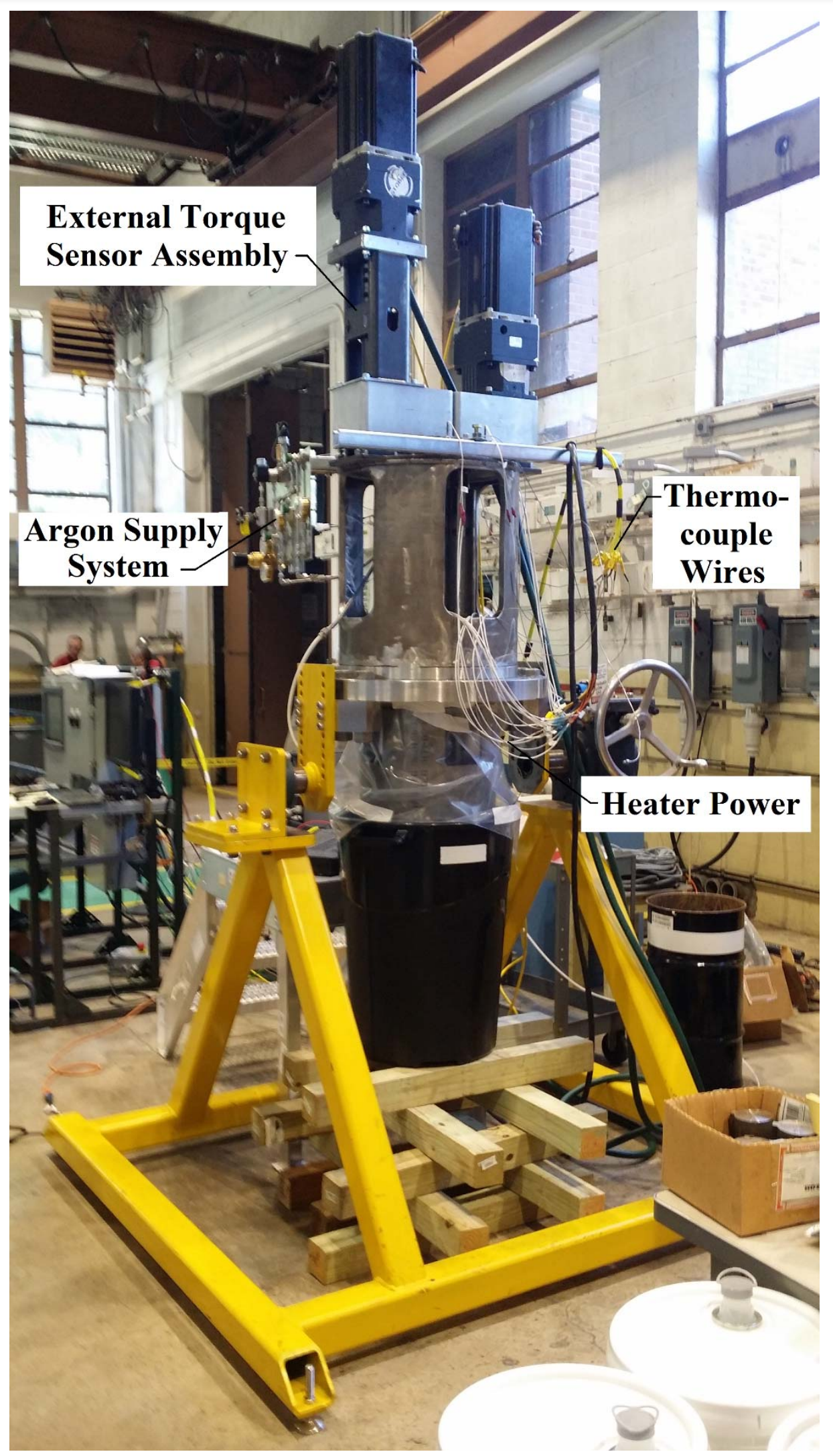

Figure 1: Gear Test Assembly testing heater and torque sensor systems 


\section{Bearing System Modification}

The original design of the Gear Test Assembly (GTA) included the use of hydrodynamic bearings to assure that the only mechanical contact in the test assembly was between the gear faces. The shear forces generated by the moving fluid was calculated to provide non-contact between the rotating shaft and fixed sleeve under maximum shaft loading at an operational speed of 350 RPM. After the full system was manufactured and assembled, the use of hydrodynamic bearings proved to be difficult as a number of manufacturing errors and "jogging" operation at slow speeds caused the inconel 718 shaft sleeves to gall against the inconel 718 bearing sleeves. The in-sodium gearboxes were machined to accept tapered roller bearings.

Tapered roller bearings manufactured by Timken were chosen to provide radial and axial support of the gears while needle thrust bearings and washers manufactured by SKF were chosen to provide axial support of the shafts. Heat treated 52100 steel tapered roller bearings were special ordered to provide a desired upper temperature limit of $350^{\circ} \mathrm{C}$. The needle thrust bearings were manufactured out of stainless steel. Installation of the roller bearings provided free shaft rotation and the motor programming and control efforts were started.

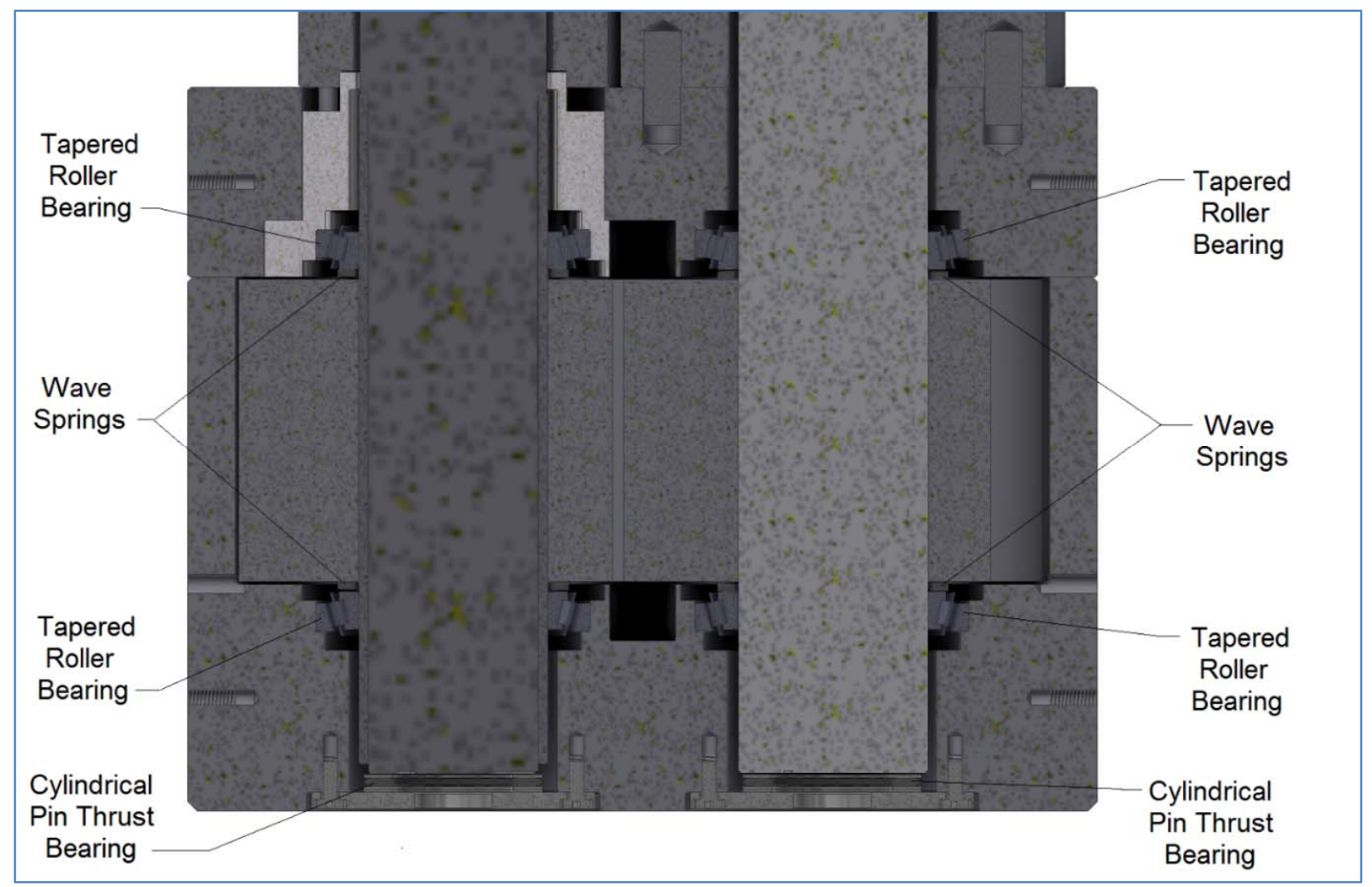

Figure 2: Replacement tapered roller and cylindrical pin roller bearings

The gears in the gear test assembly are supported in the gearboxes using pairs of tapered roller bearings and wave springs (Figure 2). The stainless steel wave springs were chosen to provide a uniform preload to the tapered roller bearings and also to prevent the spur gear side faces from 
contacting the inside of the gearbox walls due to unforeseen dynamic motion of the gears from potentially unbalanced fluid forces inside the gearboxes. The wave springs are compressed at assembly slightly more than the vendor recommended values to assure that even if the wave springs are fully compressed to a flat state, the gears do not contact the gearbox walls.

The lifetime for the stainless steel bearings (in millions of revolutions) has been calculated based upon the ANSI/ABMA Std. 11-1990 (American Bearing Manufacturers Association) standards for tapered roller bearings and cylindrical pin roller bearings. As an example, the tapered roller bearings are analyzed using the following equations to determine the radial load ratings for the particular bearing being used.

$$
\begin{aligned}
& \text { Basic Static Radial Load Rating } \quad \mathrm{C}_{\mathrm{or}}:=44 \cdot\left(1-\frac{\mathrm{D}_{\mathrm{we}} \cdot \cos (\alpha)}{\mathrm{D}_{\mathrm{pw}}}\right) \cdot \mathrm{i} \cdot \mathrm{Z} \cdot \mathrm{L}_{\mathrm{we}} \cdot \mathrm{D}_{\mathrm{we}} \cdot \cos (\alpha) \\
& \text { Basic Dynamic Radial Load Rating } \quad \mathrm{C}_{\mathrm{r}}:=\mathrm{f}_{\mathrm{cm}} \cdot\left(\mathrm{i} \cdot \mathrm{L}_{\mathrm{we}} \cdot \cos (\alpha)\right)^{\frac{7}{9}} \cdot \mathrm{Z}^{\frac{3}{4}} \cdot\left(\mathrm{D}_{\mathrm{we}}\right)^{\frac{29}{27}}
\end{aligned}
$$

Where;

$$
\begin{aligned}
& D_{\mathrm{we}} \text { - Diameter of the rolling element } \\
& \alpha \quad \text { - Contact angle of the Rolling Element } \\
& \mathrm{D}_{\mathrm{pw}} \text { - Pitch Diameter of Roller Set } \\
& \mathrm{i} \quad-\text { Number of Rows of Rollers } \\
& \mathrm{Z} \quad-\text { Number of Rolling Elements } \\
& \mathrm{L}_{\mathrm{we}}-\text { Length of rolling elements } \\
& \mathrm{f}_{\mathrm{cm}}-\text { Radial Bearing Factor (Interpolated from Table 1 Part 1) }
\end{aligned}
$$

Similarly, the axial load ratings are calculated for the tapered thrust bearing selected using the following equations. 
Basic Dynamic Axial Load Rating for Thrust Bearings

Basic Static Axial Load Rating for Thrust Bearings

$$
\begin{aligned}
& \mathrm{C}_{\mathrm{a}}:=\mathrm{f}_{\mathrm{cm}} \cdot\left[\mathrm{L}_{\mathrm{we}} \cdot\left(\frac{1}{\mathrm{~mm}}\right) \cdot \cos (\alpha)\right]^{\frac{7}{9}} \cdot \mathrm{Z}^{\frac{3}{4}} \cdot\left[\mathrm{D}_{\mathrm{we}} \cdot\left(\frac{1}{\mathrm{~mm}}\right)\right]^{\frac{29}{27}} \cdot \tan (\alpha) \\
& \mathrm{C}_{\mathrm{oa}}:=220 \cdot\left(\frac{\mathrm{N}}{\mathrm{mm}^{2}}\right) \cdot\left(1-\frac{\mathrm{D}_{\mathrm{we}} \cdot \cos (\alpha)}{\mathrm{D}_{\mathrm{pw}}}\right) \cdot \mathrm{Z} \cdot \mathrm{L}_{\mathrm{we}} \cdot \mathrm{D}_{\mathrm{we}} \cdot \sin (\alpha)
\end{aligned}
$$

The lifetime of the bearings is calculated based upon the axial and radial loadings for the tapered roller bearing.

TABLE 2. Values of $X$ and $Y$ for Radial

Roller Bearings

\begin{tabular}{|c|c|c|c|c|c|}
\hline \multirow{2}{*}{ Bearing Type } & \multicolumn{2}{|c|}{$\frac{\mathbf{F}_{\mathrm{a}}}{\mathbf{F}_{\mathbf{r}}}<\mathbf{e}$} & \multicolumn{2}{|c|}{$\frac{\mathbf{F}_{\mathrm{a}}}{\mathbf{F}_{\mathbf{r}}}>\mathbf{e}$} & \multirow{2}{*}{$\mathbf{X}$} \\
\cline { 2 - 5 } & $\mathbf{X}$ & $\mathbf{Y}$ & $\mathbf{X}$ & $\mathbf{Y}$ & $\mathbf{e}$ \\
\hline Single row, $\alpha \neq 0^{\circ}$ & 1 & 0 & 0.4 & $0.4 \cot \alpha$ & $1.5 \tan \alpha$ \\
Double row, $\alpha \neq 0^{\circ}$ & 1 & $0.45 \cot \alpha$ & 0.67 & $0.67 \cot \alpha$ & $1.5 \tan \alpha$ \\
\hline
\end{tabular}

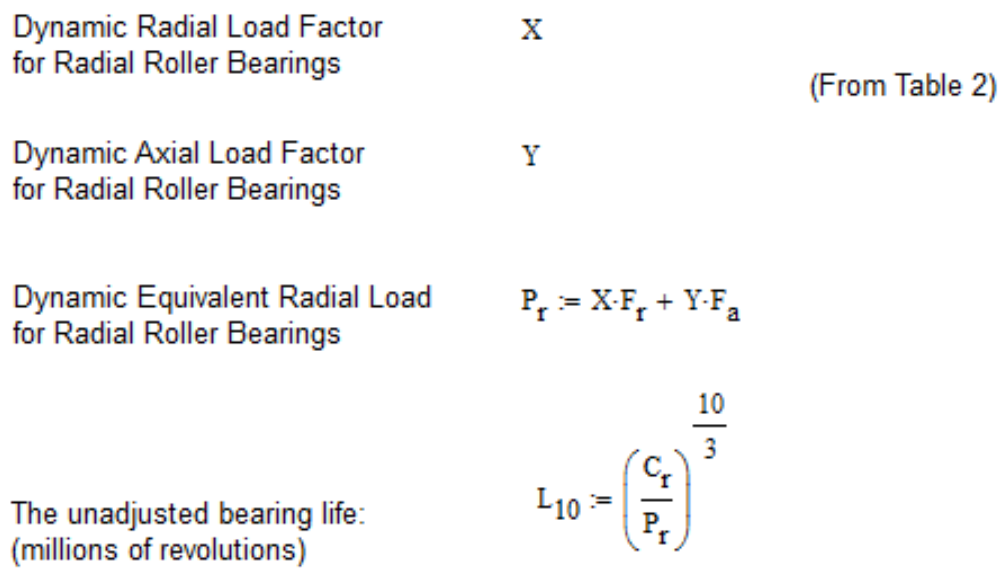

Where;

$$
\begin{aligned}
& \mathrm{F}_{\mathrm{r}}-\text { Maximum Static Radial Load } \\
& \mathrm{F}_{\mathrm{a}}-\text { Maximum Static Axial Load }
\end{aligned}
$$

Although the calculations do not include the effects of lifetime reduction for being operated in high temperature liquid sodium, these factors will be estimated based upon observed accelerated wear during periodic inspections over the course of the testing cycle. Wear of the components will be measured during inspection and excessively worn components will be replaced with new components over the course of each experiment. 


\section{Gear Inspection}

After initial testing in air and water was completed, the gears were visually inspected. Uneven wear was observed on the gears. Closer inspection indicated a faceted appearance on the gear contact faces. This implies that the EDM process used straight lines connected at points to the curves to cut the gears in lieu of following the continuous non-uniform rational basis spline which was provided to the manufacturer.

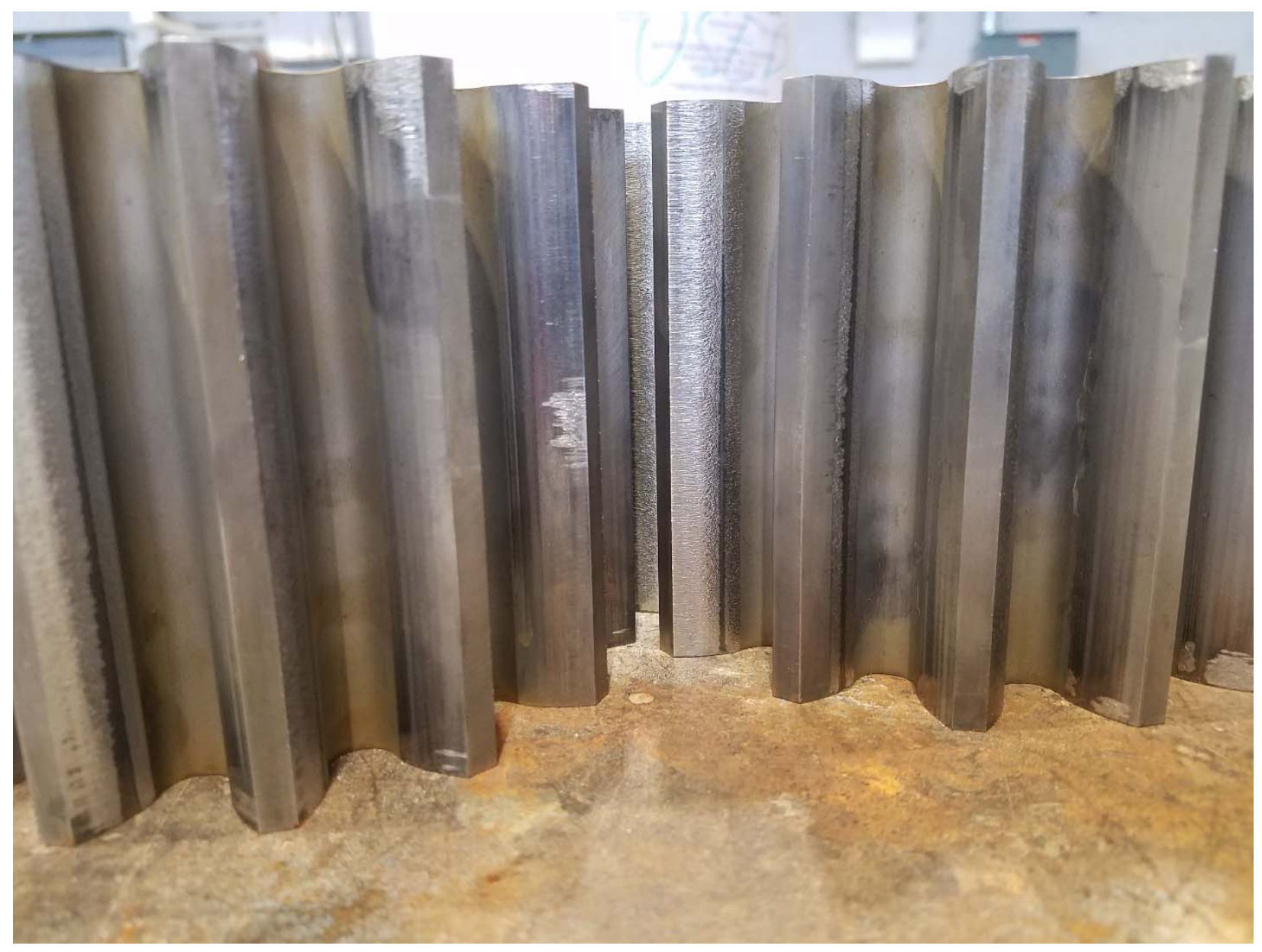

Figure 3: Wear on inconel primary drive gears after initial air and water tests

Percussive gear noise was detected in the external gearboxes during initial operation, so the audio signal was analyzed to determine the frequency sound wave profile, the audio data was processed using the Audio Director Software package. Later, accelerometers were attached to the external gearboxes to provide a more accurate and cleaner vibration amplitude profile. The data from the accelerometers indicate four peaks in the vibration output from the accelerometers per revolution of the shaft (Figure 4). 
These peaks are aligned with the gear contact timing frequency and indicate that each gear may have a pair of flaws in their machined profile. The separation in the pair of peaks indicate that they are offset by approximately 3 teeth. The most likely causes of the peaks are manufacturing errors in the gear tooth profile. The bearings were inspected after disassembly and showed no abnormal signs of wear or cracks in the races or rollers.

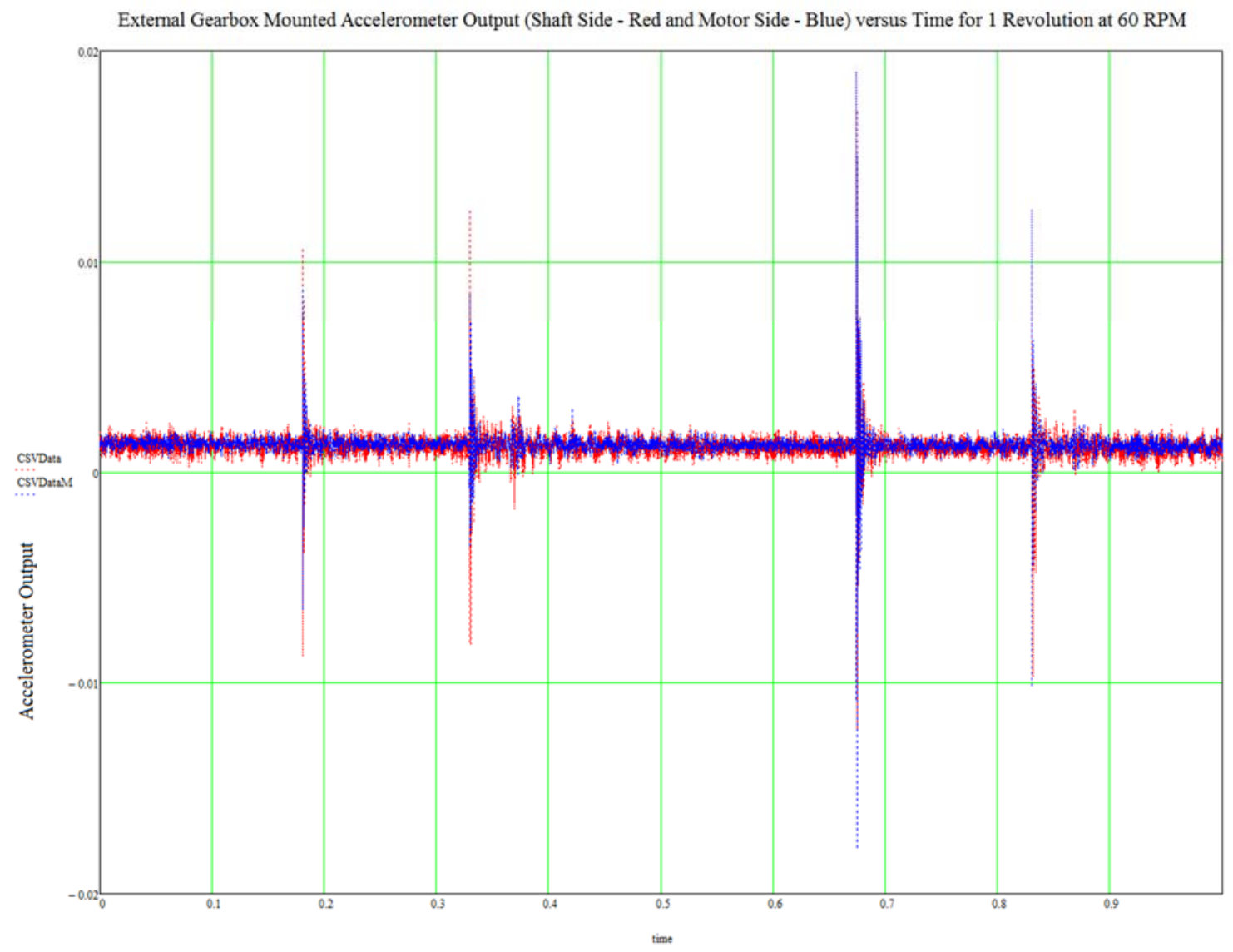

Figure 4: Output for pair of accelerometers mounted on external gearbox

The internal test and drive gears were inspected after disassembly using the "pin over" inspection technique which uses a pair of dowel pins of known diameter placed between gear teeth opposite one another (Figure 5) to determine the accuracy of the machined gears. This information was provided to the gear manufacturer for inspecting the gears during manufacture.

Although there was some scuffing on the gear faces from operating in air and water (which will affect the accuracy of the measurements), the initial over pin measurements (Figure 6) indicate that the gears are slightly oversize from 0.009 " to 0.024 " and the uniformity of the gear profile varies from 0.005 " to $0.014 "$. 


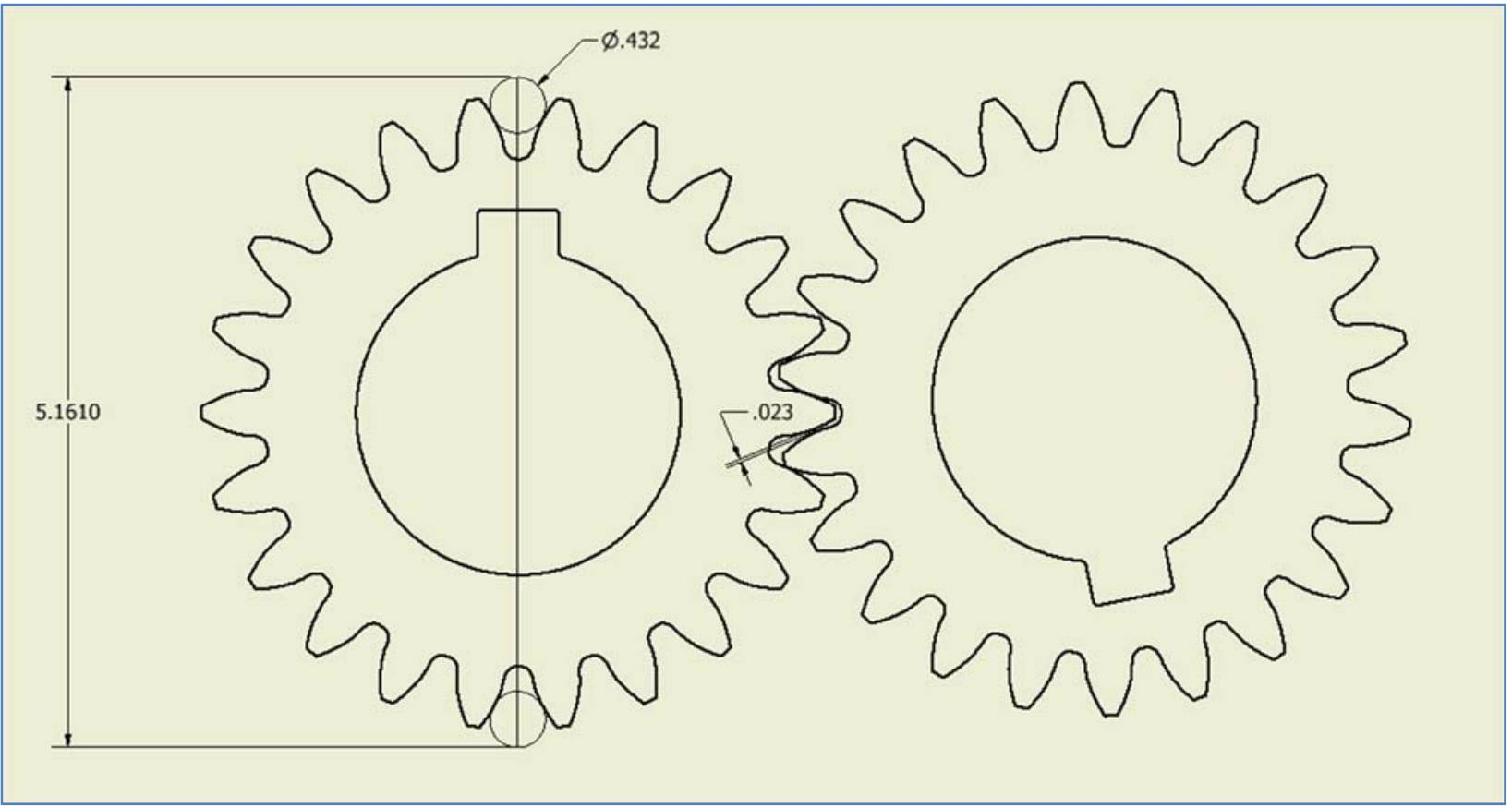

Figure 5 - Pin over dimensions for test gears and normal backlash dimension
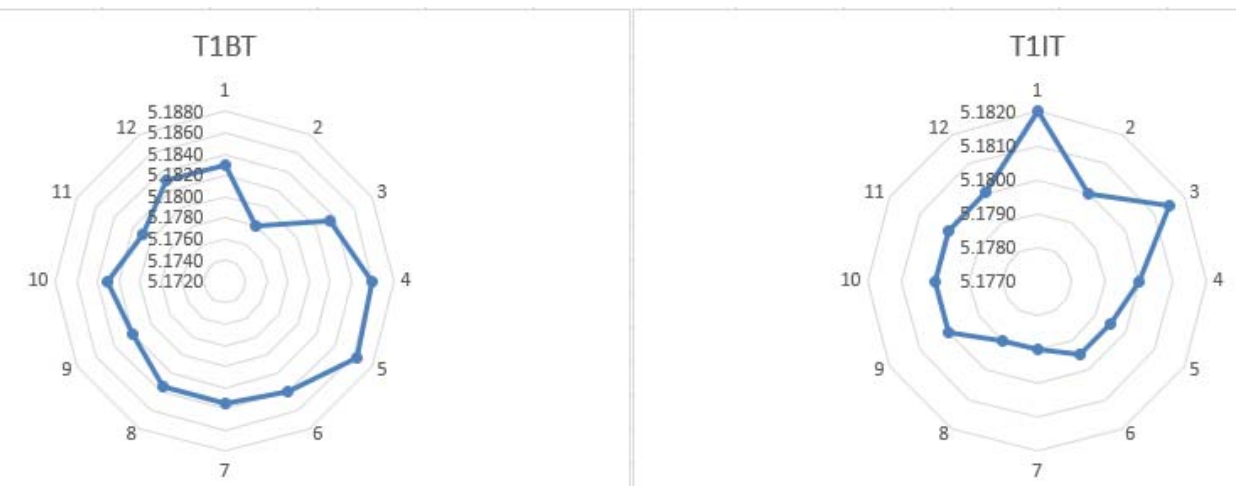

Figure 6 - Polar plots of test gear measured dimensions

These imperfections in the gears (which may in part be due to the scuff marks from the initial air and water testing) are acceptable for use in the testing process as they will provide a variation in contact and release (impact) forces and locations on the gear faces. This data can be used to verify the initial size and location of potential pitting on the gear contact faces. The measurement of increased wear on specific faces will also be invaluable as data in evaluating the wear profiles of the overall gear geometry based upon these imperfections. Changes to the gear geometric profile over time (due to wear, etc.) will be recorded at specific inspection intervals over the testing cycle and the data will be analyzed as part of the overall testing program. 


\section{Motor Programming and Control}

The drive system for the GTA uses a pair of Parker MPP1908P1E-KPSV brushless servomotors. Each motor has a max rated speed of 2,781.5 RPM, max continuous current of 30.31 Arms, and a peak torque of 1,381.38 inch-pounds. Each motor is equipped with a 7:1 Stober reducing gearhead to attain the designed maximum torque of 6,000 inch-pounds. Each motor is powered by a separate Compax3 Servo Drive. Each Compax3 H050V4 F12I30T11M00 has an input voltage of $480 \mathrm{VAC}$ and has a maximum output current of 43 Arms. Each Compax3 is configured using the C3 ServoManager software to properly operate the selected servomotor. Individual motor control is possible using the ServoManager software, but dual motor control requires additional hardware. The ACR 9040 P1UOBO motion controller can communicate with up to 16 devices using the ETHERNET Powerlink (EPL) communication protocol. The ACR is programmed using the ACRView software, where motor motion programs can be written using the AcroBASIC command language. Up to 16 unique motion programs can be loaded on the $\mathrm{ACR}$ at a time, and selectively run via a control computer.

A Windows based workstation was has been used to do the preliminary configuration and programming of the system, as well as run a National Instruments (NI) LabVIEW VI capable of monitoring system parameters and conducting limited control. A Parker EPX215X-EVAA-1 Human-Machine Interface (HMI) using the InteractX 3.0 runtime has also been installed. This will give an additional means of monitoring the system and switching between motion programs on the ACR. Figure 7 shows a diagram of the motor power and control setup.

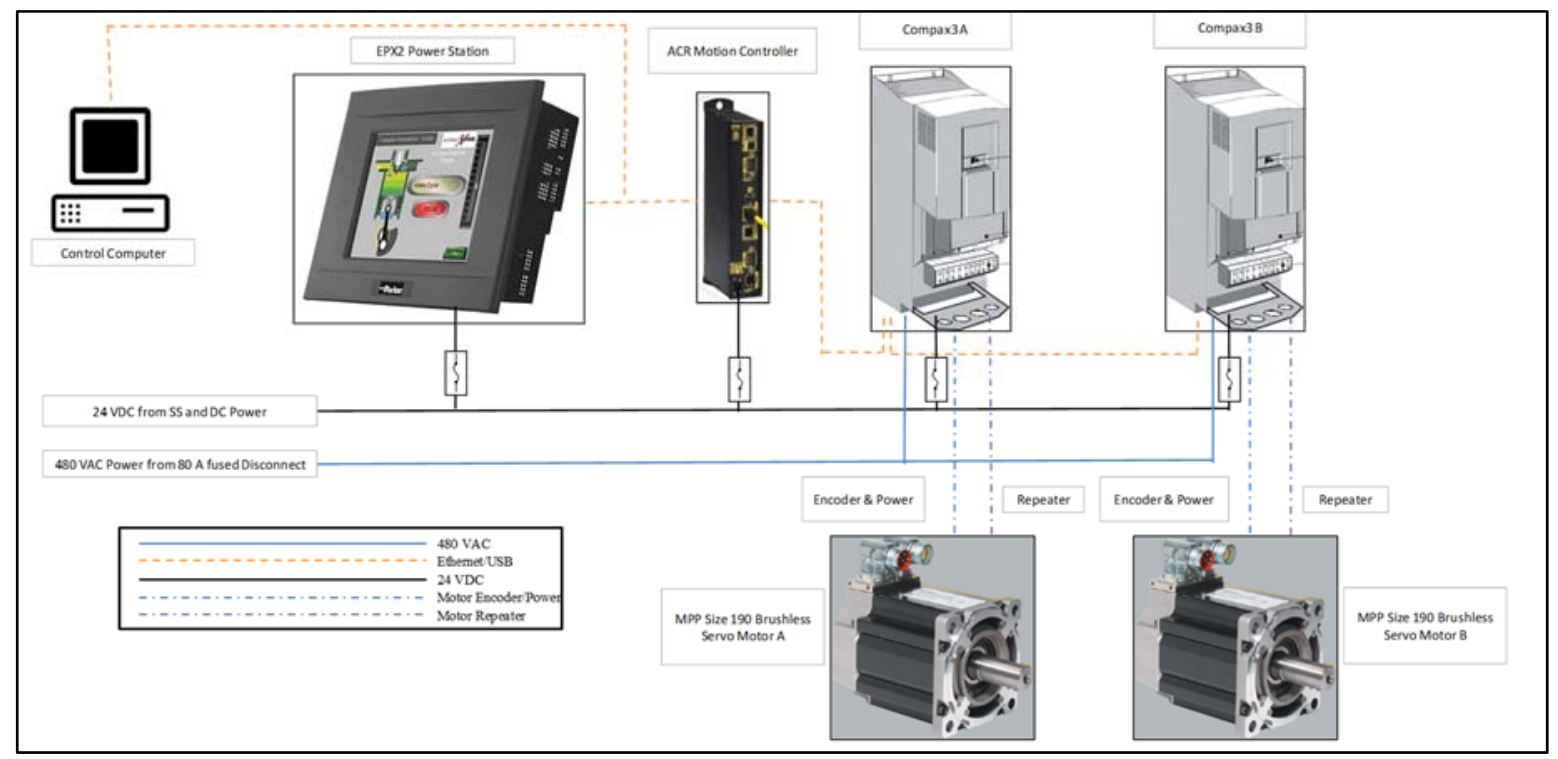

Figure 7: Motor Power and Control Diagram

For the system to mimic the fuel loading sequence previously described, each motor will need to perform a different function. One motor will act as the drive motor, operating a velocity profile motion program that mimics the function of manipulating the fuel bundle. The other motor will act as the load motor, operating a velocity profile motion program that will mimic the forces associated with moving the fuel bundle. Developing the drive motor's motion program is a 
relatively simple task. It will tell the motor to rotate one direction, pause, rotate back, pause, and repeat. The load motor's motion program is a more atypical task. This will be accomplished by operating the motor in a "stalled" state, where the motor will try to hold position using the maximum configured torque. To change torque values, this maximum configured torque can then be changed programmatically. This coordinated control scheme will be refined during the inwater testing.

The first step was to communicate with a single motor via its Compax 3 servo motor drive. The Compax 3 supplies power and read/writes data to the motor via a power/encoder umbilical and a repeater umbilical. With the power supplied to the Compax3 and the motor, the $\mathrm{C} 3$

ServoManager software was booted up. The C 3 software was used to set the default operating parameters the motor uses during operation. There is a "Setup Wizard" that can be used to walk through the process in a logical manner. Figure 8 shows the configuration panel after running the "Setup Wizard".

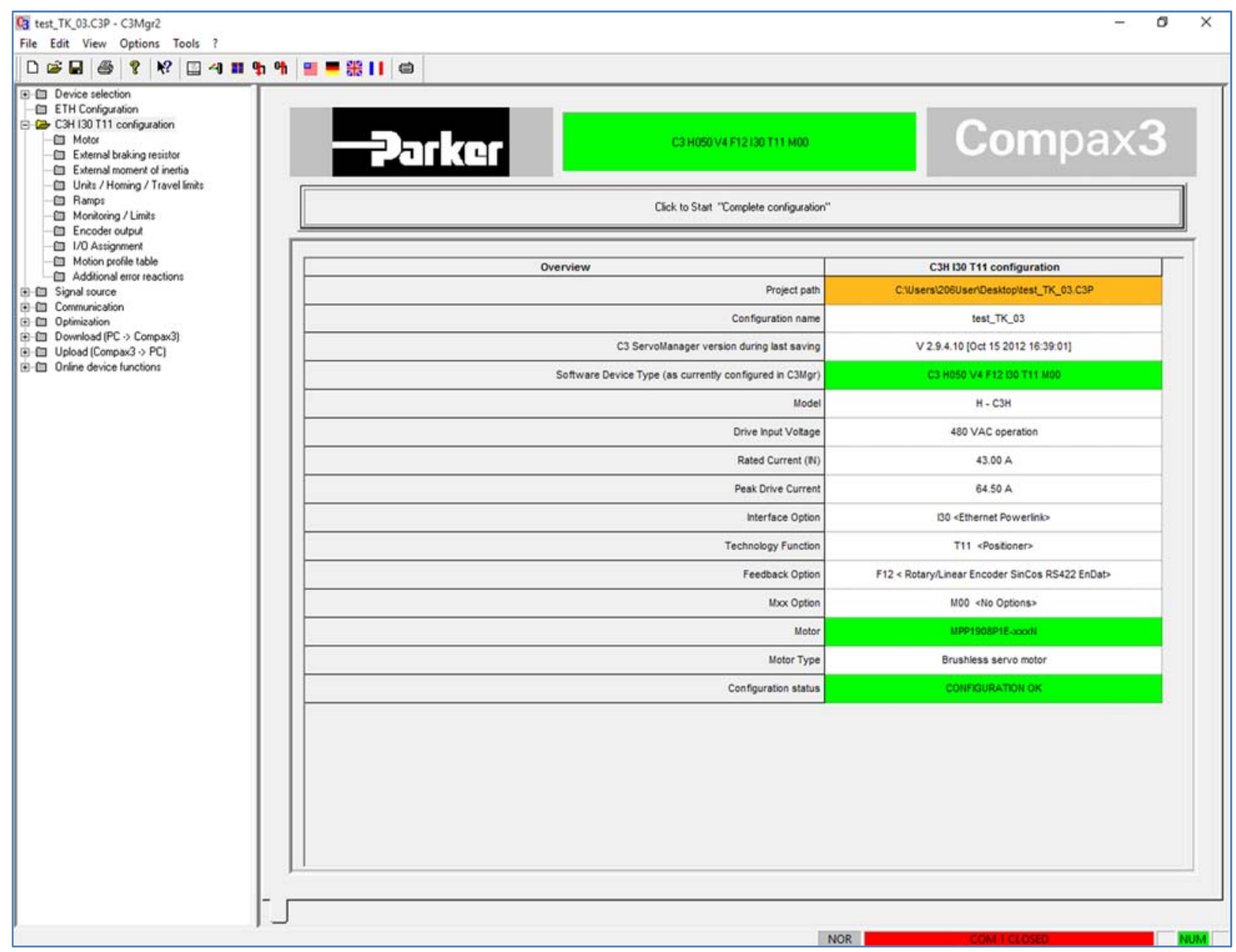

Figure 8: C3 ServoManager Configuration Panel

Once the proper parameters were selected and uploaded to the Compax 3 , the motor was ready for motion. The motor was tested using an optimization panel (Figure 9) by performing simple motions such as jog forward, jog back, or operating some simple velocity profiles. For more 
complicated operations, including dual motor control, programming the motors via the ACR was required.

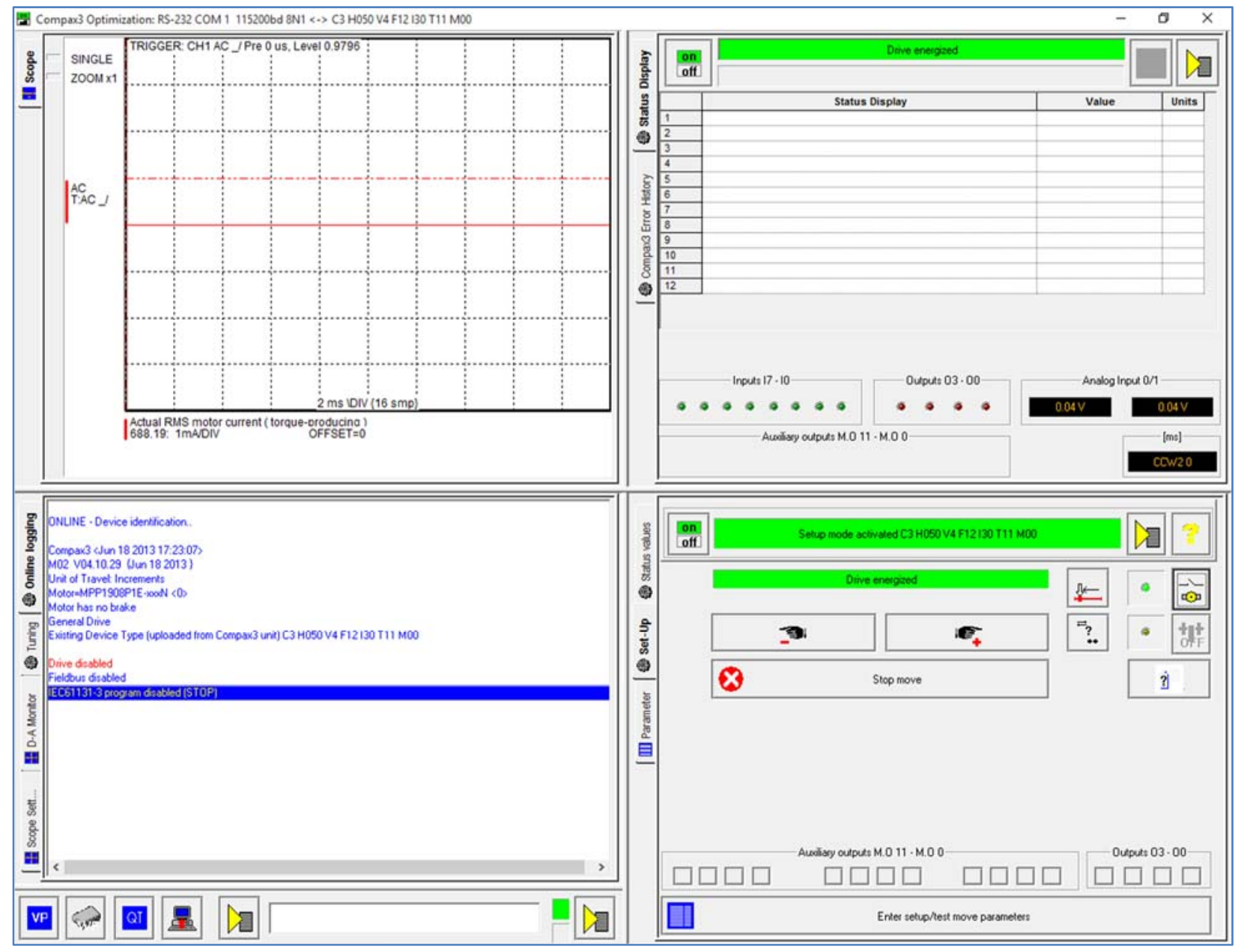

Figure 9: C3 Servo Manager Optimization Panel

With both motors set up using their respective Compax 3 servo motor drives, programming via the ACR could proceed. The ACR communicates with both Compax3s simultaneously and can perform complex multi-axis operations. The ACRView software also features a "Setup Wizard" that aids in programming the parameters required to perform motion operations. With these parameters loaded onto the ACR, simple motion operations were performed to test the motors. This was accomplished using a terminal simulator (Figure 10) and entering specific commands in the AcroBASIC language. Dual motor control was achieved and more complex coordinated motion was performed. The command library for this language is extensive, and can be used to perform complex coordinated motion. With basic understanding of the motor control software achieved, a series of dynamic tests were performed to examine the performance of the system. 


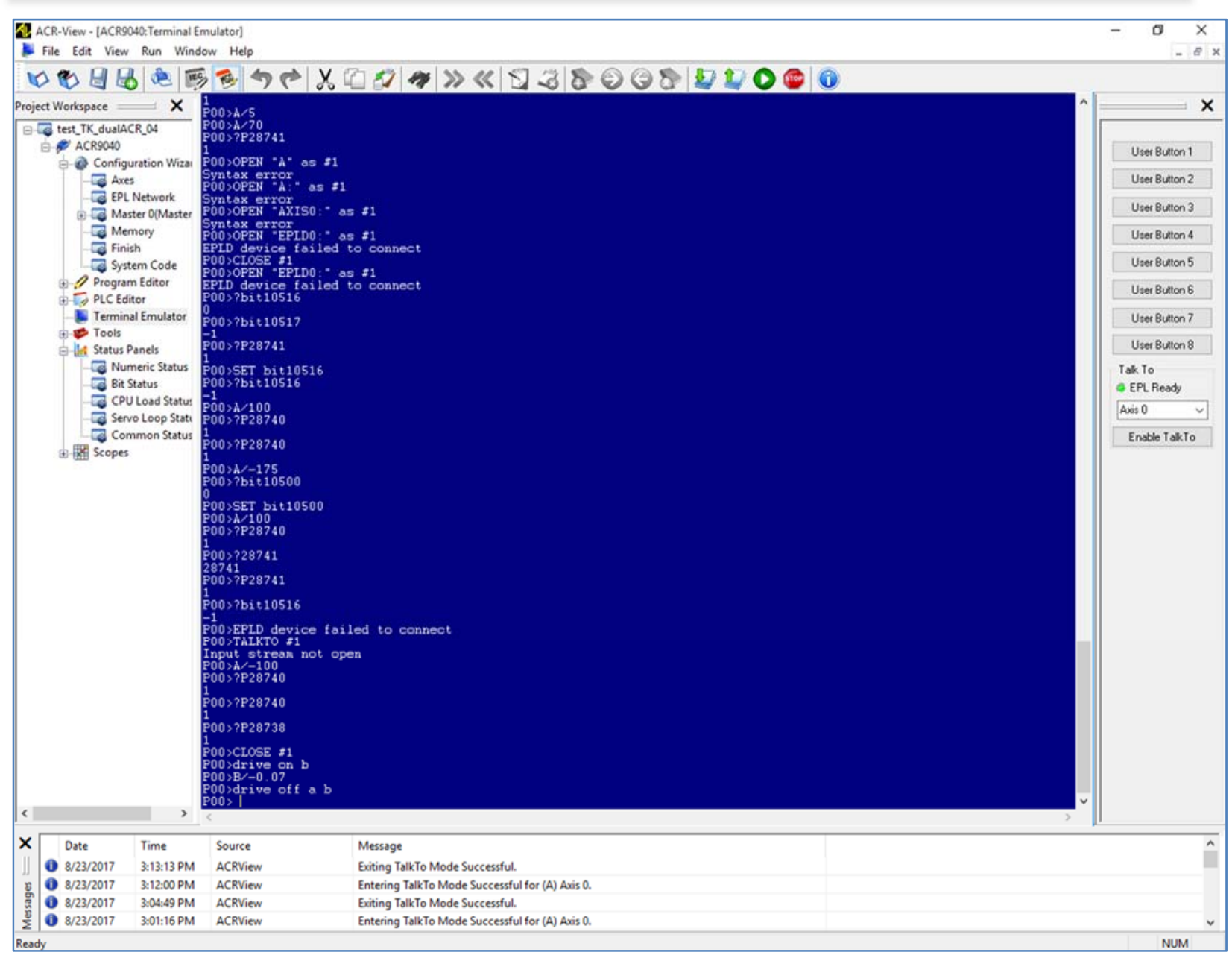

Figure 10: ACR Terminal Emulator Panel

\section{Dynamic Testing}

Pre-sodium testing was conducted in 206 High Bay to commission the motor control system and observe the system torque. The majority of the testing was performed with the lower gearbox submerged in distilled water that acted as a sodium analogue. This provided a slight amount of lubrication as well as mimicked the hydrodynamic properties of the liquid sodium. The first series of testing examined the torque needed to rotate the shafts when the system is fully assembled. To accomplish this, a simple program was written that drove one motor for a period of 10 minutes at 350 RPM. The data collected during this operation was the current output commanded to the servo motor. This number can be used to roughly calculate the torque applied by the motor, but there is a reported error of roughly $\pm 10 \%$. Note that this is not a direct measurement of torque applied to the system. Later inclusion of a torque sensor provided this measurement. Two tests were performed using this motor program. The first test was performed with the gears only exposed to ambient air. The data from this test is presented in Figure 11. The second test performed ran the same motor program, but now the gears were submerged in distilled water. The data from this test is presented in Figure 12. 


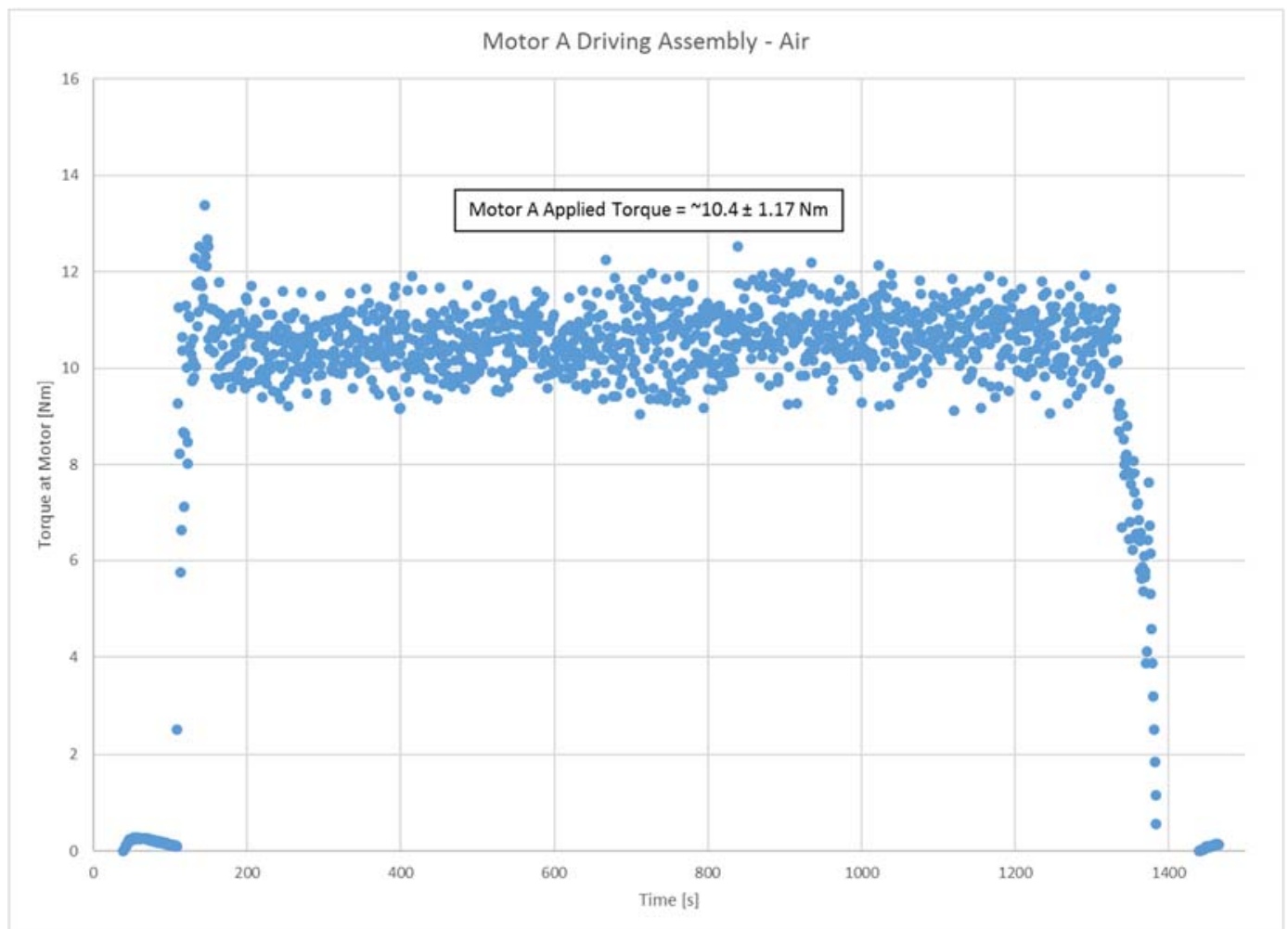

Figure 11: Ambient Air Testing

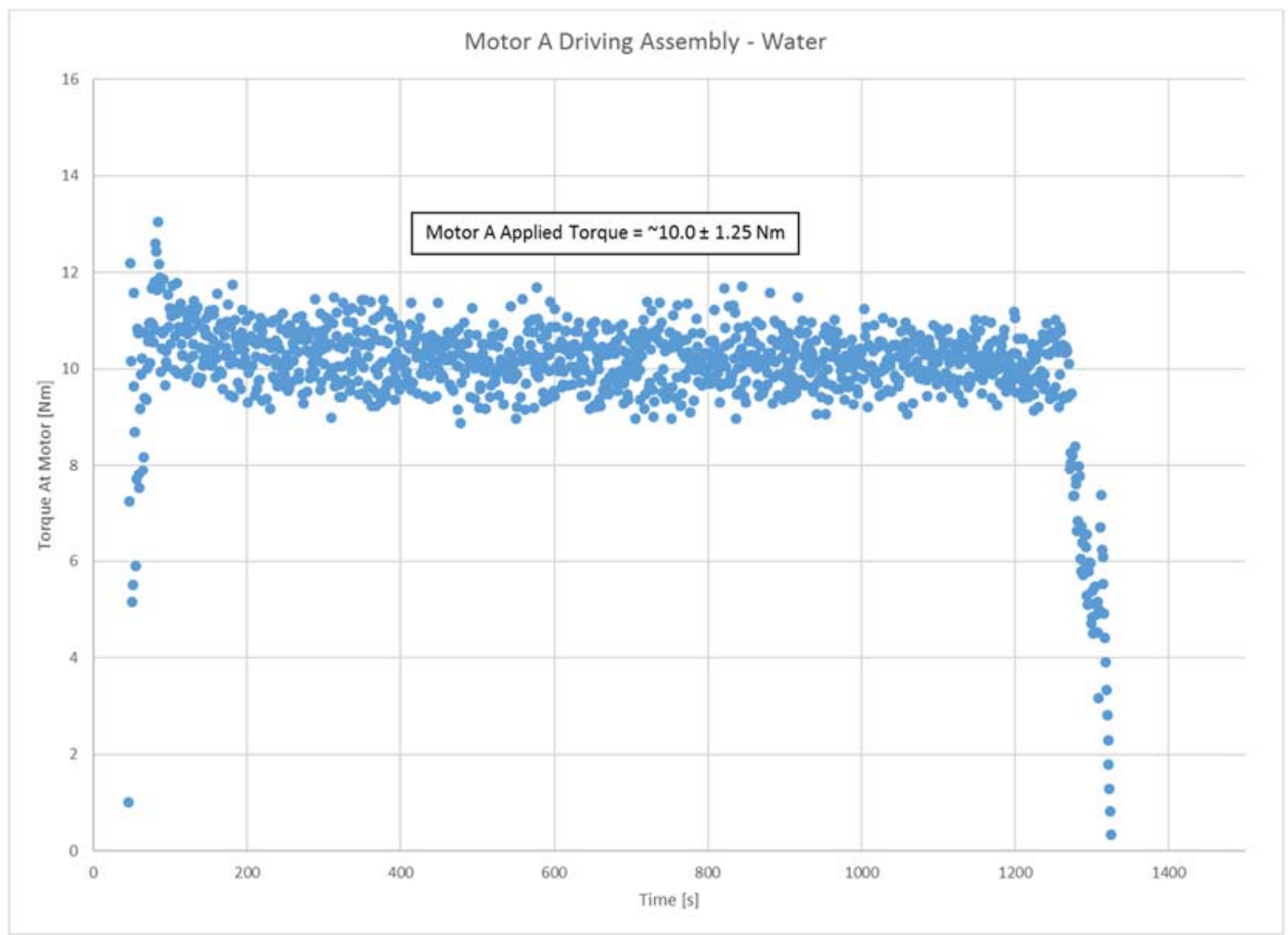

Figure 12: Water Testing 
The data collected during the first dynamic tests show that the system torque is roughly $10 \mathrm{Nm}$. The testing also suggests that the water used in the second run did provide a slight amount of lubrication, but not a significant amount.

The next round of testing aimed at testing the torque control logic planned for the experimental program. As previously mentioned, the resistance applied to the second shaft is controlled by limiting the maximum current output of the load motor while operating this motor in a stalled state. The desired experimental torque profile, shown in Table 1, requires that the load be changed mid-routine.

Table 1: Desired Initial Experimental Torque Profile

\begin{tabular}{|c|c|c|c|c|c|}
\hline $\begin{array}{r}\text { Load } \\
\text { Step }\end{array}$ & $\begin{array}{l}\text { Torque } \\
\text { at Gear } \\
\text { [in-lbs.] }\end{array}$ & $\begin{array}{c}\text { Time } \\
\text { [s] }\end{array}$ & $\begin{array}{l}\text { Motor A } \\
\text { Operation } \\
\text { Mode }\end{array}$ & $\begin{array}{l}\text { Motor B } \\
\text { Operation } \\
\text { Mode }\end{array}$ & $\begin{array}{l}\text { Equivalent Process in Core } \\
\text { Assembly Handling Procedure }\end{array}$ \\
\hline 1 & 6,000 & 2.0 & Driving & Resisting & $\begin{array}{l}\text { Lifting core assembly with resistance } \\
\text { due to load pad and nose piece to } \\
\text { inlet plenum contact }\end{array}$ \\
\hline 2 & 1,000 & 58.0 & Driving & Resisting & Lifting core assembly weight \\
\hline 3 & 0 & 30.0 & Dwell & Dwell & $\begin{array}{c}\text { Core assembly vertical position } \\
\text { unchanged during horizontal traverse } \\
\text { (motor direction and operation } \\
\text { reverses) }\end{array}$ \\
\hline 4 & 1,000 & 58.0 & Resisting & Driving & Lowering core assembly weight \\
\hline 5 & 6,000 & 2.0 & Resisting & Driving & $\begin{array}{l}\text { Lowering core assembly with } \\
\text { resistance due to load pad and nose } \\
\text { piece to inlet plenum contact }\end{array}$ \\
\hline 6 & 0 & 30.0 & Dwell & Dwell & $\begin{array}{c}\text { Core assembly vertical position } \\
\text { unchanged during horizontal traverse } \\
\text { (motor direction and operation } \\
\text { reverses) }\end{array}$ \\
\hline
\end{tabular}

To accomplish this, a series of programs were written and loaded on the ACR that can change the maximum current output allowed to the load motor when they are run. A master program loaded on the ACR is used to direct the motion of the drive motor, while running the current change programs at the proper time. Sample data displayed in Figure 13 shows the drive motor operating at a high torque for two seconds, then the load motor is reprogramed to operate at a lower torque. This lower torque segment is ran for several more seconds. This test validated the torque manipulation efforts needed to meet the experimental requirements. 


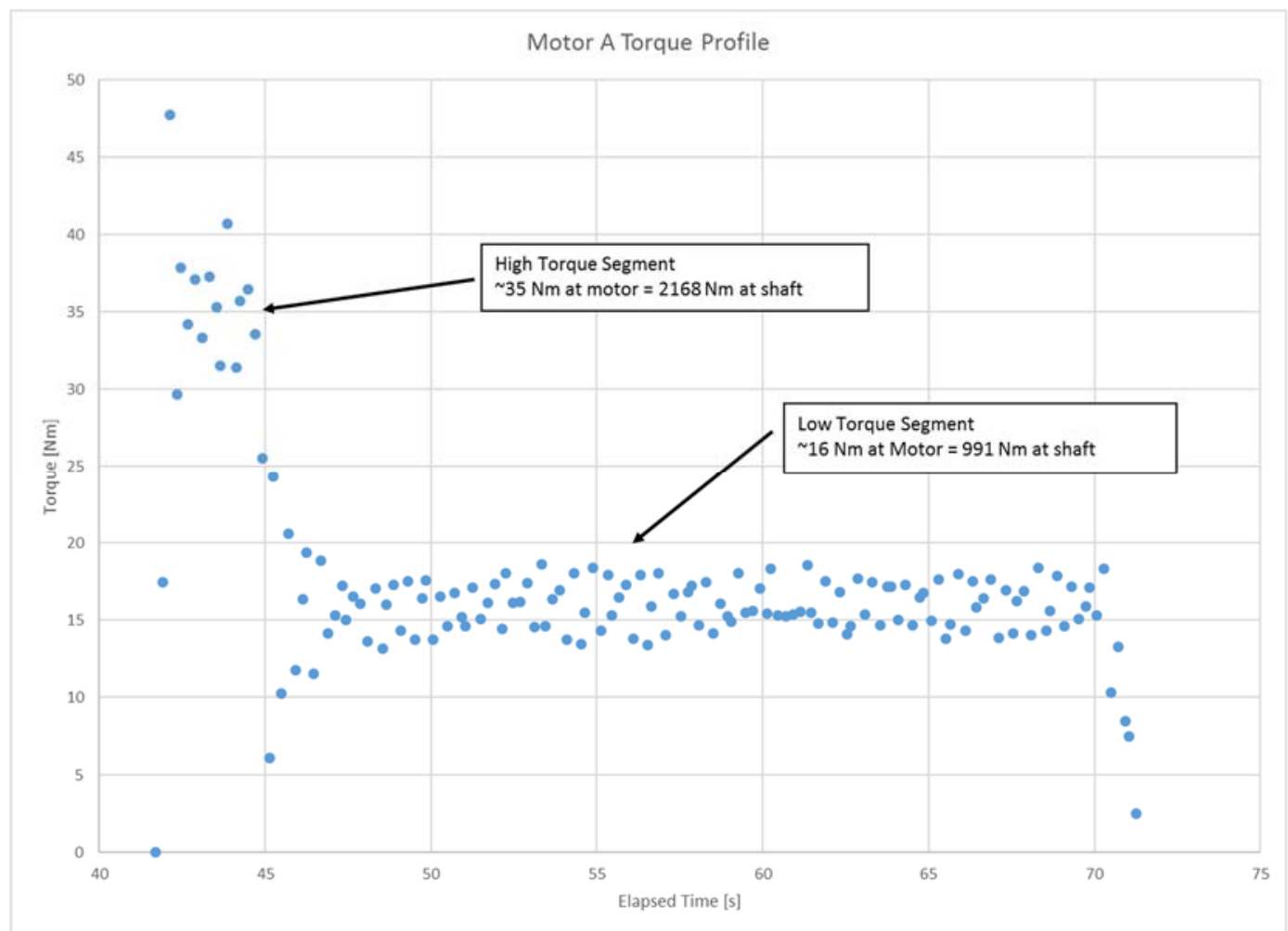

Figure 13: Load Manipulation Test Data

The next series of testing examined the performance of an in-line torque sensor that has been incorporated into the system. The uncertainty of the current output (and therefore the torque measurements) suggested the need for a more direct measurement of the torque applied to the system. A Futek brand in-line torque sensor was purchased and a housing was fabricated to house the sensor between the motor planetary reduction gearbox and the top of the external gearbox. This allows for direct measurement of torque applied to the shafts. Figure 1 shows the sensor and its housing when installed on the GTA and Figure 14 shows an exploded assembly view of the external torque sensor assembly. 

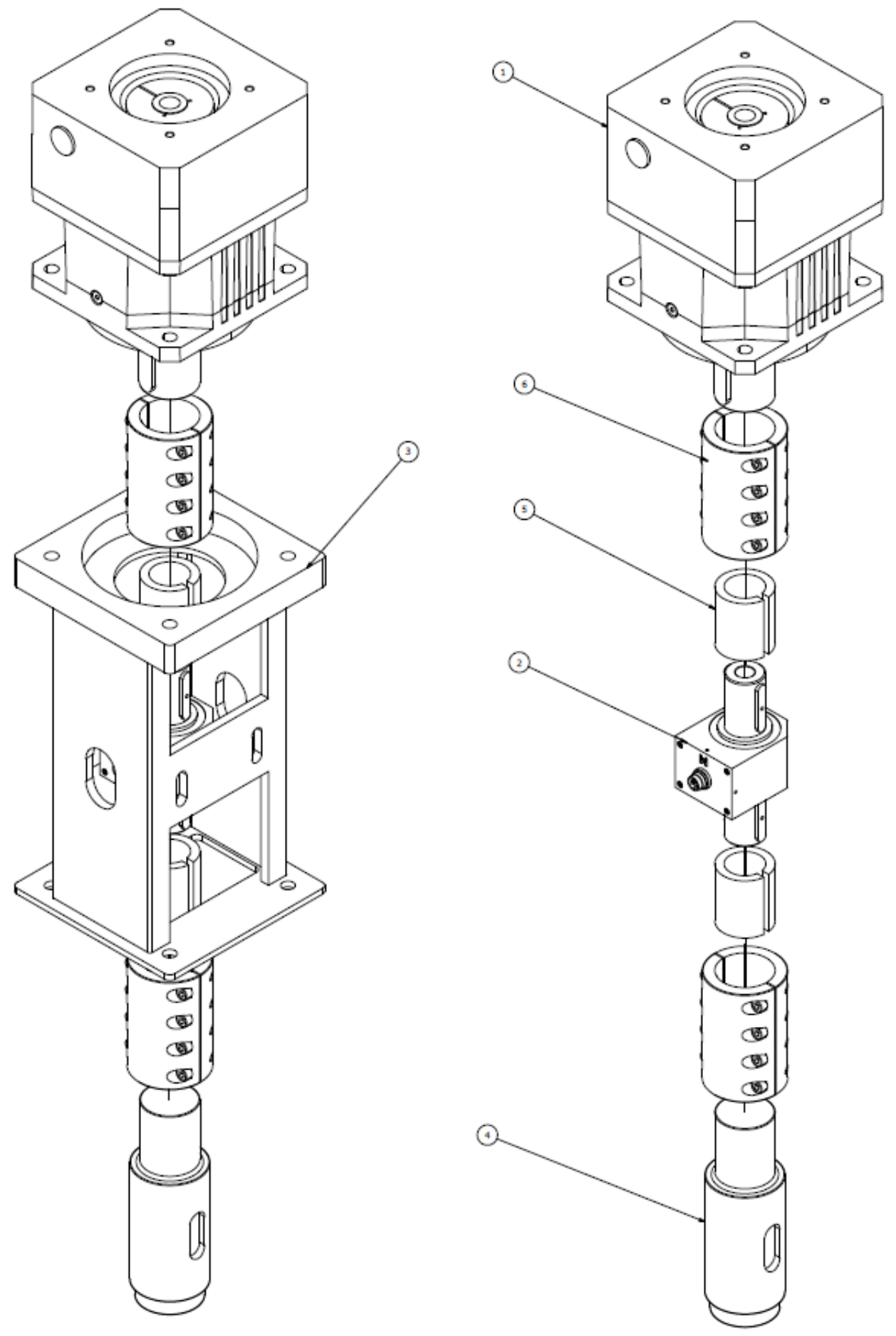

Figure 14 Exploded assembly view of external torque sensor assembly

Testing was performed to compare the torque measurements collected via the motor controller and the new torque sensor. A simple program was written to operate the drive motor in one direction for a period of time with a constant load applied. The data from this testing is presented in Figure 15. The data shows a good correlation between the two sensors. 


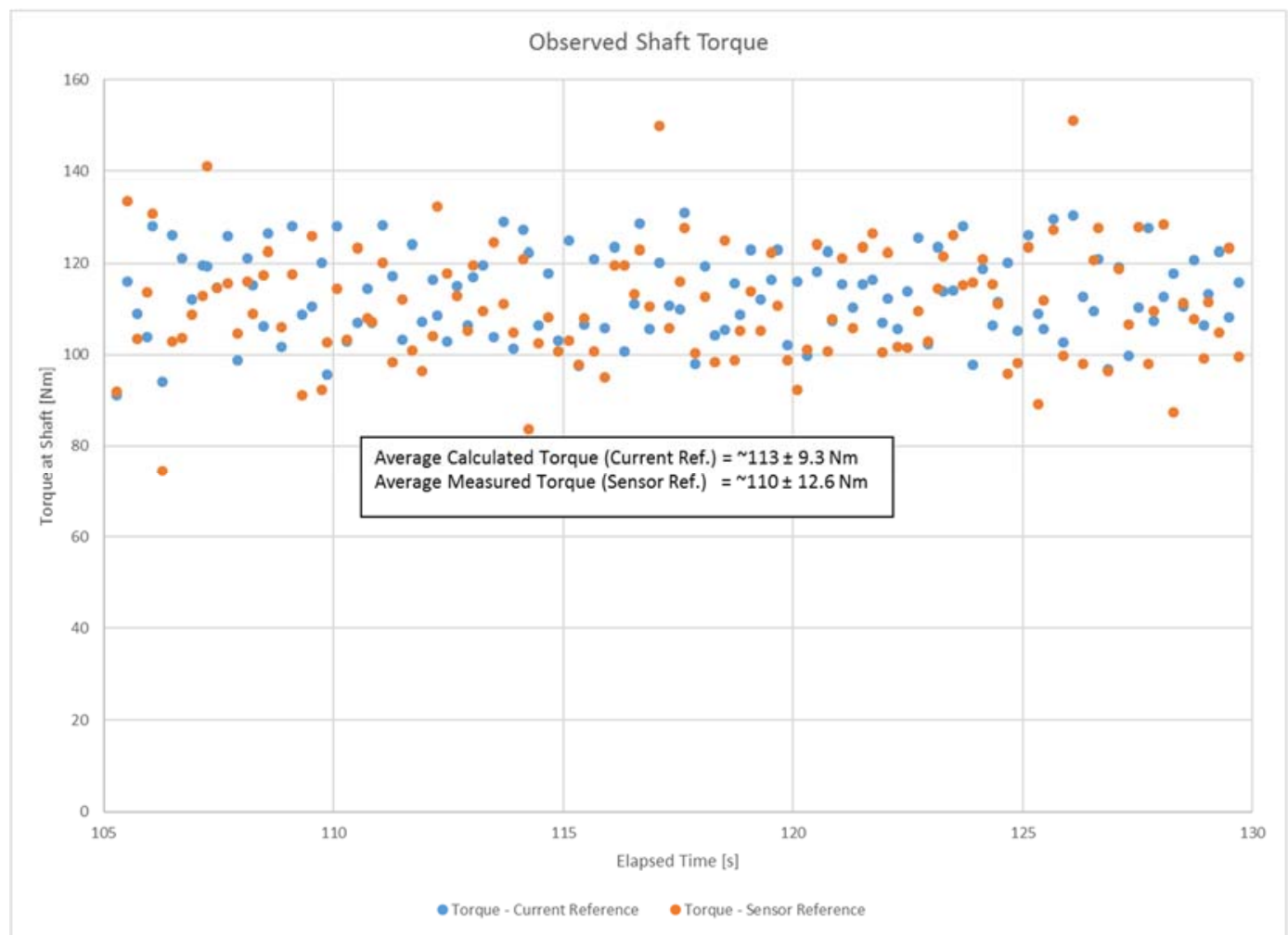

Figure 15: Torque Measurement Comparison

The series of testing currently underway aims to fully commission the experimental motor programming. This will operate the system in distilled water where the motor program will perform the full experimental torque profile. This program also incorporates several fault mitigation subprograms aimed at minimizing the need for operator involvement.

\section{Heating System}

Temperature regulation of the test apparatus is required to protect heat sensitive components such as the electric motors and elastomeric seals while maintaining certain components at stable temperatures, such as the hollow drive shafts, in order to reduce thermal stress. Thermal control of these components is used to minimize cyclical bending stresses in the drive shafts during system operation. Because of differential temperatures of structural support components inside and outside the liquid sodium test vessel, a temperature control system has been designed to minimize bending in the hollow drive shafts that penetrate the vessel cover.

A Watlow temperature control system was designed that utilizes type $\mathrm{K}$ thermocouples, strip heaters, and cartridge heaters to equalize the temperatures of the vessel top flange and thermal expansion bars. Power is supplied to the heaters through a 240VAC solid-state relay (SSR). The SSR is operated on a PID loop run via three Watlow rail mounted control (RMC) modules. These modules take temperature readings from the type $\mathrm{K}$ thermocouples as input data, and control the SSRs such that the heaters maintain a desired temperature. A Watlow rail mounted 
access (RMA) module is used to program the three RMC modules simultaneously in a straightforward manner. The RMA module can be programmed via the control workstation, as well as by two available Watlow remote user interfaces (RMI). The RMIs display temperature data, can be used to change temperature set points, and can upload various control programs preloaded on the modules. Figure 16 displays a diagram of the temperature control system. Commissioning of the heater system in currently underway. The testing looks to achieve robust control of the heater system hardware, as well as observe the steady state temperature of the system with the heaters operating at several different duty cycles.

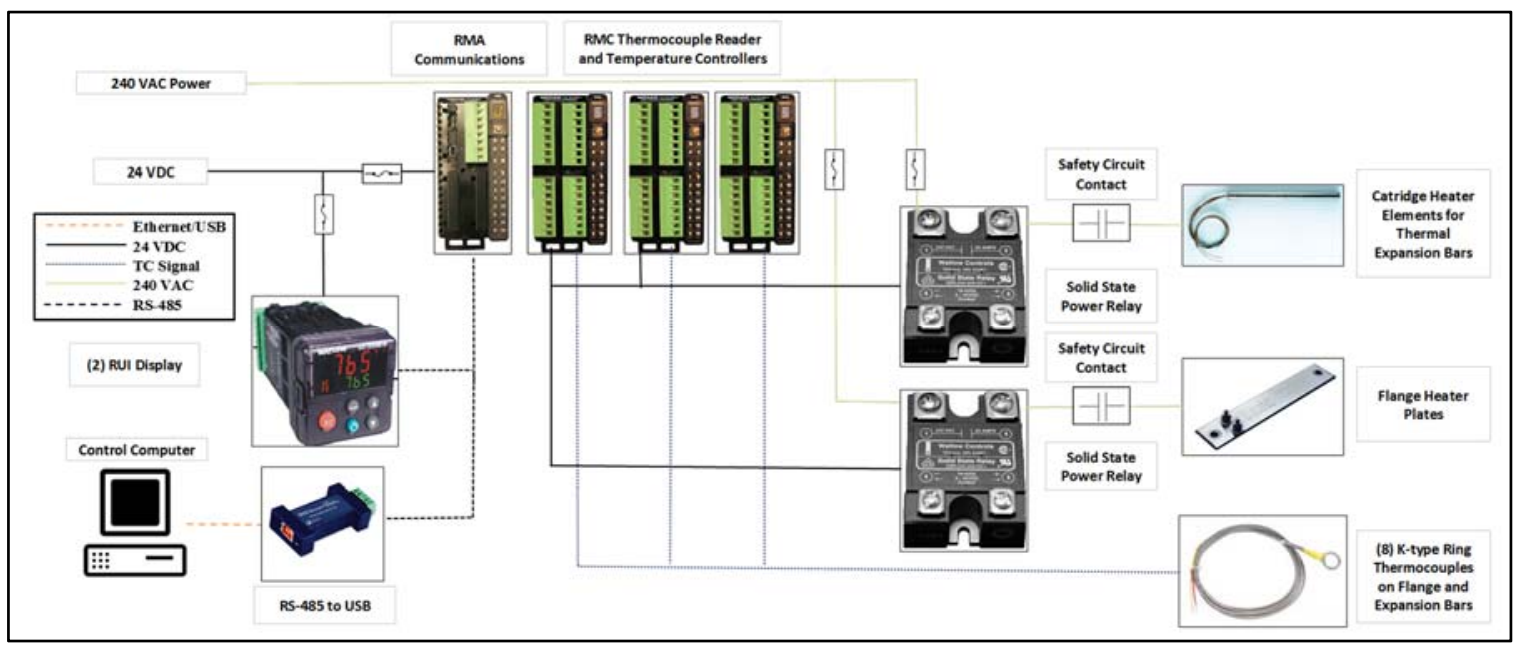

Figure 16: Heater Temperature Control System Diagram

To determine the heating cycle time for the heaters (the power on-off cycle time) the one dimensional heat equation was solved to determine the transient temperature distribution for a stainless steel plate exposed to a constant heat flux at the surface.

According to the Watlow heater catalog, the strip heaters specified provide a maximum thermal flux of 78,500 watts per square meter. Using this value, the transient temperature distribution through the depth of the plate was calculated (Figure 17) as a first step in determining the time that the heaters could be turned on before the allowable stresses in the stainless steel surface were achieved. As the heating of the stainless steel is cyclic based upon the heaters being turned on or off, the issue of fatigue failure must be addressed.

The ASME Boiler and Pressure Vessel Code Section III Division 5 (High Temperature Reactors) provides a table of allowable stresses as a function of temperature and number of loading cycles for various materials. The table for solution annealed type 316 stainless steel (Figure 18) is used for the dual certified 304/316 stainless steel material used in the construction of the tank cover.

The number of cycles chosen from the table was $10^{6}$ as the system will be in use for more than a year and the heater is estimated to be cycling over a thousand times per day. 


$$
\text { In }(z, t)=\frac{h \cdot q_{0}}{12 \cdot k} \cdot\left[\frac{6 \cdot k \cdot t}{h^{2}}+3 \cdot\left(\frac{z}{h}\right)^{2}+6 \cdot\left(\frac{z}{h}\right)-1-\frac{48}{\pi^{2}} \cdot \sum_{n=1}^{N}\left[\frac{(-1)^{n}}{n^{2}} \cdot e^{\frac{-n^{2} \cdot \pi^{2} \cdot k \cdot t}{4 \cdot h^{2}}} \cdot \cos \left[n \cdot \pi \cdot \frac{(z+h)}{2 \cdot h}\right]\right]\right]
$$

Transient Temperature Distribution vs Plate Depth

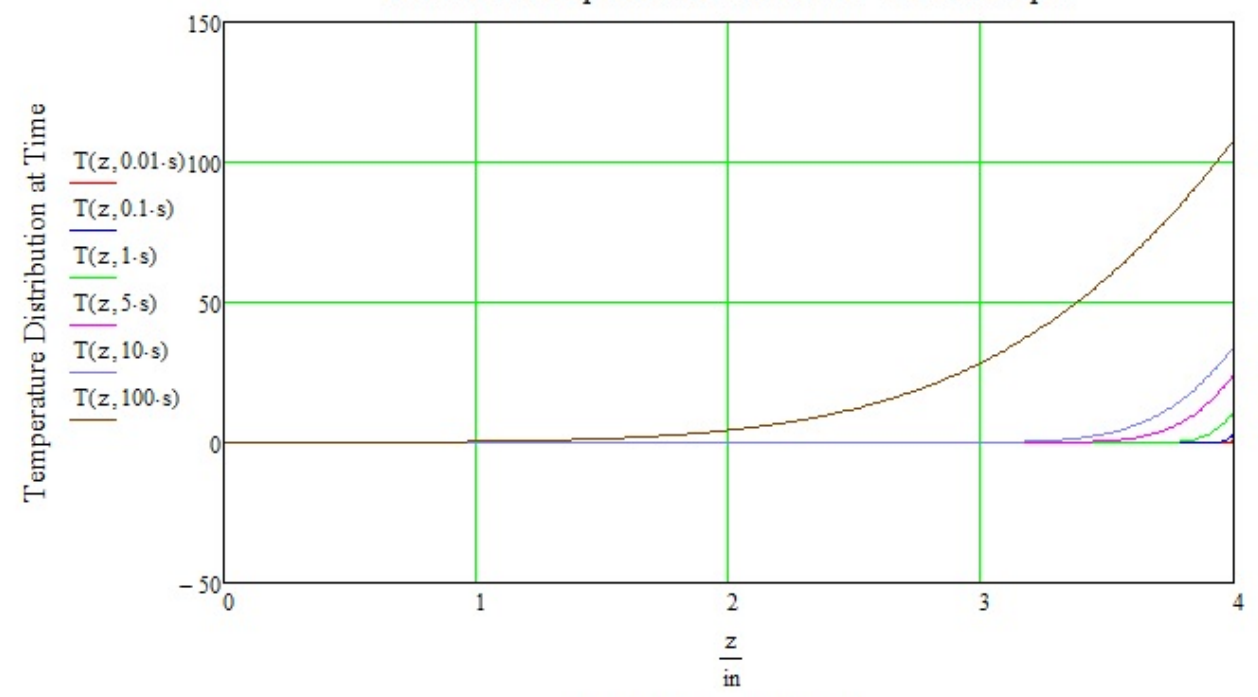

Depth Through Plate (in)

Figure 17: Transient Temperature Distribution through Stainless Steel Plate

TABLE HGB-II-3222.4-2

DESIGN FATIGUE LIMITS FOR SOLUTION ANNEALED TYPE 31655

\begin{tabular}{|c|c|c|c|c|c|}
\hline \multicolumn{6}{|c|}{ U.S. Customary Units } \\
\hline \multirow[b]{2}{*}{$N_{d}$, Number of Cycles } & \multicolumn{5}{|c|}{$S_{a}$, Allowable Stress Amplitude, ksi } \\
\hline & $100^{\circ} \mathrm{F}$ & $800^{\circ} \mathrm{F}$ & $900^{\circ} \mathrm{F}$ & $\begin{array}{c}1000^{\circ} \mathrm{F} \\
\text { Through } 1200^{\circ} \mathrm{F}\end{array}$ & $1,300^{\circ} \mathrm{F}$ \\
\hline $10^{1}$ & 659 & 569 & 491 & 413 & 278 \\
\hline $2 \times 10^{1}$ & 464 & 413 & 326 & 270 & 194 \\
\hline $4 \times 10^{1}$ & 338 & 303 & 235 & 192 & 137 \\
\hline $10^{2}$ & 230 & 207 & 160 & 127 & 92.4 \\
\hline $2 \times 10^{2}$ & 181 & 163 & 125 & 96.7 & 71.6 \\
\hline $4 \times 10^{2}$ & 143 & 124 & 98.9 & 74.6 & 56.0 \\
\hline $10^{3}$ & 106 & 93.1 & 74.2 & 55.1 & 42.6 \\
\hline $2 \times 10^{3}$ & 83.6 & 75.5 & 60.6 & 44.1 & 34.8 \\
\hline $4 \times 10^{3}$ & 67.3 & 61.9 & 49.5 & 36.3 & 29.4 \\
\hline $10^{4}$ & 52.4 & 48.9 & 39.1 & 28.7 & 24.2 \\
\hline $2 \times 10^{4}$ & 44.6 & 41.1 & 33.3 & 24.2 & 21.1 \\
\hline $4 \times 10^{4}$ & 38.1 & 35.5 & 28.7 & 20.9 & 18.7 \\
\hline $10^{5}$ & 31.9 & 29.4 & 23.7 & 17.7 & 15.7 \\
\hline $2 \times 10^{5}$ & 27.7 & 25.5 & 20.7 & 15.7 & 14.0 \\
\hline $4 \times 10^{5}$ & 24.4 & 22.5 & 18.1 & 14.2 & 12.4 \\
\hline $10^{6}$ & 21.2 & 19.6 & 15.3 & 12.5 & 10.8 \\
\hline
\end{tabular}

Figure 18: ASME B\&PV Code Fatigue Limits for Stainless Steel 
The transient stresses were then calculated using unrestrained plate theory and the temperature distribution previously calculated. The maximum surface stresses of 21,200 psi in the stainless steel plate were achieved in approximately 9.18 seconds from application of the heat flux. The maximum cycle time for heating of the plate (heater turned on) is then 9 seconds.

$$
\begin{aligned}
& \text { Plate Force per Unit Length: } \quad \mathrm{N}_{\mathrm{T}}(\mathrm{z}, \mathrm{t}):=\alpha \cdot \mathrm{E} \cdot \int_{0}^{\mathrm{h}}(\mathrm{T}(\mathrm{z}, \mathrm{t})) \mathrm{dz} \quad \mathrm{N}_{\mathrm{T}}(0,1 \cdot \mathrm{s})=6.969 \times 10^{4} \frac{\mathrm{kg}}{\mathrm{s}^{2}} \\
& \text { Plate Moment per Unit Length: }
\end{aligned}
$$

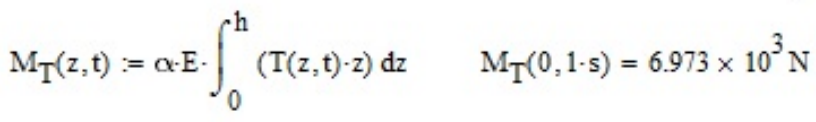

$$
\begin{aligned}
& \text { Transient Stress: } \\
& \sigma_{z}(z, t):=\frac{1}{1-\nu} \cdot\left(-\alpha \cdot E \cdot T(z, t)+\frac{1}{2 \cdot h} \cdot \mathrm{N}_{T^{(}}(z, t)+\frac{3 \cdot z}{2 \cdot h^{3}} \cdot M_{T^{(}}(z, t)\right)
\end{aligned}
$$

Transient Stress vs Depth thru $10 \mathrm{~cm} 316 \mathrm{SS}$

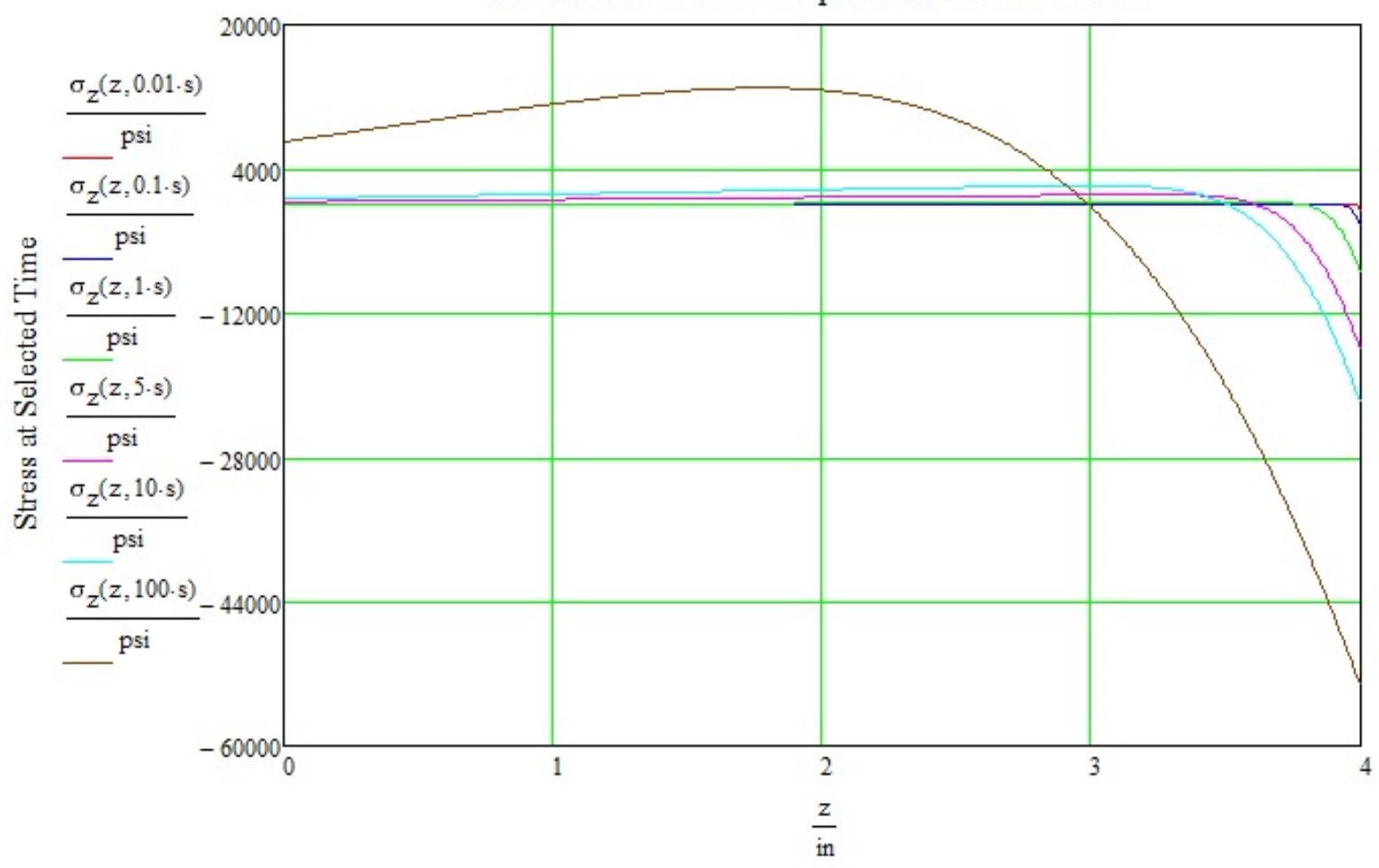

Depth Through 316 Stainless

Allowable Surface Stress Time at $100 \mathrm{~F}$

$\sigma_{z}(4 \cdot$ in,, $9.18 \cdot \mathrm{s})=-2.12 \times 10^{4} \cdot \mathrm{psi}$

Several transient thermal finite element analyses were performed using ANSYS to determine the time required for the heat to distribute and stresses to reduce in a fixed edge plate before turning the heater back on. The analyses performed indicate that the heaters can be turned back on after approximately 50 seconds, so a duty cycle time for the heaters was chosen as 8 seconds on and the 52 seconds off (Figure 19). This heater duty cycle assures that the maximum surface stresses in the stainless steel do not exceed the ASME allowable fatigue stress. 


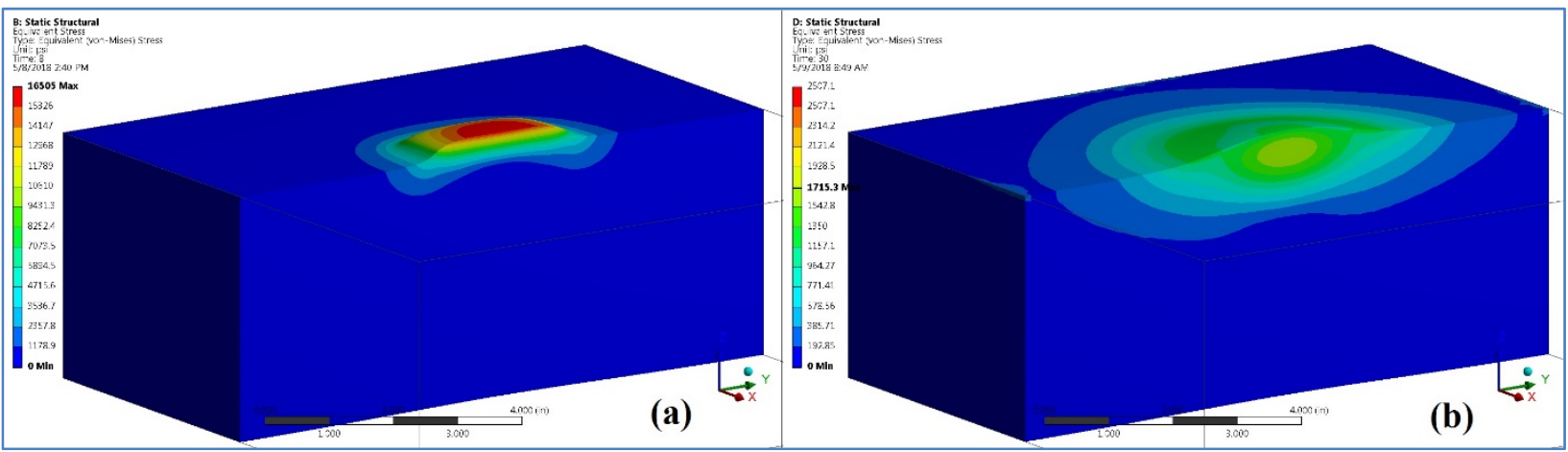

\section{Figure 19 - Equivalent stresses at (a) 8 seconds heater on (b) 52 seconds heater off}

As the temperature of the heater increases, the heat flux supplied by the strip heater decreases (Figure 20). This reduction in heat flux of approximately $32.2 \%$ from room temperature to $250^{\circ}$ $\mathrm{C}$ (test temperature -refueling temperature for a typical sodium-cooled fast reactor), assures that for the specified heating cycle that the surface stresses of the stainless steel tank structure does not reach or exceed the ASME Code allowable fatigue stress limits.

\section{$\underline{\text { Strip Heater Heat Flux per Square Inch vs Temperature }}$}

The purpose of this calculation is to develop an equation which relates the Heat Flux supplied by the Strip Heaters on the GTA to determine the time at which the plate surface stresses reach the allowable stress (according to ASME B\&PV Code Allowable Fatigue Limits Table)

$$
\begin{aligned}
& I_{w}=0,1.1000 \quad T_{i}=1000 \\
& \mathrm{q}(\mathrm{T})=0.000000027972028 \cdot \frac{\mathrm{W}}{\mathrm{in}^{2}} \cdot \mathrm{T}^{3}-0.000047785547786 \cdot \frac{\mathrm{W}}{\mathrm{in}^{2}} \cdot \mathrm{T}^{2}-0.064172494172503 \cdot \frac{\mathrm{W}}{\mathrm{in}^{2}} \cdot \mathrm{T}+111.209790209795000 \cdot \frac{\mathrm{W}}{\text { in }^{2}} \\
& q\left(I_{i}\right)=27.224 \cdot \frac{W}{\text { in }^{2}}
\end{aligned}
$$

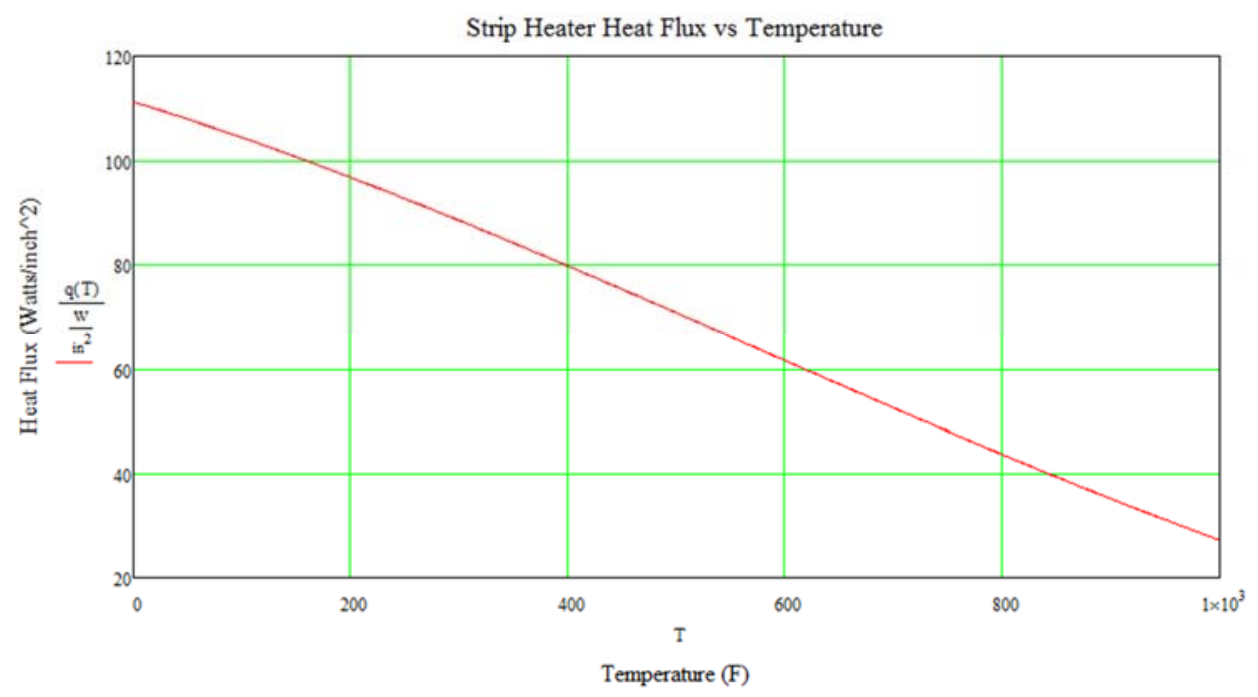

Figure 20: Strip Heater Supplied Flux vs Temperature 
The insulation type and thickness was changed from the original specification (six inches of Durablanket S) to a thinner and more effective insulation material combination (two inches of Cerablanket and three inches of Pyrogel).

To verify the performance of the updated insulation configuration, several rounds of steady state computational fluid dynamics analysis were performed (Figure 21) to verify the temperature distribution and assure that no additional heaters were required to keep the experimental assembly within the required temperature range. The results of the analyses indicate that the internal experimental assembly temperature was within 1 degrees $\mathrm{C}$ of the design temperature of 250 degrees $\mathrm{C}$. The overall temperature of the vessel is within 15 degrees $\mathrm{C}$ of the design temperature and thermal stresses are well below the ASME allowable stresses.

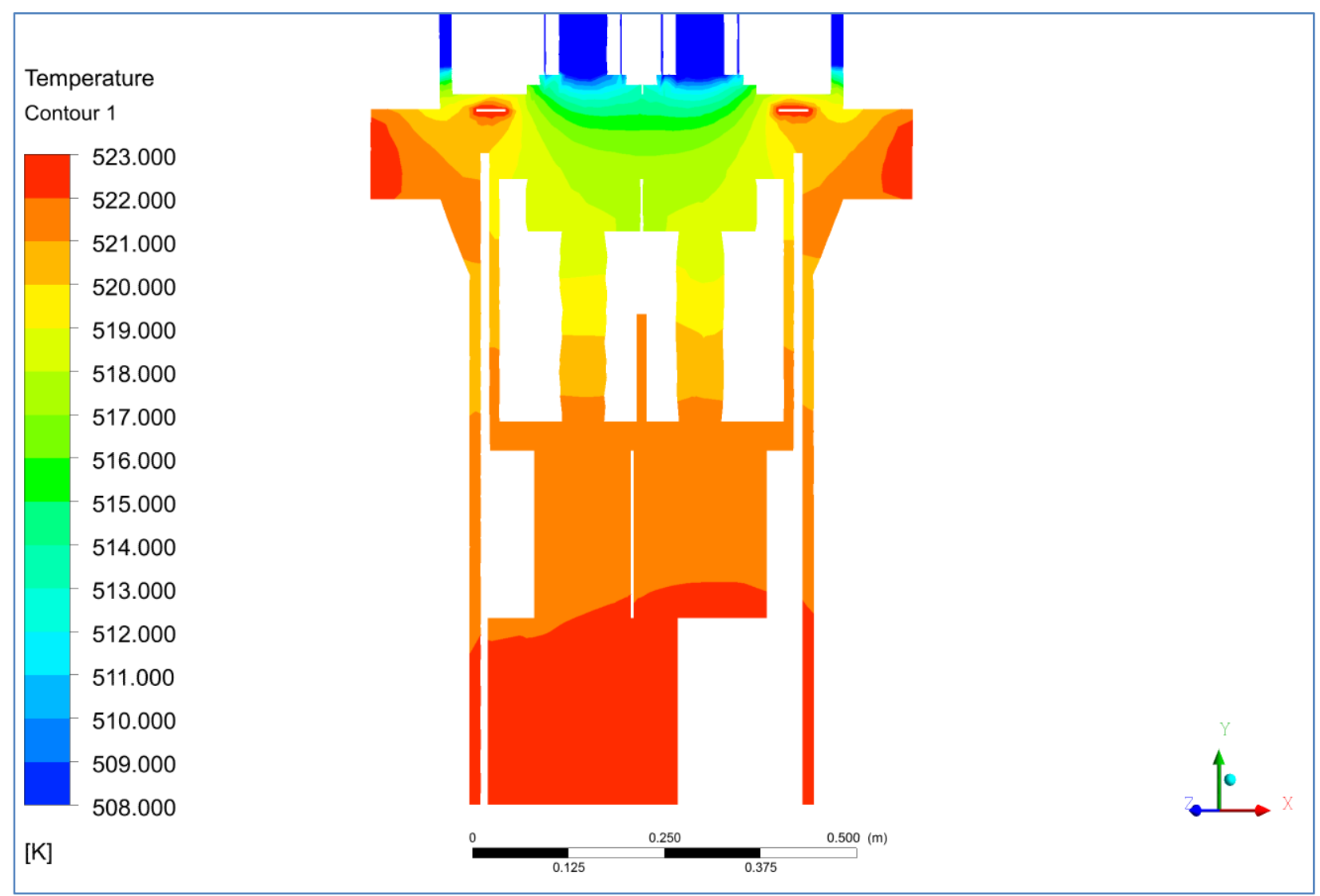

Figure 21 - Steady state temperature distribution in the stainless steel

The overall temperature distribution through the mid-plane of the gear test assembly including all new insulation and the cooling air velocity vectors is shown in Figure 22. The surface temperature of the exposed insulation (outside of the personnel protection shield) is below the OSHA allowable temperature for human contact. 


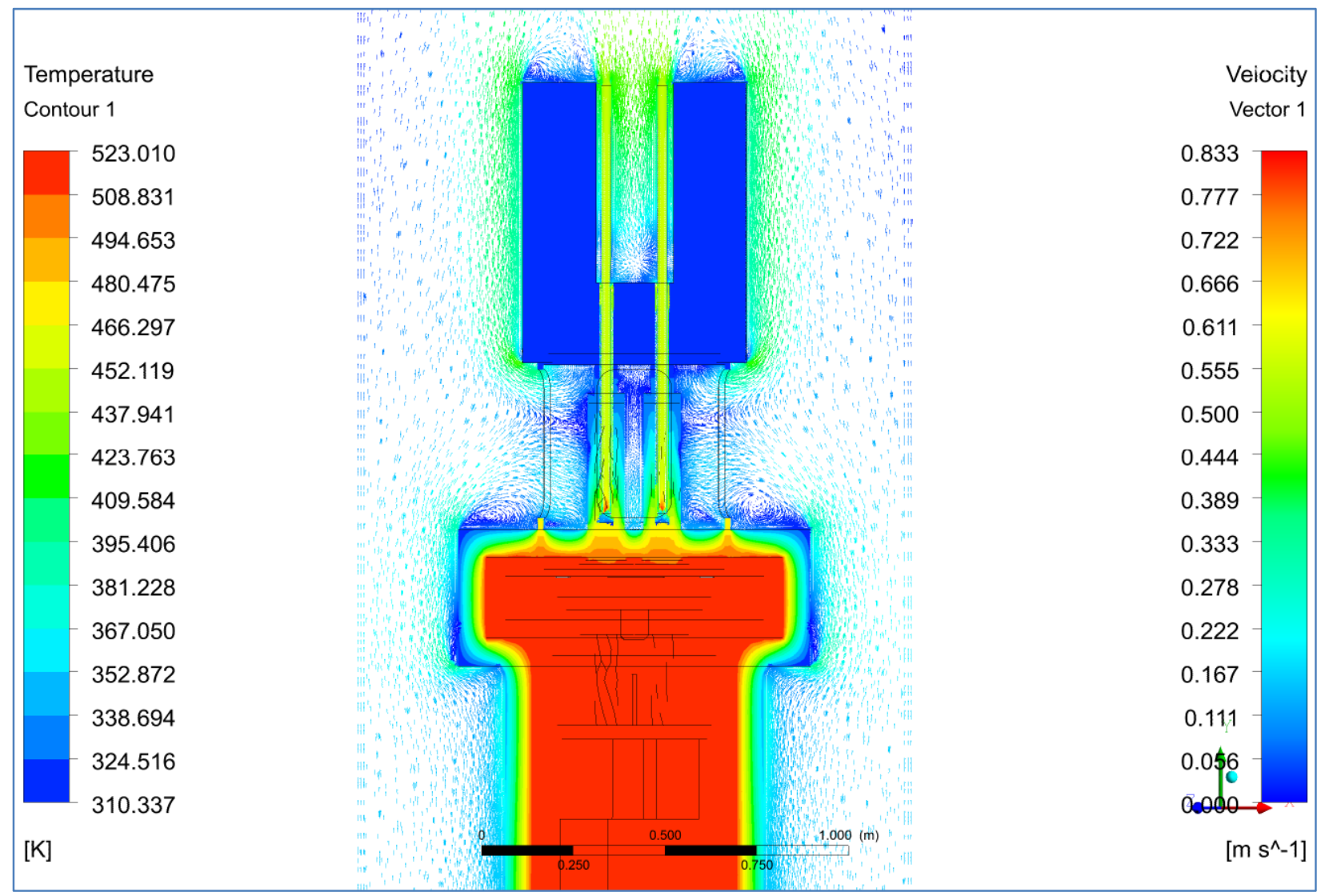

Figure 22 - GTA Mid-plane temperature distribution and air velocity vectors

The heater testing was performed without insulation installed and outside of the test vessel in Building 206. Only the strip heaters were installed on the top of the tank flange during the test and the band heaters were not placed around the outside of the tank flange. Thermocouples were located at various positions to record the temperature as a function of time while the specified heating cycle was executed by the heater control system. Without insulation and fully exposed to ambient air in the Building 206 high bay, the heat lost to the environment exceeded the power of the heaters to bring the assembly to the appropriate temperature. The testing was performed only to test the heater control system and programming of the control system.

It was noted during assembly that the heater thickness dimension was larger than the dimension listed in the vendor catalog. This increased heater thickness will require re-machining of the heater recesses in the external support weldment. The depth dimension of the heater holes will be increased to accept the as-built heater dimension plus room for stainless steel Belleville washers which will be placed on top of the heaters at installation to provide firm contact of the heater to the tank flange and limit the contact of the heaters to the external weldment. 


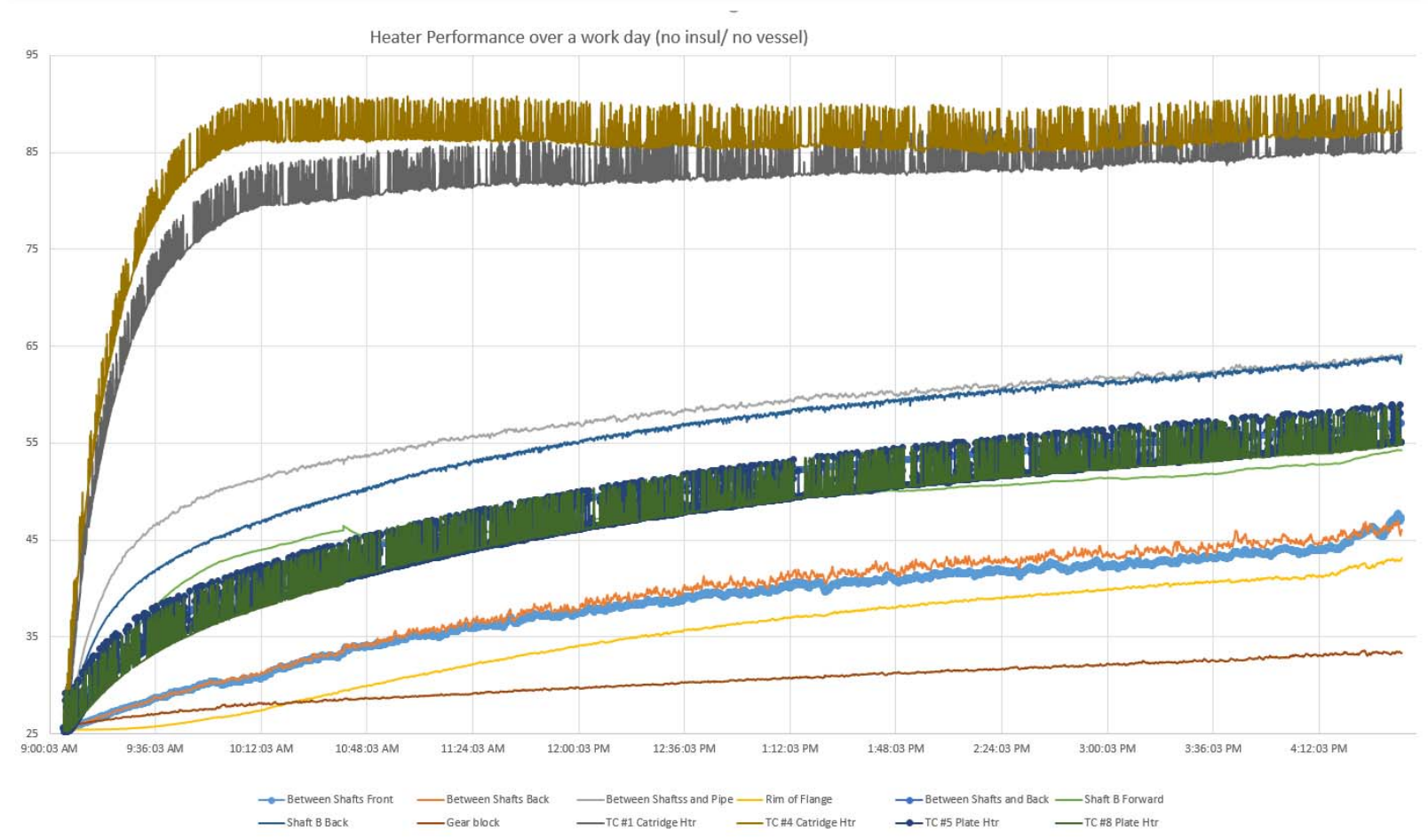

Figure 23 - Heat up rate of for GTA for various thermocouples on tank cover

Additional mounting holes will also be placed in the external weldment for additional thermocouples and wire harness connectors for the thermocouples for convenience at assembly.

\section{Shaft Alignment}

The gear test assembly was assembled and disassembled several times to take measurements of;

1. The shaft parallelism while supported by the inner weldment and gearboxes

2. The perpendicularity of the shafts to the tank flange while supported by the inner weldment and gearboxes

3. The alignment of the shafts to the external weldment gearbox bearing races while supported by the inner weldment and gearboxes

4. The alignment of the shafts to the tank flange when the external weldment gearbox bearings were installed while supported by the inner weldment and gearboxes

These measurements were taken between the counter bore in the tank flange for the Grafoil packing and the shaft for each of these cases to determine movement and alignment of the shafts to the counter bore during each phase of the assembly. The measurements (Figure 24) were taken using a combination of a pin of known diameter and a set of feeler gages. 

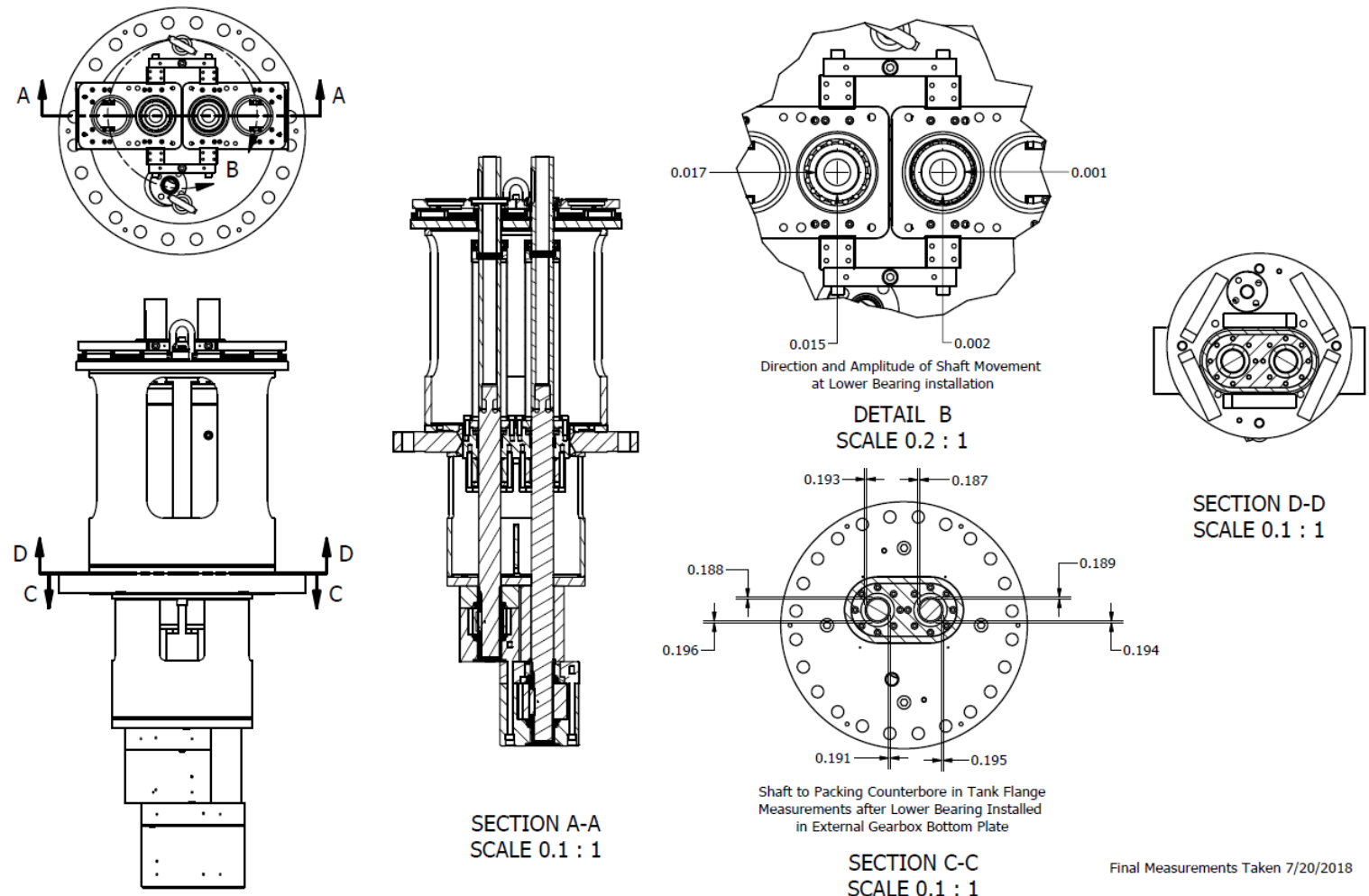

SECTION D-D SCALE $0.1: 1$

SECTION A-A SCALE $0.1: 1$

Shaft to Packing Counterbore in Tank Flange Measurentents atter Lower Bearing Install

SECTION C-C SCALE $0.1: 1$

Final Measurements Taken 7/20/2018

Figure 24 - Final Measurements of Shaft Alignment to Packing Counter Bore

Shims were added between the internal gearboxes to make the shafts more parallel while they were supported by the internal weldment and gearboxes (Figure 25).

While there is a possible slight bow in the shafts and some small play from the inner support bearings, the dimensions were taken with the shafts turned to a fixed orientation to assure the dimensions were as repeatable as possible. 


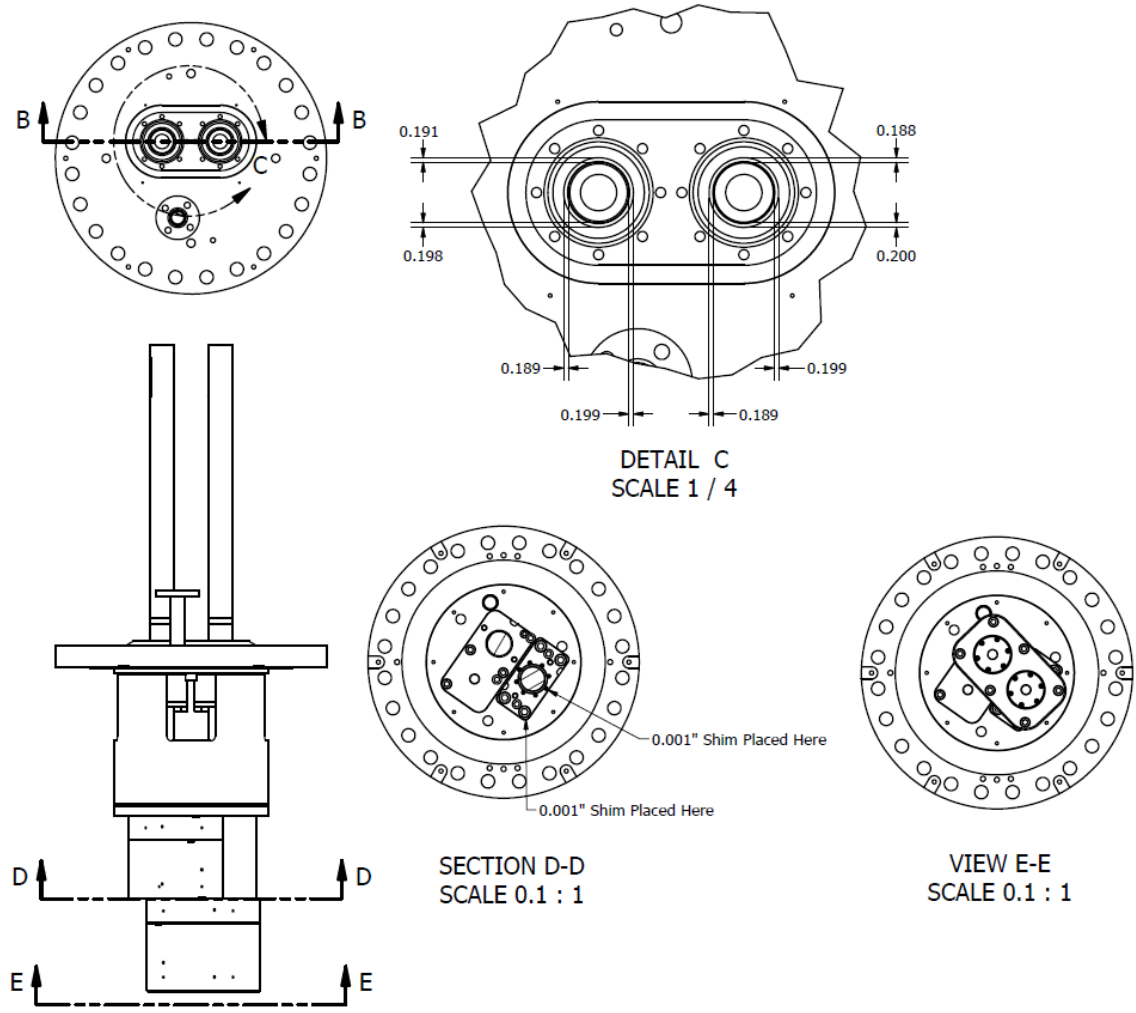

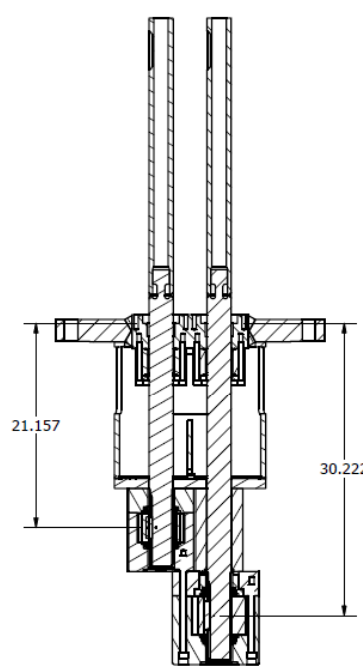

SECTION B-B SCALE $0.1: 1$

Figure 25 - Location and thickness of shims required to improve shaft parallelism

\section{Gas Seal System}

An argon gas supply system was built to provide pressurized argon to the seal chambers for performing leak testing of the elastomer seals and Grafoil packing (Figure 26).

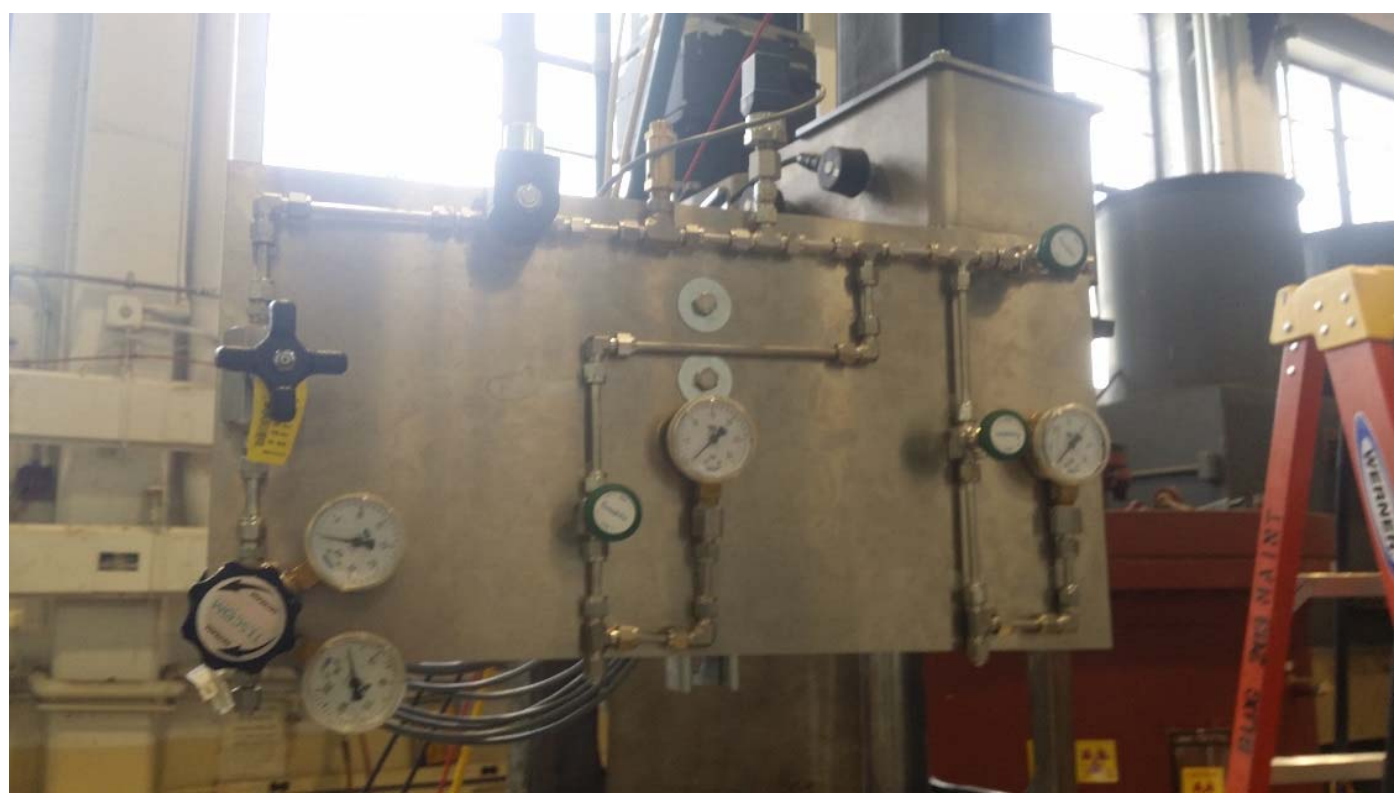

Figure 26 - Argon gas supply system for seal leak testing 
Testing commenced on the pressurized argon seal chambers. Static leak tests were performed at room temperature to initially check the seal performance, but slow leaks were detected in the system. The usage of a liquid solution indicated leakage between the flange of the argon gas seal chamber and the top of the vessel cover. A spring energized c-ring seal located between the chamber flange and the vessel cover is leaking due to possible debris or scratches between the seal and sealing surface or the machined seal groove depth may be out of tolerance. No leakage was observed at the top of the pressurized argon seal chambers where the elastomeric seals are located.

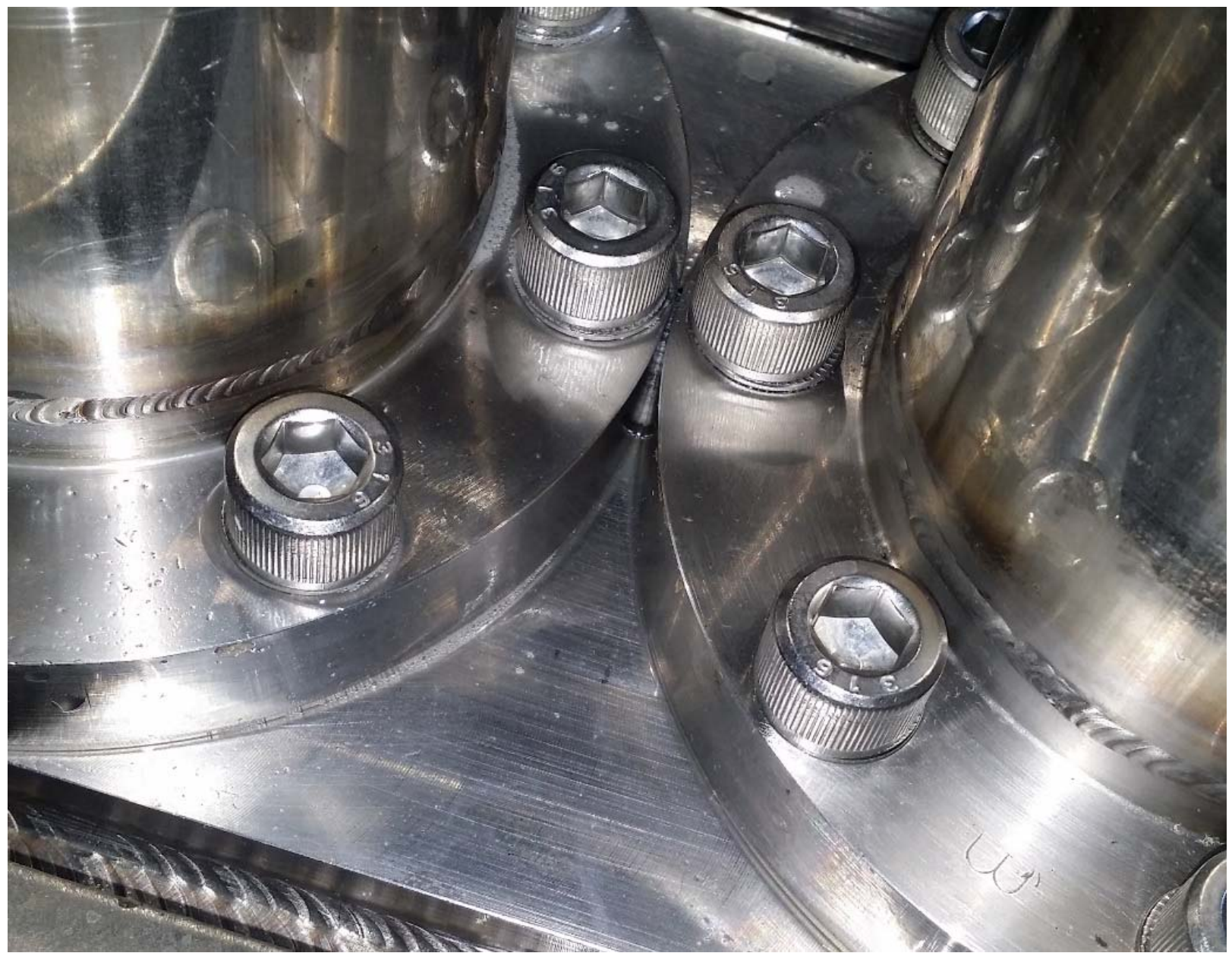

Figure 27: Leakage detected between seal chamber flange and tank cover

Upon disassembly of the argon pressurized seal chambers, it was noted that the Grafoil packing was severely damaged. The center three layers of softer graphite packing was crumbling and the volume of material in the packing was greatly reduced.

To check the dimensions of the packing, a new set of Grafoil packing was installed with the load spreader, Belleville washers (0.054" spacer washer was not installed) and the argon pressurized seal chambers were placed in the assembly location but not torqued down. Measurements were then taken between the machined top surface of the tank cover welded insert and the bottom seal surface of the argon pressurized seal chamber. Without the 0.054 " spacer washer, the dimension 
recorded was $0.105 "$ ". The dimension per the drawings should have been $0.065 "$ ". Adding the 0.054 " spacer increased the compression dimension of the packing to 0.159 ".

Due to excessive compression of the Grafoil seals during the leakage tests of the argon pressurized seal chambers, the spacer washers were removed and the load spreader thickness was reduced to 0.430 " from 0.5 " to reduce the clamping pressure. The spacer washers were originally added to provide additional compression of the Grafoil packing to make up for a slight volume increase due to 0.010 " diameter oversize holes for the packing in the tank cover.

The diameter of the base alignment feature of the argon pressurized seal chamber was determined to be incorrect on the drawing which did not center the assembly on the tank flange properly at installation. The assembly will be machined to correct the alignment feature diameter. This excessive play between the alignment feature and the mating counter-bore in the tank flange allowed the inner diameter of the bottom flange of the weldment to contact the shaft during operation. The contact caused some gall marks on the drive shafts which will be removed by Central Shops.

A graphite thrower was designed and the tank cover bearing support was modified as a "catch cup" to replace the shaft scraper which quickly wore out and allowed graphite powder to enter the vessel.

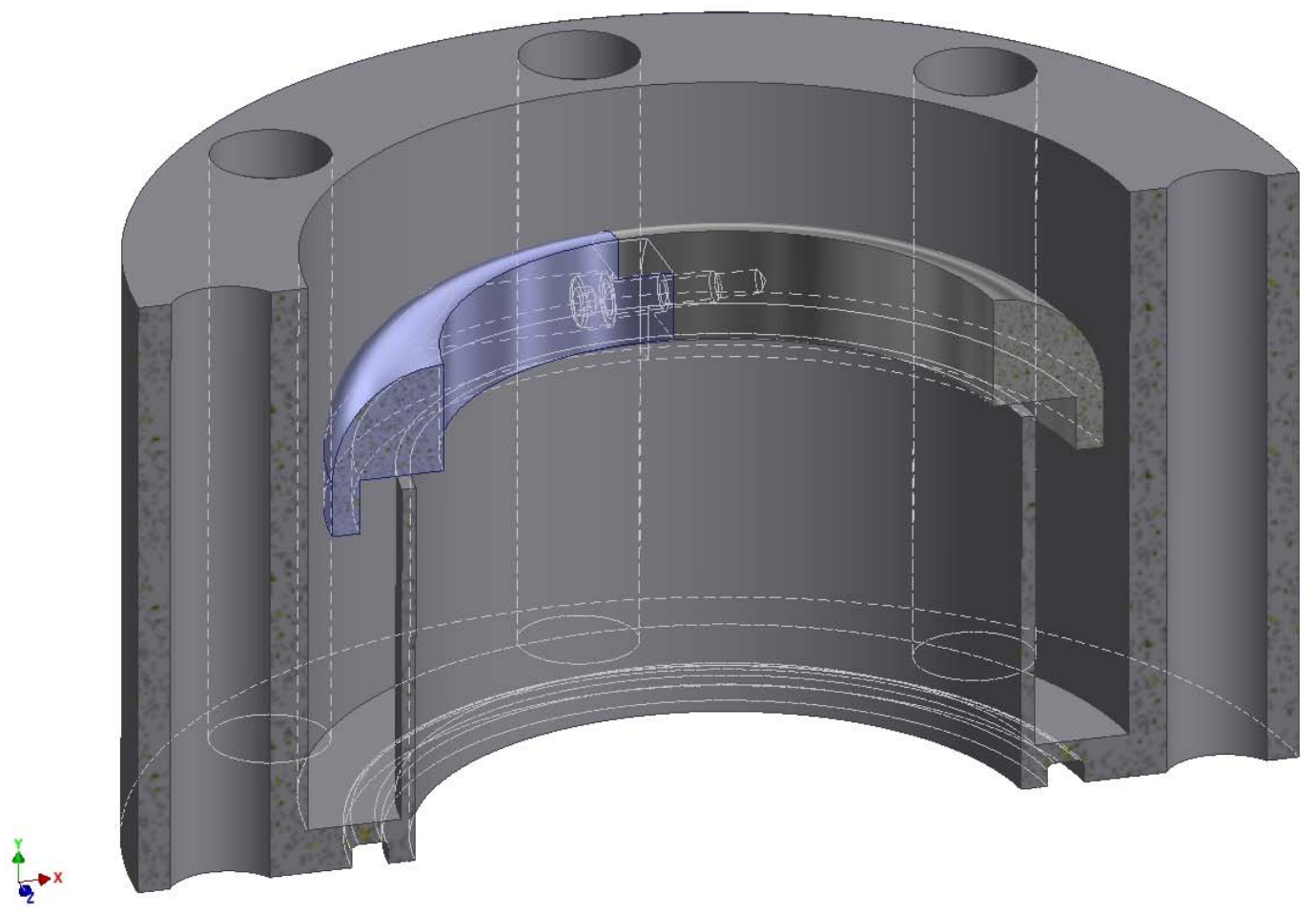

Figure 28 - The graphite thrower design and the graphite catch cup

The original compression dimension of the pair of Belleville washers was reduced from 0.065" (which applied a 10,000 pound compressive load on the packing) to 0.012 " which provide a 
compression load of 2,000 pounds on the packing (Figure 29). Non-linear analyses were performed using ANSYS.

A: Static Structural
Total Deformation
Type: Total Deformation
Unit: in
Time: 1
7/10/2018 12:13 PM
\begin{tabular}{|l}
$\mathbf{0 . 0 1 2 2 0 1}$ Max \\
0.01133 \\
0.010458 \\
0.0095865 \\
0.008715 \\
0.0078435 \\
0.006972 \\
0.0061005 \\
0.005229 \\
0.0043575 \\
0.003486 \\
0.0026145 \\
0.001743 \\
0.0008715 \\
$\mathbf{0}$ Min
\end{tabular}

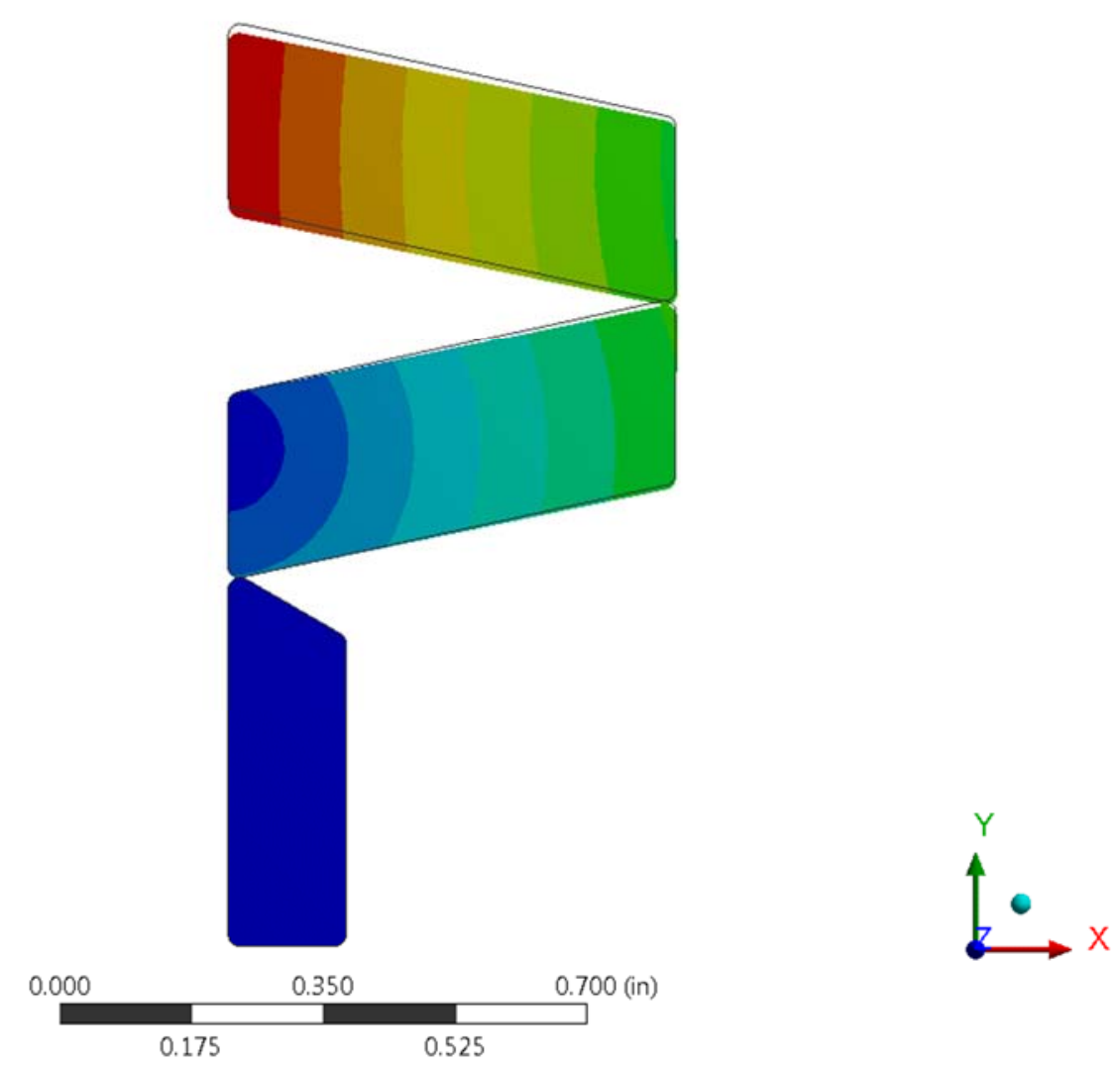

Figure 29 - Deflection for Reduced Compressive Load of 2,000 pounds 


\section{Failure Mechanisms in Gears}

Failure in gearing components occurs by several mechanisms which depend on the type of loading condition applied to the gear while in operation, below is the list of failure modes and the associated loading condition.

1. Shock loading which can cause permanent (plastic) deformation in the gear teeth. In severe cases, shock loading can cause rapid crack formation and propagation at the root of the gear tooth which breaks the gear tooth from the gear. This type of failure occurs via brittle fracture, ductile fracture or a combination of both.

2. Initiation of sub-surface cracks below the contacting faces of the mating gears (due to cyclically varying contact stresses which are highest below the surface) propagate over time under cyclic loading conditions and material "spalls" (forms pits) on the gear contact surfaces. The contact of the pitted surfaces of the mating gear faces causes increased vibratory loading in the gears, their supporting bearings and other mechanical components in the system which accelerates the reduction in their useful lifetimes.

3. Cracks at the root of the gear teeth which are initiated by cyclically varying bending stresses (fatigue) occur in 10,000 loading cycles or less due to overloading of the gear in cases of low cycle fatigue. High cycle fatigue failure occurs at lower stress levels for loading cycles above 10,000 cycles.

4. Wear occurs on contacting surfaces of the gear teeth usually due to normal loading or the presence of abrasive particles in the lubricating medium and reduces the locational accuracy (of the driven component) and efficiency of the gear, continued wear over time weakens the gear teeth and causes early failure of the gear teeth.

5. Scuffing is caused by galling or "self-welding" of the gear material by adhesion of the gear material from mating gear teeth surfaces and can be caused by improper lubrication of the gears.

6. Material property changes (chemistry, hardness, corrosion and structural) due to environmental considerations during operation can cause early failure of the gearing components by increasing wear rates on the gear material.

\section{Non-Destructive Evaluation of Gears}

\subsection{Baseline NDE of Advance Reactor Components}

In continuation of activities in connection with development of nondestructive evaluation (NDE) methods for detection and characterization of damage and degradation in advanced reactor components, baseline inspections were performed on a set of spur gears that are part of a 
manipulator assembly. The primary NDE methods used in this application are eddy current testing (ECT) for detection of surface and subsurface flaws and ultrasonic testing (UT) for local and volumetric examinations. Baseline electromagnetic and ultrasonic inspection data were collected on two pairs of spur gears (a total of four test pieces) of two different dimensions. A description of the NDE methods used for those tests as well as representative NDE data for each sample are presented below. Attempts were also made to perform radiographic testing (RT) of the parts. Based on the limited number of tests conducted to date using the available $420 \mathrm{keV} \mathrm{X-}$ ray source and solid-state linear detector, the RT method does not provide sufficient spatial resolution to reliably detect small defects in the parts examined in this work. The limitation associated with the output power of the X-ray tube limits the ability to obtain sectoral images along the symmetry axis of the gears examined in this work. As such, the current system does not allow utilization of computerized tomography (CT) of such dense and thick components such as the spur gears. Efforts are currently underway to assess alternative approaches RT of the gear samples including use of improved CMOS array detectors and alternative sample illumination configurations.

\subsubsection{Eddy Current Inspection of Spur Gears}

The eddy current (EC) inspection system assembled earlier in this work for in-situ examination of complex parts was used to collect baseline NDE data on four manipulator spur gears, which had been exposed to in-manipulator testing. The drawings of Alloy 718 gears of two different sizes are displayed in Figs. 30(a) and (b). Shown in Fig. 30(c) are photos of all four gears with the teeth numbered in the order they were scanned. Except for one gear, labeled as L1AT, the teeth numbering is in $\mathrm{CCW}$ direction with the rotation of the stage being in $\mathrm{CW}$ direction. Raster scan data was collected from the top and the bottom surface of all teeth by scanning the sample once with the front (f) side and once with the back (b) side of the gear facing outward. The numbering of the teeth starts with the one that is closest to a horizontal surface when the gear is mounted on the rotational stage and with the notch being in vertical position. In reference to Figure 30. 1, the teeth with notable features used for identification purposes in the data are marked on the photos.

The EC inspection system consisting of a MIZ-200 multi-frequency tester with PC-based data acquisition and analysis software, probes, and a four-axis translation/rotation stage is shown in Figure 31. Also shown in that figure are photos of a gear mounted on the stage with the probe in one photo scanning over the gear tooth and in another photo over the calibration block. Figure 31 also shows the EC inspection data associated with the calibration block, which is displayed in image, strip chart and lissajous formats using the ANL computer aided data analysis tool. The user interface, which was developed under MATLAB ${ }^{\mathrm{TM}}$ environment, allows processing and visualization of NDE data using various algorithms developed previously and adopted to the application at hand. The presence of three subsurface machined flaws are clearly visible in the data, which associated with the $500 \mathrm{kHz}$ frequency channel. In agreement with EC skin depth attenuation, the intensity of the flaw signals are inversely proportional to the thickness of the remaining conductor material over the machined holes on the calibration standard block. For reference, a drawing and a photo of the backside of the calibration block, also made Alloy 718 material, is shown in Figs. 32(a) and 32(b), respectively. For the tests conducted on the spur gears the calibration block was scanned prior to inspecting each gear. That data was then used to uniformly normalize the amplitude and adjust the phase angle of the EC data in reference to the 
probe response from known flaws in the calibration piece. Figure 33 shows screen captures of the three user interfaces implemented in C Sharp $(\mathrm{CH})$ programming language that are used for controlling the motion of the four-axis translation/rotation stage. Shown in Fig. 33(a)-(c) are the main scan configuration panel, the manual control panel, and the raster scan control panel, respectively.

As noted above, complete baseline EC inspection data were collected on both surfaces of every tooth of the four spur gears supplied for NDE assessments. Data was simultaneously collected at multiple frequencies ranging from $50 \mathrm{kHz}$ to $500 \mathrm{kHz}$, with the highest frequency providing the finest spatial resolution and the highest sensitivity to near-surface flaws. Representative EC inspection data associated with the $500 \mathrm{kHz}$ frequency channel are presented next that exhibit the range of variation on the state of damage to the gear teeth observed in this work. The examples include data associated with gear teeth having no detectable damage to those having moderate to relatively significant surface-initiated volumetric damage. The observed damage in all cases appears to be associated with mechanical wear, with the more severe damage occurring near the edges of the teeth. Based on the initial analysis of the EC inspection data, no detectable cracklike signals were observed in any of the samples. Efforts are underway to perform a more detailed analysis of the baseline NDE data collected on the four samples.

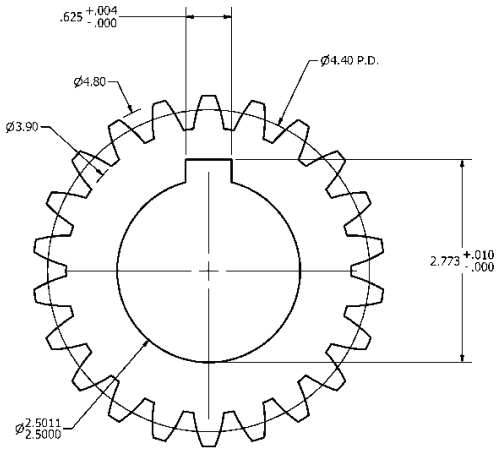

(a)

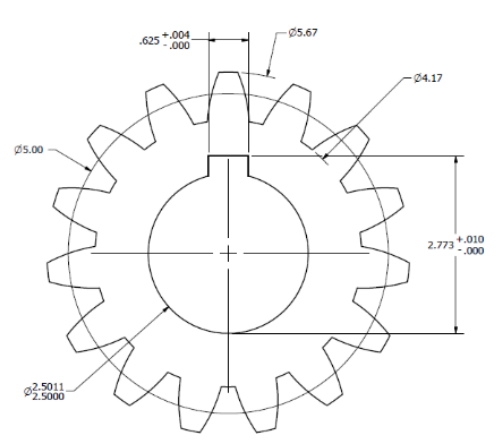

(b)
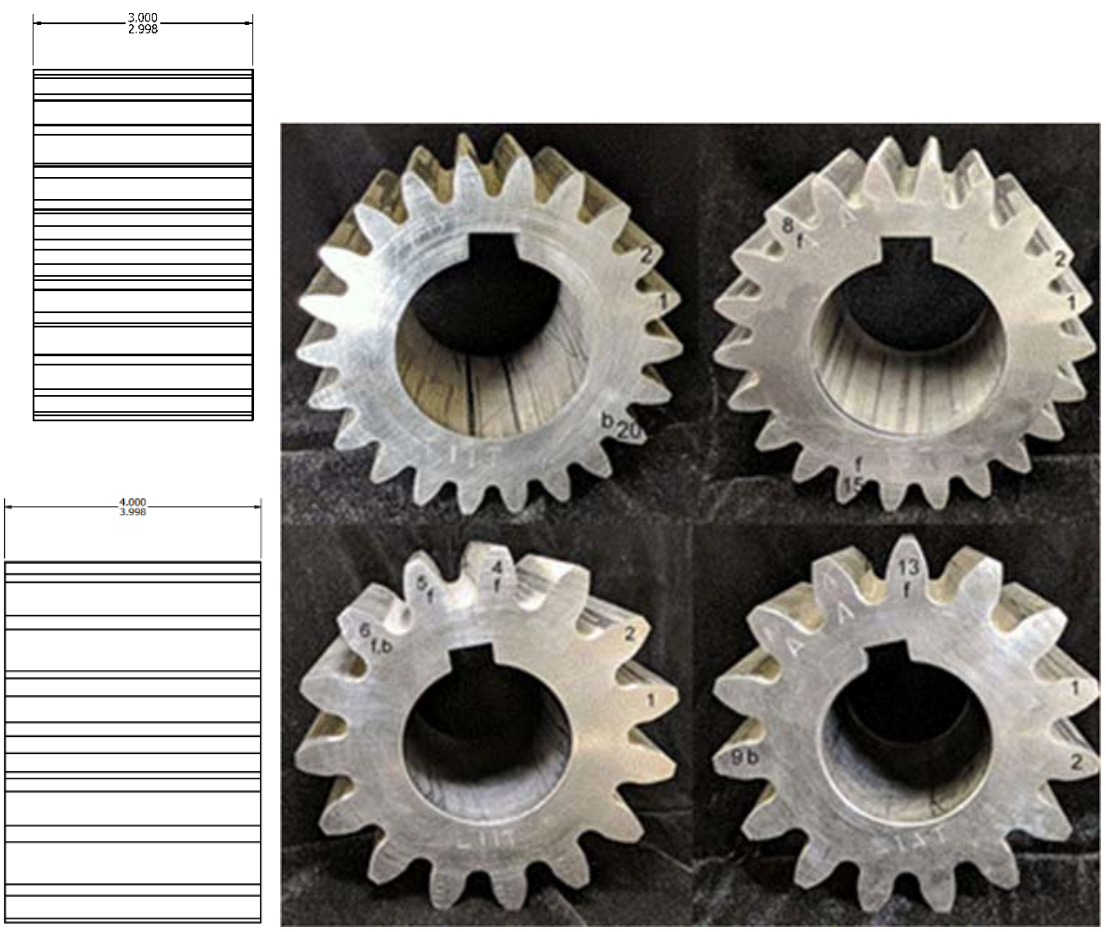

(c)

Figure 30 - (a,b) Drawings of spur gears of two different sizes made of Inconel 718 material. Also shown are (c) photos of the four gears on which baseline NDE was performed. The teeth are numbered on the figure in accordance with the order in which EC scans were performed. 


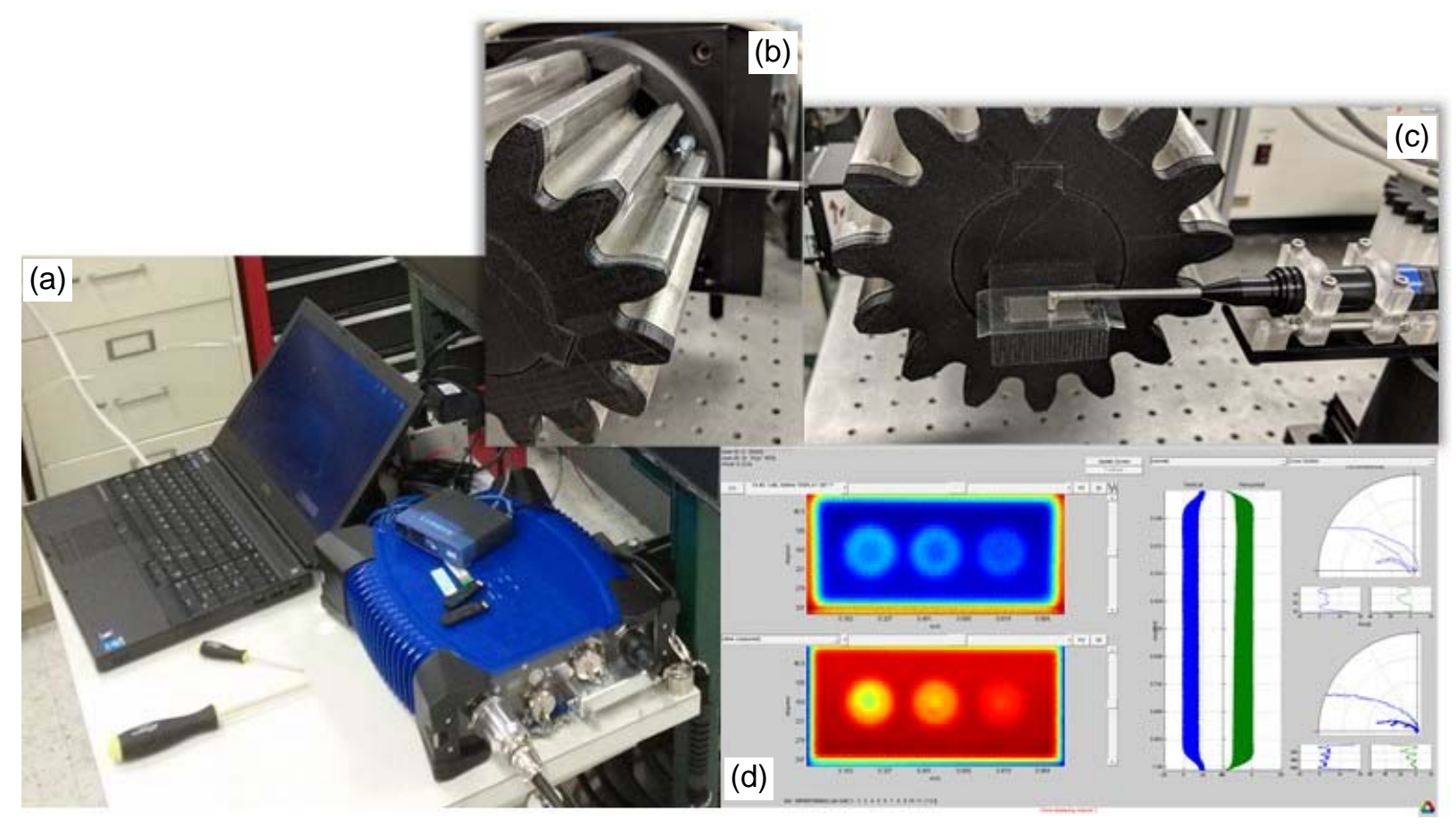

Figure 31 - Eddy current inspection system consisting of (a) an MIZ-200 acquisition unit, probes, and an in-house assembled four axis translation/rotation stage. Shown in the figure are photos of a gear mounted on the stage with the probe scanning (b) the gear tooth and (c) the calibration block. Also shown in the figure is (d) the EC inspection data associated with the calibration block in image, strip chart and lissajous formats displayed using the ANL computer aided data analysis tool. 


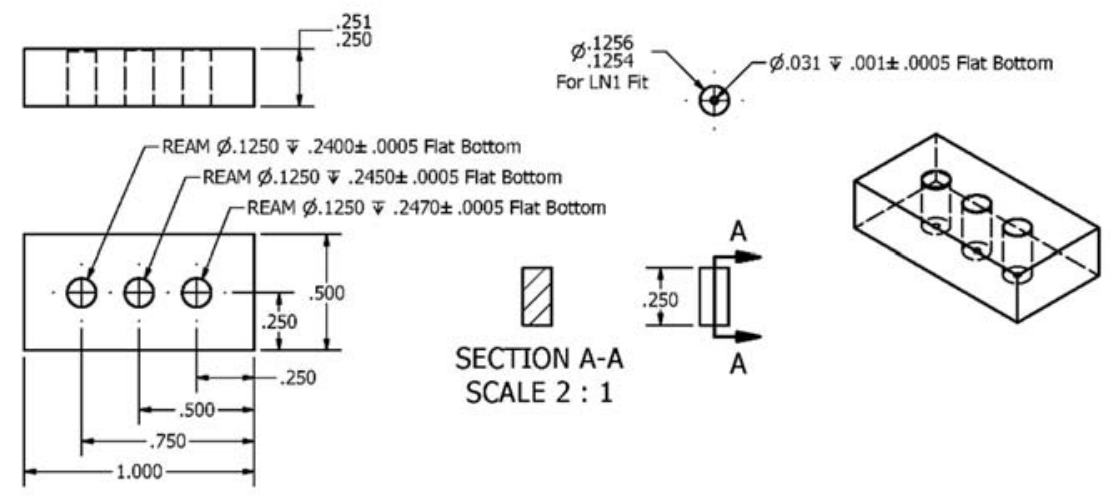

Figure 32 - Drawing of the Alloy 718 calibration block with three machined subsurface flat-bottom holes. Also shown is a photograph of the backside of the sample manufactured at ANL and the three cylindrical inserts that fill the holes. 


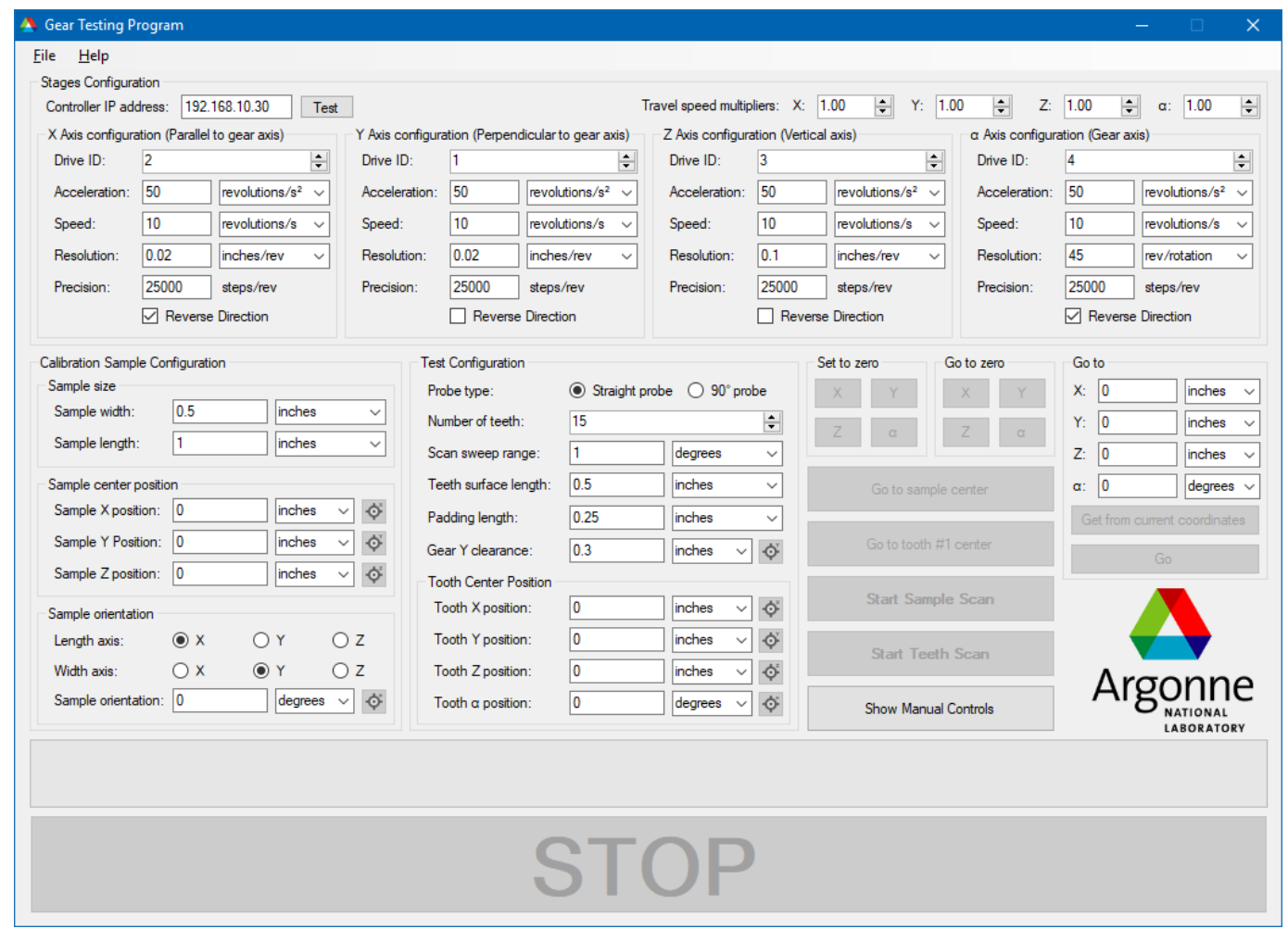

(a)

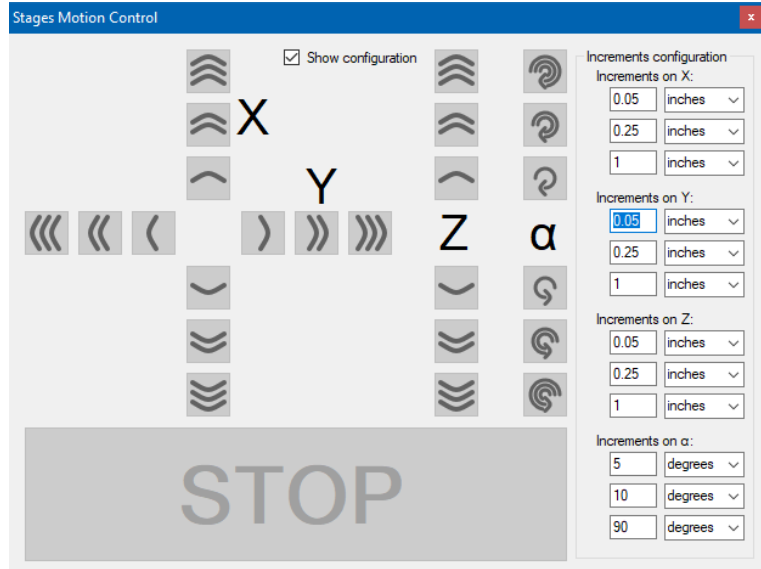

(b)

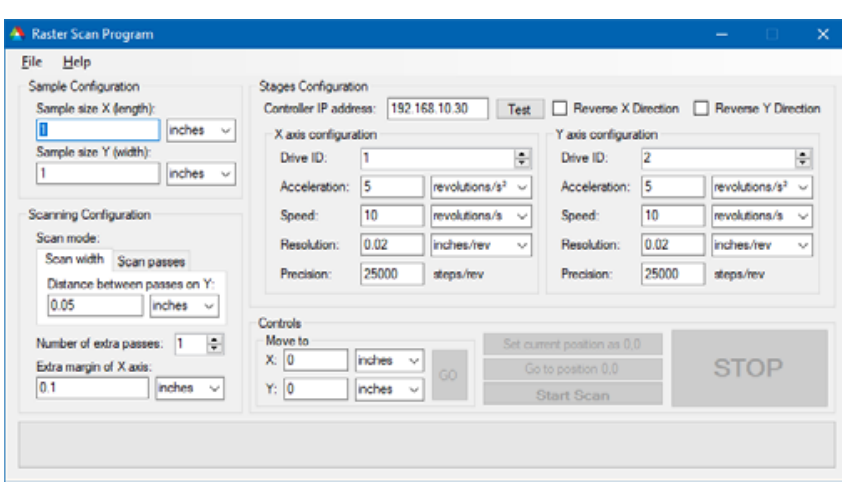

(c)

Figure 33 - Screen captures of the user interfaces implemented at ANL in C\# for controlling the four-axis translation/rotation stage. Shown in Fig. 33(a)-(c) are the main scan configuration panel, the manual control panel, and the raster scan control panel, respectively 
Figure 34 displays representative NDE data collected on a gear tooth with no detectable damage or degradation. Figure 34(a) displays a photo of the gear, marked as L1AT, with a red rectangle delineating tooth \#7 for which EC inspection results are presented in that figure. Figure 34(b) shows the expanded photo of the tooth delineated in Figure 34(a). The EC inspection data over the entire backside of tooth \#7 is shown in Figure 34(c). The data is displayed using the ANL data analysis tool. Finally, Figure 34(d) shows the expanded view of the vertical component of the measured impedance in image format for the area shown in Figure 34(b). The EC examination data in this case exhibits a uniform pattern with no indication of a flaw-like signal.

Representative baseline NDE data collected on a gear tooth with moderate volumetric damage is shown in Figure 35. Figure 35(a) displays a photo of the gear, marked as T1BT, with a red rectangle delineating the tooth that was inspected. Figure 35(b) is an expanded photo of the delineated area showing the front side of tooth \#1. The EC inspection data over the entire area of the tooth, displayed using the ANL data analysis tool, is shown in Figure 35(c). Finally, Figure 35(d) shows the expanded view of the vertical component of the measured impedance in image format for the area shown in Figure 35(b). Comparison of Figures 35(b) and (d) indicates a close correspondence between the optical and the EC image. The damage in this case is mostly in the form of scratch marks except for a few zones, which based on EC examination results exhibit deeper penetration of damage in the form of mechanical wear.

Representative baseline NDE data collected on a gear tooth with a relatively more significant surface-initiated damage in comparison with the previous example is presented in Figure 36. Once again, Figure 36(a) displays a photo of the gear, marked as L1AT, with a red rectangle delineating the area of the tooth with higher degree of volumetric damage. Figure 36(b) is an expanded photo of the delineated area showing the backside of tooth \#1. The EC inspection data over the area of the tooth marked in Figure 30(a) is shown in Figure 36(c). Finally, Figure 36(d) shows the expanded view of the vertical component of the measured impedance in image format for the area shown in Figure 36(b). As in previous example, comparison of Figures 36(b) and (d) indicates a close correspondence between the optical and the EC image. In comparison with the previous example, the damage in this case, which is mechanical wear near the edge of the tooth, is deeper as indicated by the EC examination results.

As noted earlier, a large NDE database has been assembled from inspection of the four spur gears examined in this work. Planned activities under this task include conducting a more detailed analysis of the available EC inspection data as well as collecting and analyzing additional data on samples before and after exposure to realistic operating environments. Efforts are also under way to evaluate the utility flexible array probe technology for more rapid inspection of parts with complex geometry. To that end, a specialized EC array probe has been obtained and is currently being adapted, both hardware and software, for inspection of spur gears. It is expected that such probes could ultimately be used for a wide range of inspection applications associated with advance reactor components. Future plans in connection with NDE related activities also include further evaluation of the X-ray radiography and CT methods including alternative exposure configurations and use of a new CMOS linear arrays and area detectors that can provide higher spatial resolution than those currently available at the NDE facilities at Argonne. 


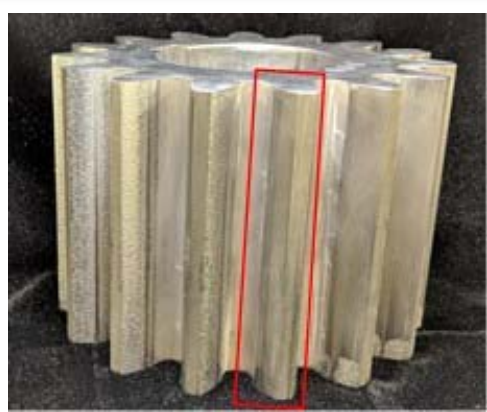

(a)

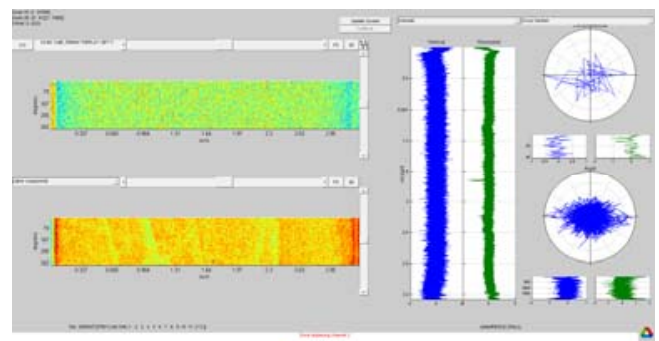

(c)

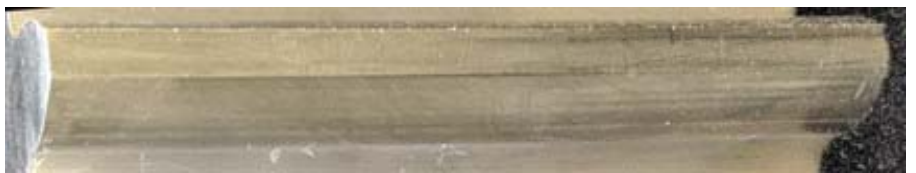

(b)

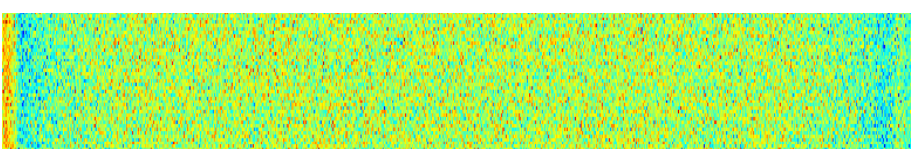

(d)

Figure 34. Representative baseline NDE data collected on a gear tooth with no detectable damage or degradation. Shown above are (a) photo of gear L1AT with a rectangle delineating the scanned tooth (b) photo of the tooth, (c) EC inspection data from back of tooth \# 7 displayed with ANL data analysis tool and (d) expanded view of the vertical component of data in image format.

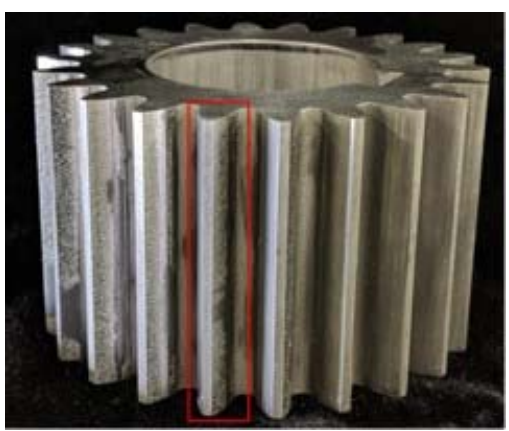

(a)

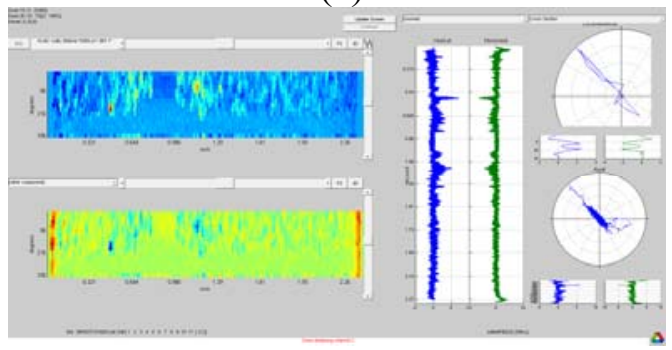

(c)

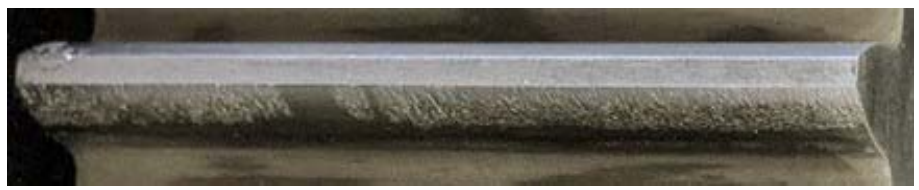

(b)

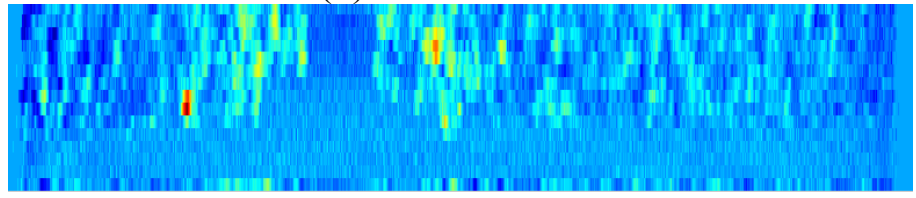

(d)

Figure 35 - Representative baseline NDE data collected on a gear tooth with mechanical wear type damage over its entire surface. Shown above are (a) photo of gear T1BT with a rectangle delineating the scanned tooth (front of tooth \#1) (b) photo of the tooth, (c) EC inspection data displayed with ANL data analysis tool and (d) expanded view of the vertical component of data in image format. 


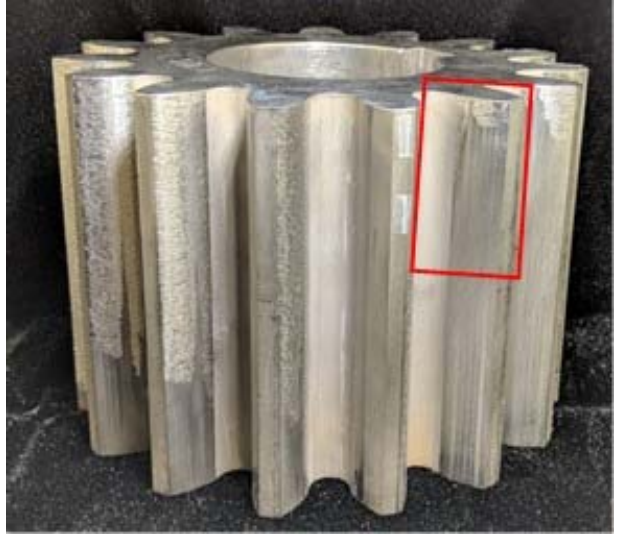

(a)

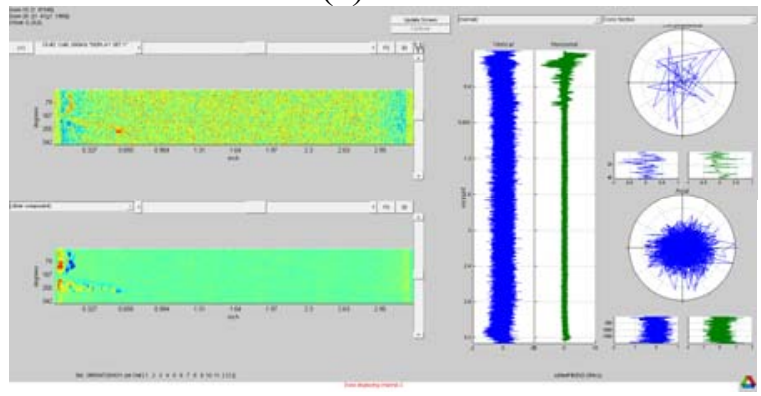

(c)

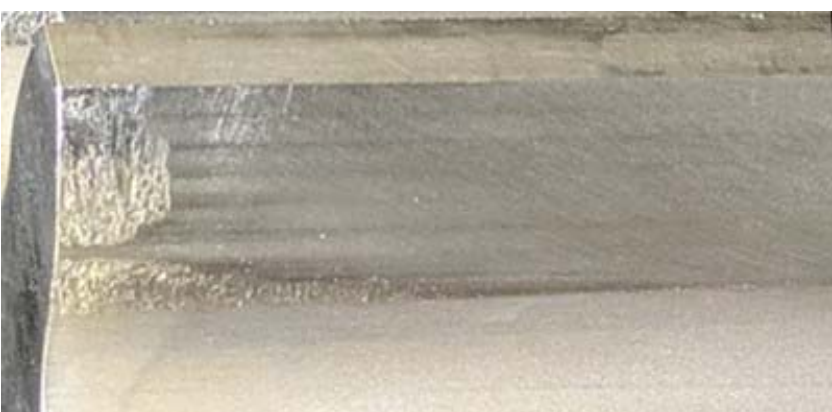

(b)

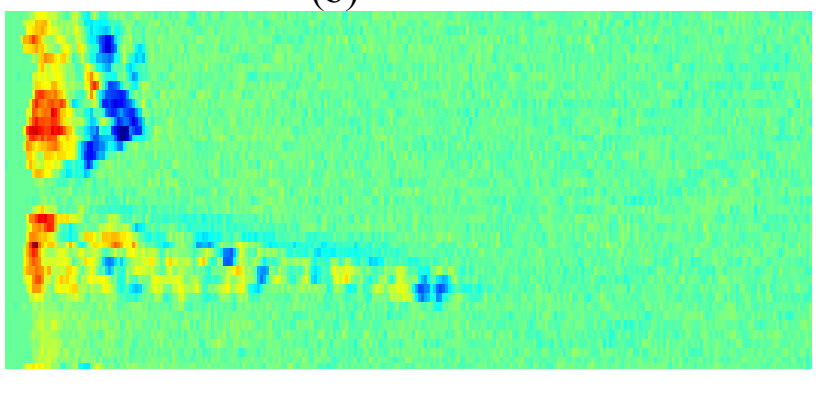

(d)

Figure 36 - Representative baseline data collected on a gear tooth with detectable volumetric damage. Shown above are (a) photo of gear L1AT with a rectangle delineating the damaged area (backside of tooth \#1) (b) photo of the delineated area, (c) EC inspection data over the entire area of tooth displayed with ANL data analysis tool and (d) expanded view of the vertical component of the data in image format for the region shown in (b).

\subsubsection{Ultrasonic Inspection of Spur Gears}

The ultrasonic testing (UT) is an NDE technique used for in-situ examination of complex parts for detection and volumetric sizing of defects. An UT inspection system is assembled to collect baseline NDE data on four manipulator spur gears, shown in Figure 30 that had been exposed to in-manipulator testing. The system, shown in Figure 37, consisting of an ultrasonic pulser/receiver (Imaginant DPR-300), a submergible ultrasonic transducer, a water tank, a gainpass filter (Krohn-Hite Model 3944), a two-axes scanning module, and a data acquisition (DAQ) unit. Two UT techniques, pulse-echo and through-transmission, have been commonly used for UT inspection. The selection between them is based on both accessibility and defect types. To detect internal defects, rather than surface defects as for EC, of the manipulator spur gears, the pulse-echo technique was selected. An ultrasonic transduce is held by a mounting unit that is mounted on a three-axes scanning translation module. Each linear translation stage is translated by a step motor with a minimum moving resolution of 2 micrometer. Through an XY-scanning, both the 2D intensity and time-of-flight (TOF) images are generated to locate and size of any internal defects between the front and back mounting surfaces. However, limited by the scanning distance of the XY-translation stages, the UT inspection system can only scan an area less than 2"x2". Figure 9 shows the setup of UT inspection of a manipulator spur gear in water test. The gear and transducer was submerged in water and the placement and distance between them was 
fixed. To scan a gear completely as well as keep the same dimension, the gear was manually rotated clockwise by several teeth or $\sim 45$ degrees after each scan and totally eight scans were taken.

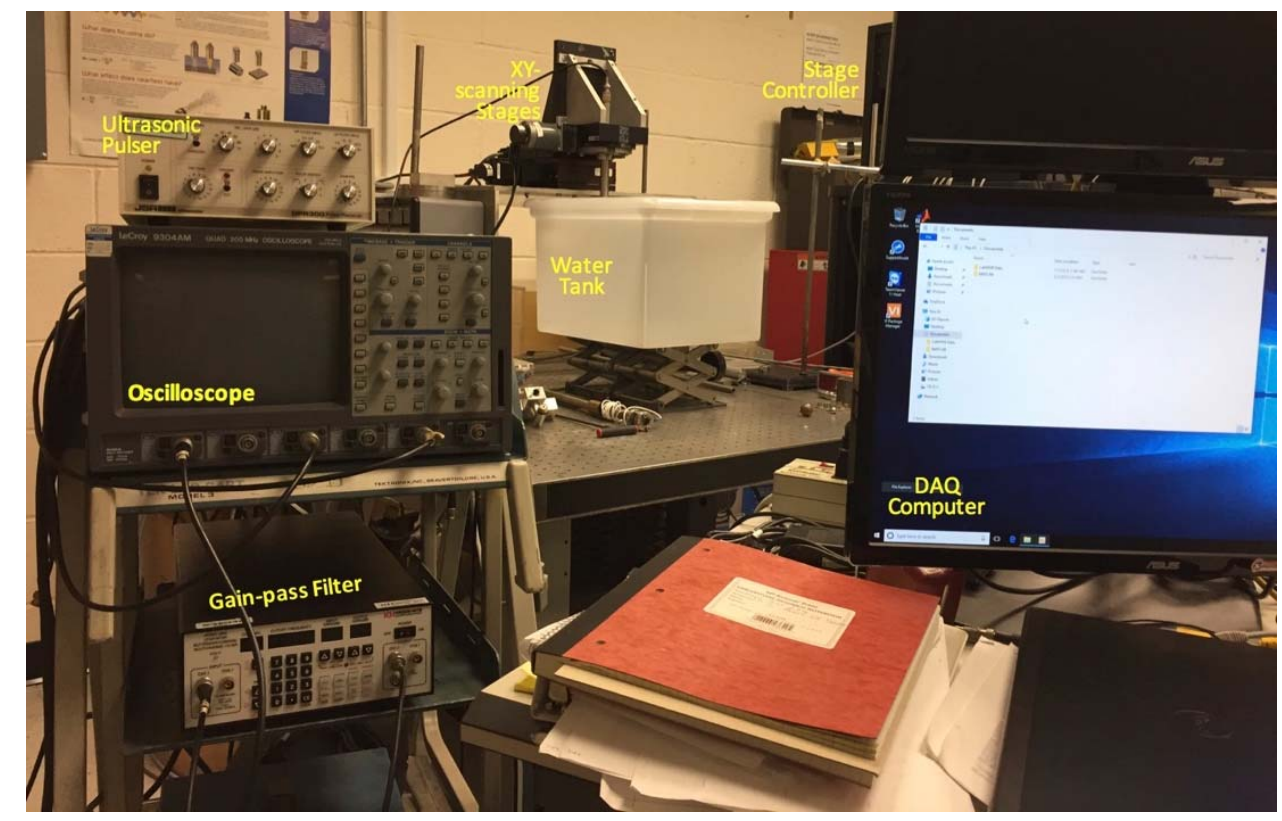

Figure 37 - Ultrasonic inspection system consisting of an ultrasonic pulser, a submergible ultrasonic transducer, a water tank, a three-axes step-motor scanning module, and a data acquisition (DAQ) unit.

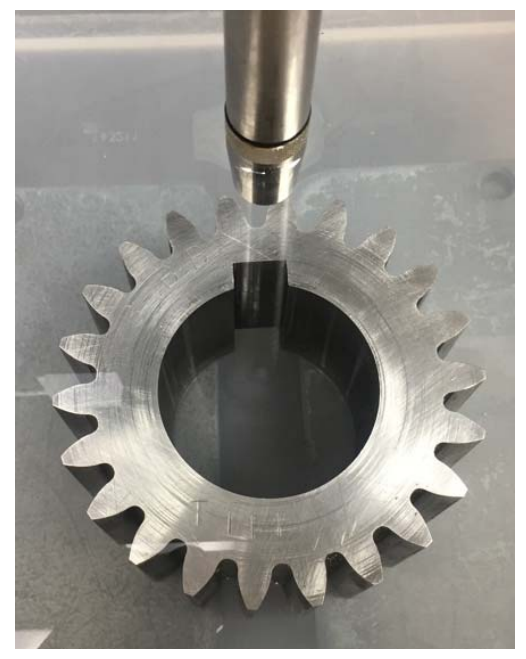

Figure 38 - UT inspection of a manipulator spur gear in water test.

Due to the relatively large thicknesses (3" and 4" illustrated in Figures 30(a) and (b) respectively) of the gears, it is important to evaluate and select an ultrasonic transducer with optimal operation frequency, output power, beam size and focal distance such that a clean 
ultrasonic reflection signals from both sides of a gear mounting surfaces could be received and better detection resolution can be achieved. To evaluate the effect of beam size, focused and unfocused ultrasonic transducers were used. An unfocused one would have a larger beam size. The focused transducer, in contrast, would have a smaller beam size at the focal point and should produce a much clear and sharp image. The transducers selected have an operation frequency of $5 \mathrm{MHz}$ and a diameter of 0.5 inch. The focused transducer has a focal distance of 2 " and the gear being tested was placed at the focal distance. Figure 39 shows a typical real-time ultrasonic RF signal received by the focused transducer from a pulse-echo test of a manipulator spur gear. Any internal defects could produce a reflection echo in between the front and back surfaces depending the orientation and size. Figure 40 demonstrates the real-time ultrasonic intensity images of Gear B-T1BT by using a focused and an unfocused ultrasonic transducer. The focused transducer clearly produces a much better image for defect detection and sizing. The distorted image of the gear generated by an unfocused transducer might be caused by the combination of large beam size, ghost double reflection, and translation issue.

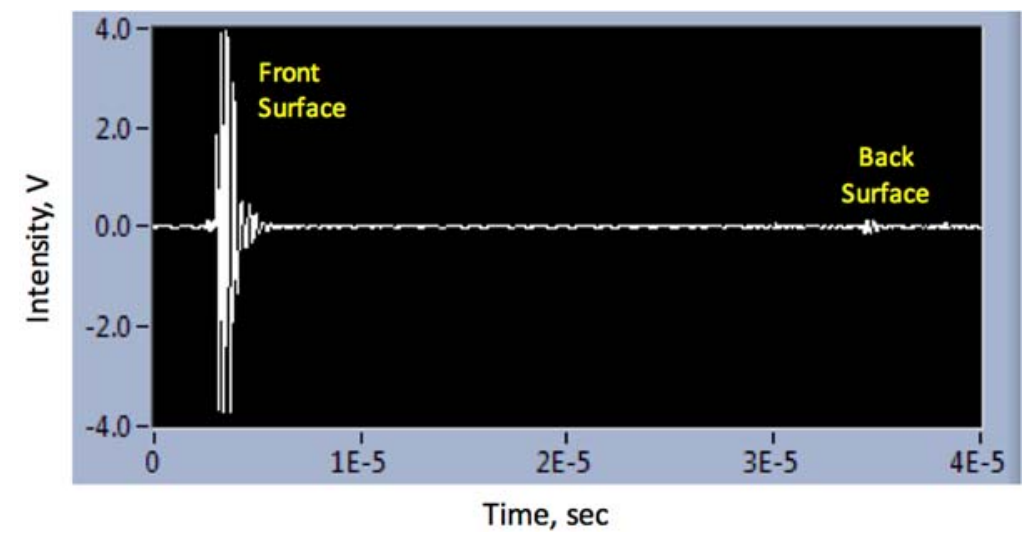

Figure 39 - Typical real-time ultrasonic RF signal of from a pulse-echo test of a manipulator spur gear.

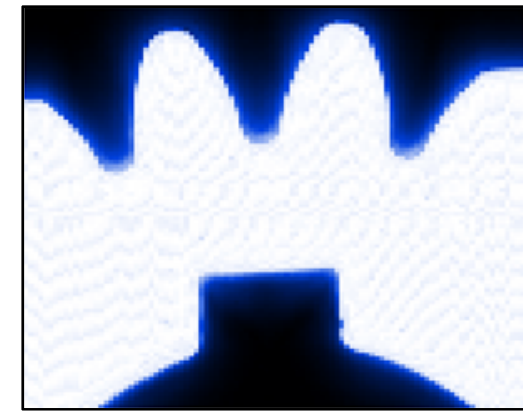

Focused

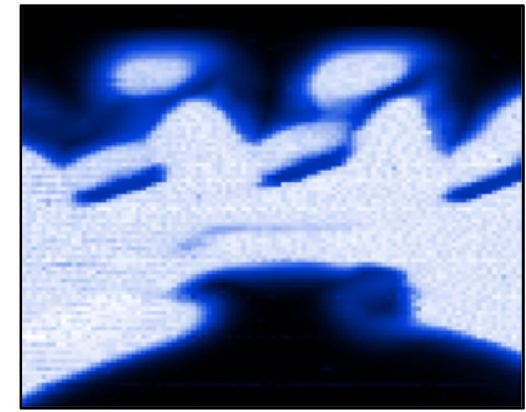

Unfocused

Figure 40 - Real-time ultrasonic intensity images of Gear B-T1BT generated by using (left) a focused and (right) an unfocused ultrasonic transducer.

From the transducer evaluation, it was concluded that the transducer (Panametrics A309R, series \# 2911425) with an operation frequency of $5 \mathrm{MHz}$, a diameter of $0.5 \mathrm{inch}$, and a focal length of 1 
inch produced better image for defect detection and sizing and were used for inspection of all of the four gears. Figure 41 shows the real-time ultrasonic intensity images of Gear B-T1BT. The gear was manually rotated by three teeth clockwise after each scan. Each image is 2.0"x1.6" in dimension and 100x100 pixel in resolution. Figure 42 shows the composited ultrasonic intensity image generated from the images in Figure 41 and a photo of Gear B-T1BT. Defect location and size can be determined by using a MATLAB based image process package, named imagingGUI, and developed at Argonne for advanced data image processing and 2D/3D data visualization. Applications for various NDE techniques, such as millimeter wave ( $\mathrm{mmW})$, ultrasonics, eddy current (EC), and photoacoustic spectroscope (PAS), various toolboxes and plug-in features were developed and embedded in imagingGUI. It contains plug-ins to translate existing data from different platforms into the proper format. Different data types acquired from various NDT techniques or different layouts of one particular data type can be processed and displayed with imagingGUI (Figure 43). Various user-generated filters and functions are also available with different data types and different NDT techniques. Scanning through the RF signals of image \#1 for teeth \#2-1-22-21, there was extra reflection signals, shown in Figure 43(top), found in between the front and back surfaces of the gear. A narrow digital gate was put at the extra reflection such that only the data within the gate (i.e. the cross-section of the gear within the gate) were then analyzed and displayed. Figure 43 (left) and (right) show the TOF and intensity images of the gated area, respectively. It clearly shows that there could be defects locating around $1 / 4$ to $1 / 3$ of the gear thickness underneath the front surface and along the edge of the gear's shaft key. Further evaluation needed to be conducted once we have the access of the gear. The profiles of the TOF and intensity at the cursor along X and Y axes are also displayed at the left and the top of each images accordingly. The intensity profiles directly show the defect dimensions along the XY axes respectively.

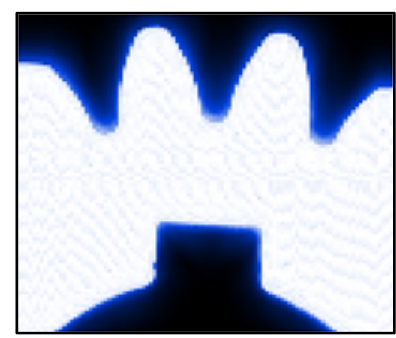

Teeth \#: 2-1-22-21

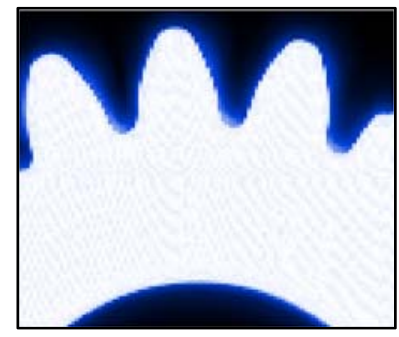

Teeth \#: 13-12-11

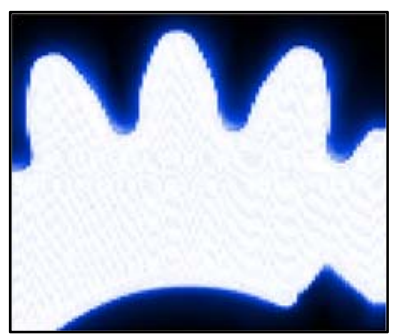

4-3-2

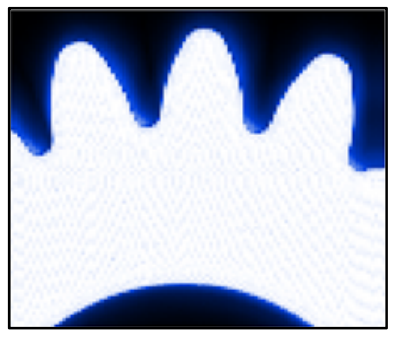

$16-15-14$

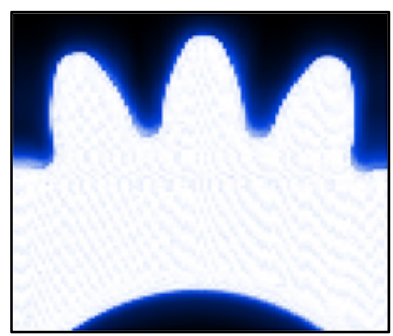

$7-6-5$

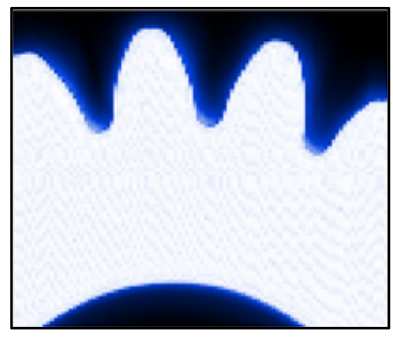

$19-18-17$

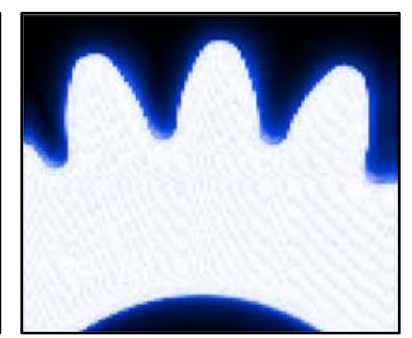

$10-9-8$

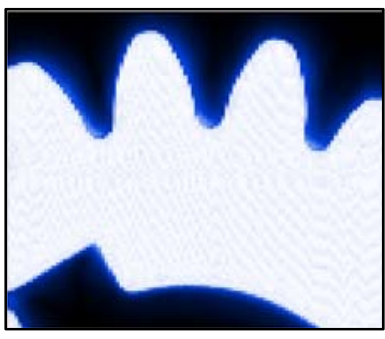

$22-21-20$

Figure 41 - Ultrasonic intensity images of Gear B-T1BT rotating clockwise every three teeth. 

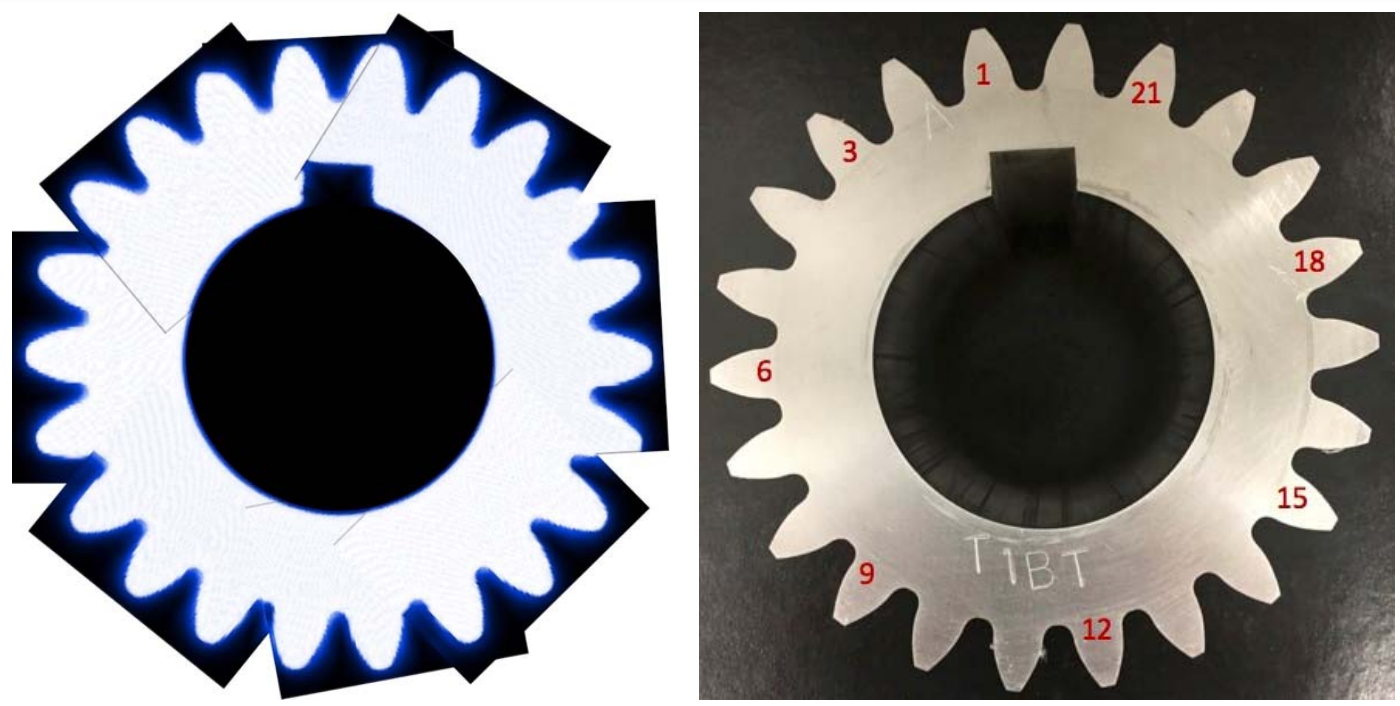

Figure 42 - (left) Composited ultrasonic intensity image and (right) photo of Gear B-T1BT.
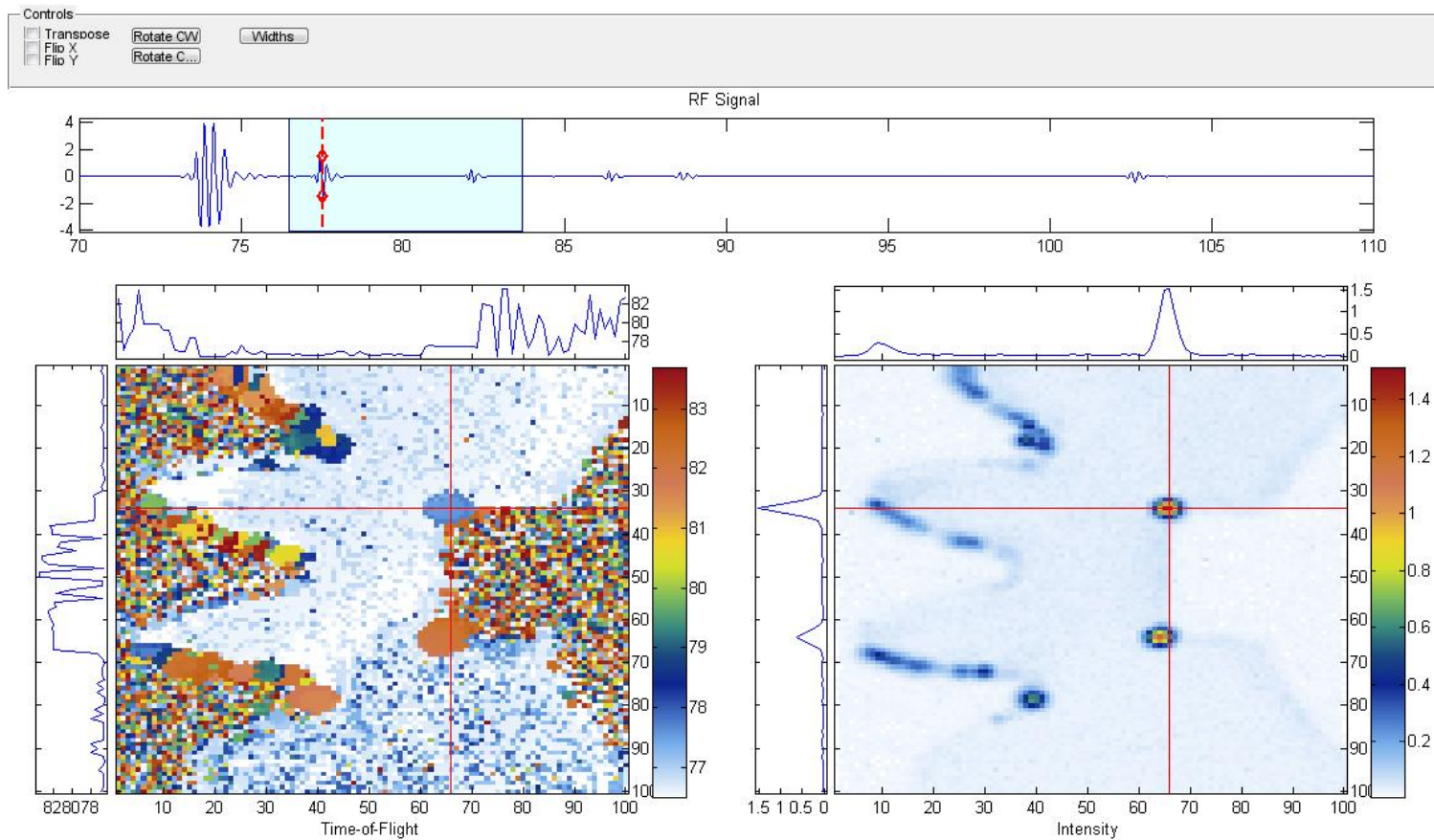

Figure 43 - (top) Ultrasonic RF signal at the cursor, (left) TOF image, and (right) intensity image.

Figure 44 shows the real-time ultrasonic intensity images of Gear A-T1IT by using the selected focused ultrasonic transducer. Each image is 2.0"x1.6" in dimension and 100x100 pixel in resolution. The gear was manually rotated by three teeth after each scan. Figure 45 show the ultrasonic RF signal (top) at the cursor, TOF image (left), and intensity image (right) of the gear, respectively. If there is a defect, by putting the cursor at the defect or at a suspected location, the TOF profiles would directly show the locations along the XY axes respectively as well as the depth underneath the front surface. 


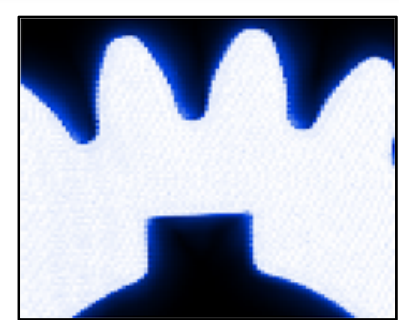

Teeth \#: 2-1-22-21

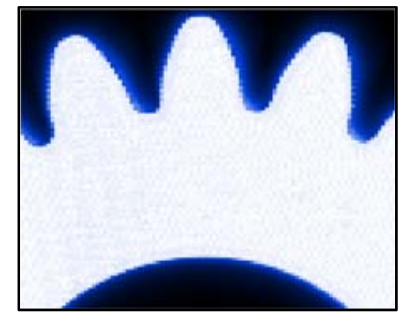

Teeth \#: 13-12-11

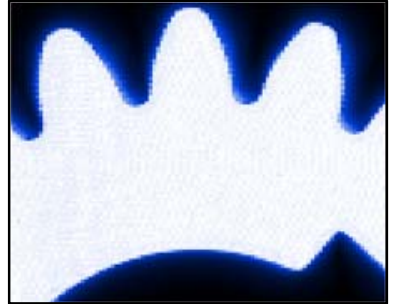

$4-3-2$

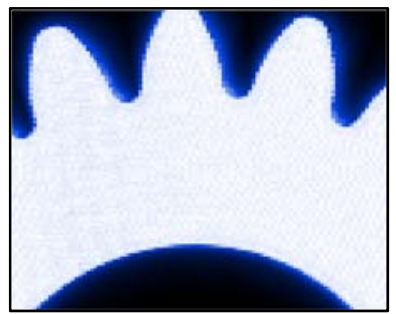

$16-15-14$

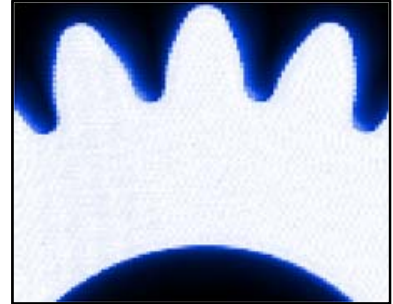

$7-6-5$

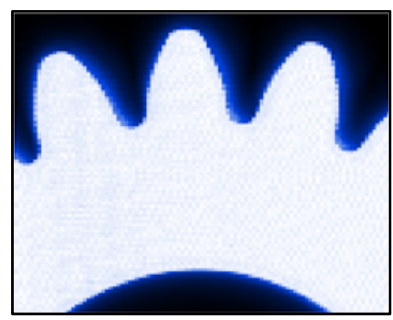

19-18-17

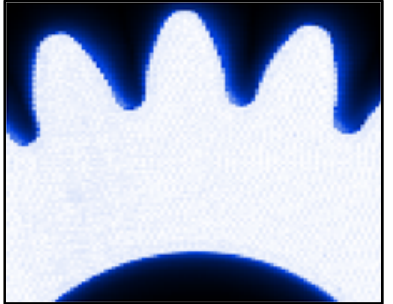

$10-9-8$

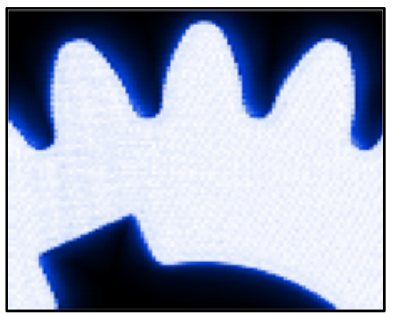

22-21-20

Figure 44 - Ultrasonic intensity images of Gear A-T1IT rotating clockwise every three teeth.
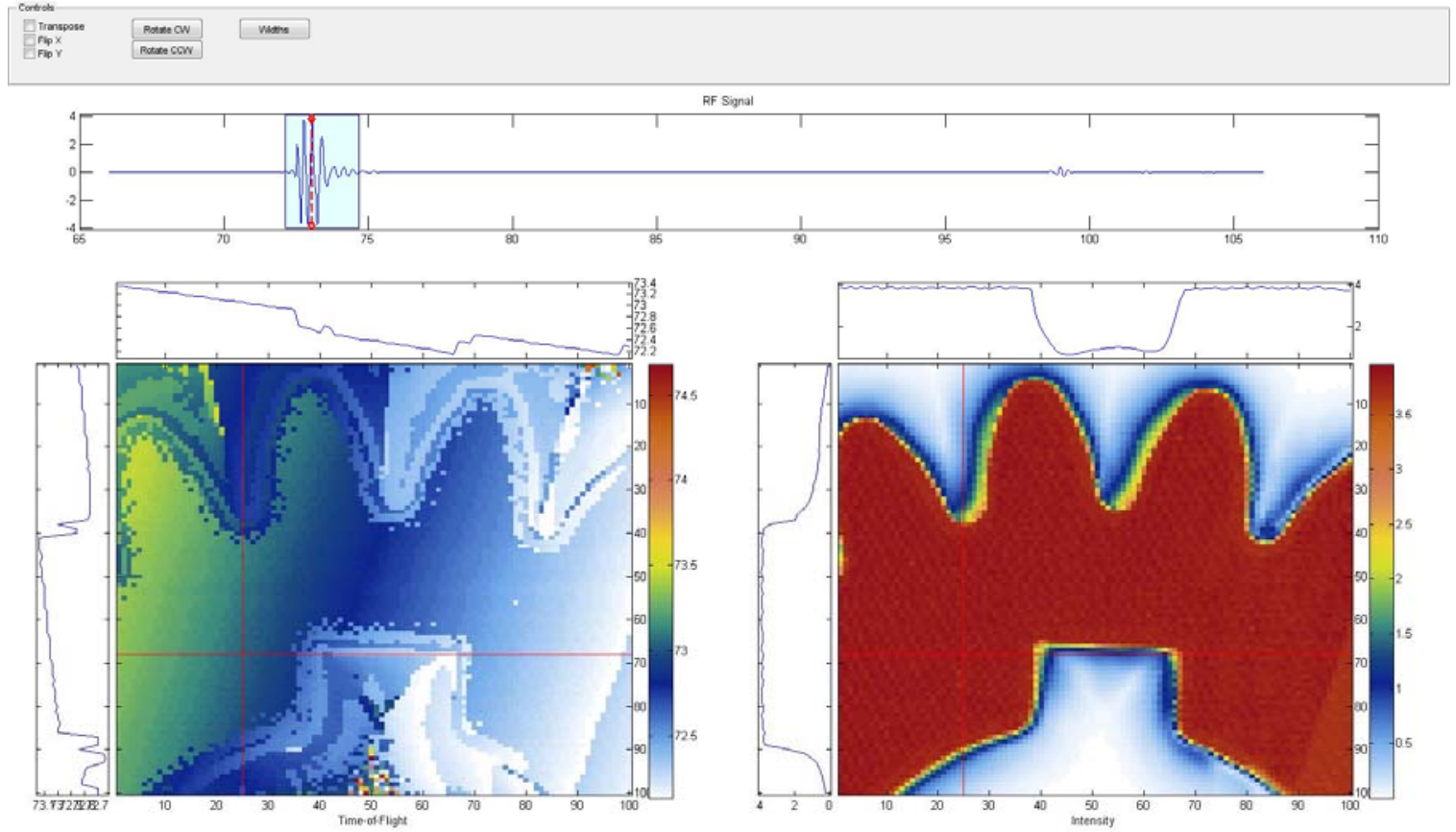

Figure 45 - (top) Ultrasonic RF signal at the cursor, (left) TOF image, and (right) intensity image.

Figure 46 shows the real-time ultrasonic intensity images of Gear AA-L1AT by using the selected focused ultrasonic transducer. Each image is 2.0"x1.6" in dimension and 100x100 pixel in resolution. The gear was manually rotated by two teeth after each scan. Figure 47 shows the composited ultrasonic intensity image generated from the images in Figure 46 and a photo of Gear AA-L1AT. 


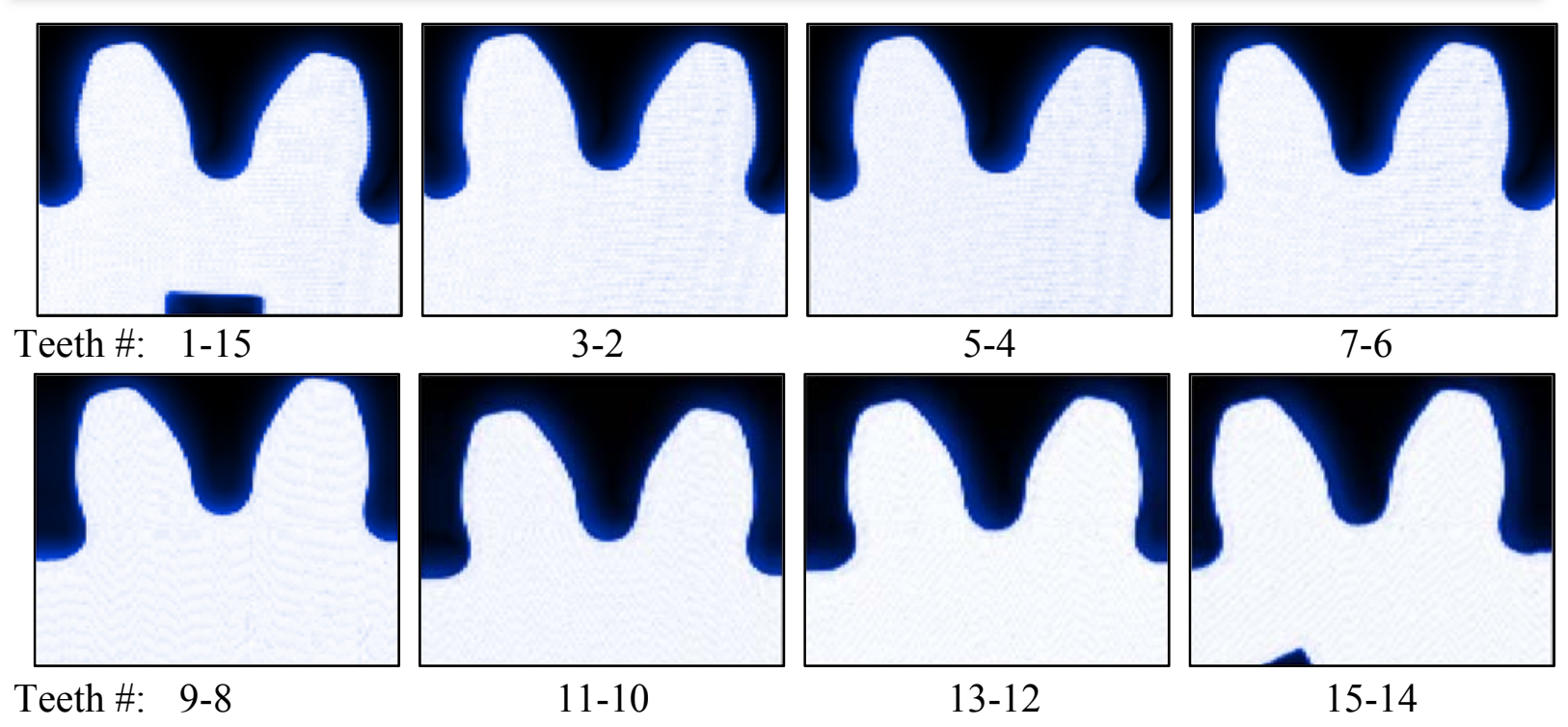

Figure 46 - Ultrasonic intensity images of Gear AA-L1AT rotating clockwise every two teeth.
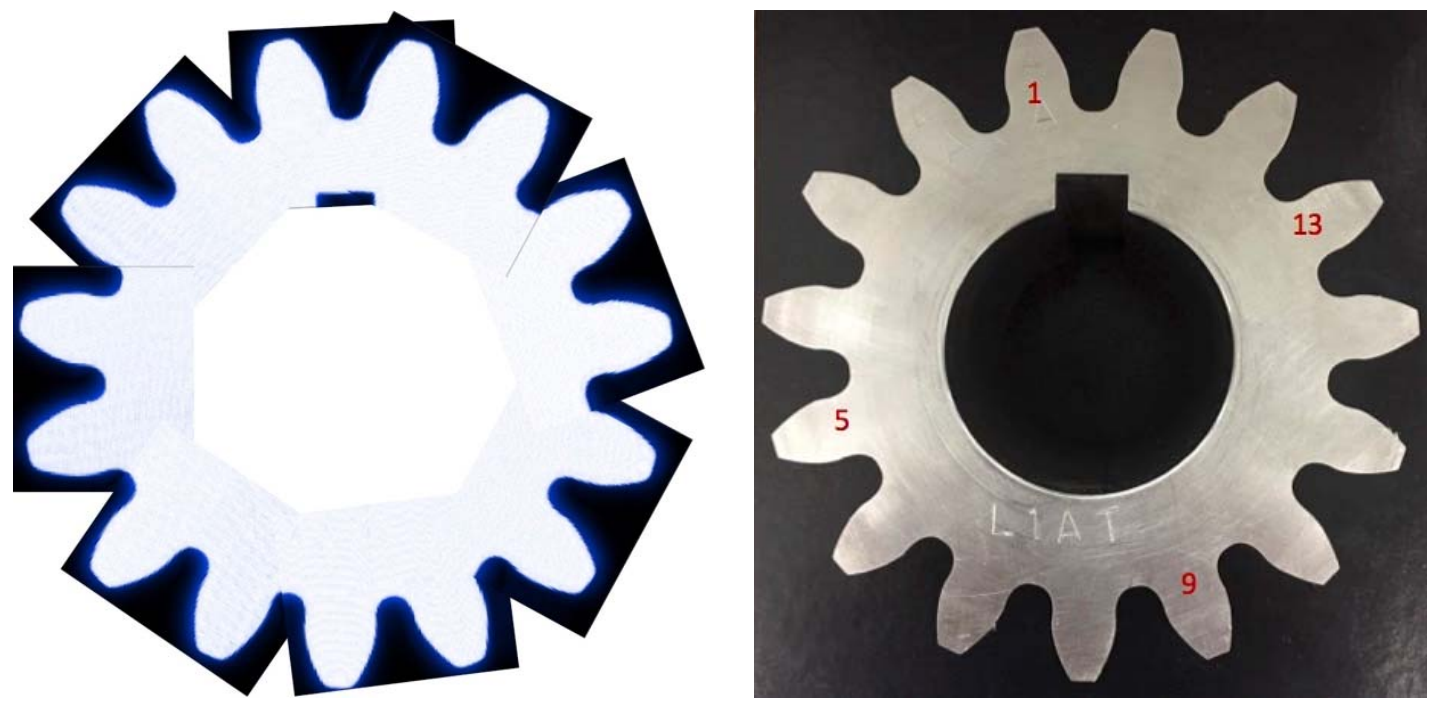

Figure 47 - (right) Composited ultrasonic intensity image and (left) photo of Gear AA-L1AT.

Figure 48 shows the real-time ultrasonic intensity images of Gear BB-L1IT by using the focused ultrasonic transducer. Each image is 1.6"x2.0" in dimension and 100x100 pixel in resolution. The gear was manually rotated by 45 degrees after each scan. 


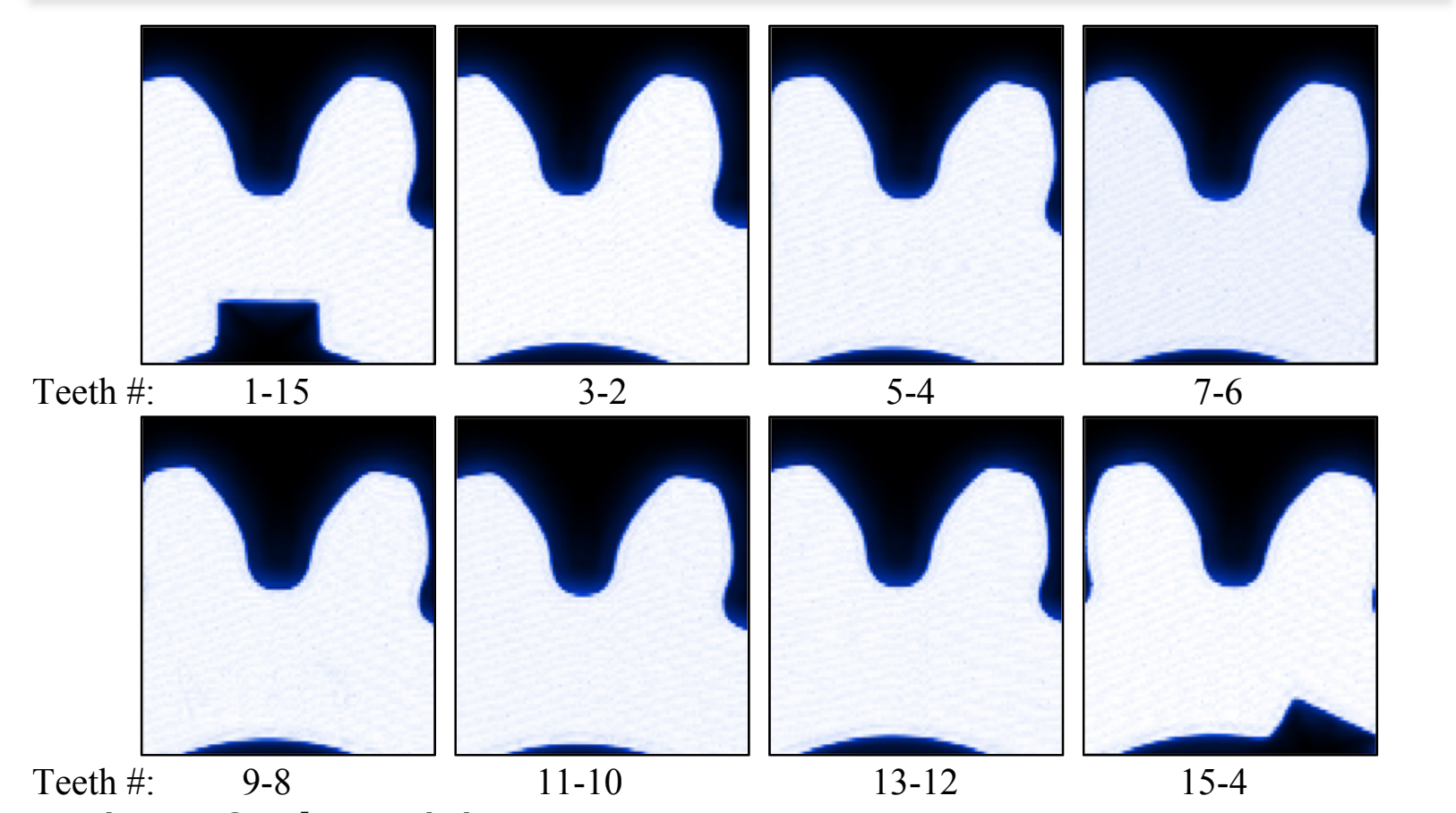

Figure 48 - Ultrasonic intensity images of Gear BB-L1IT rotating clockwise every two teeth.

\subsubsection{Conclusions and Discussions}

We have demonstrated that the ultrasonic energy is strong enough to penetrate through the manipulator spur gears made of Inconel 718 with thickness greater than 4 inches. The UT technique has also demonstrated that it is capable of detecting and sizing defects inside a component or at a location that is difficult to be reached. However, to accurately size defects, it is necessary to generate a calibrated sizing database/images using a calibration block consisting of premised holes or designed defects with different dimensions and orientations. To inspect a large component and to save effort, a larger translation system is needed, rather than inspecting a portion of the component each time. 


\section{Argonne}

Nuclear Engineering Division

Argonne National Laboratory

9700 South Case Avenue

Argonne, IL 60439

www.anl.gov 